Aus der Abteilung für Neurogenetik

(Leiter: Prof. K.-A. Nave, Ph.D.)

des Max-Planck-Instituts für experimentelle Medizin

in Göttingen

\title{
Der Einfluss von Lithium auf die Myelinisierung im peripheren Nervensystem
}

\author{
INAUGURAL-DISSERTATION \\ zur Erlangung des Doktorgrades \\ der Medizinischen Fakultät der \\ Georg-August-Universität zu Göttingen
}

vorgelegt von

Tobias Nientiedt

aus

Kassel 
Dekan:

Referent/in:

Ko-Referent/in:

Drittreferent/in:
Prof. Dr. med. W. Brück

Prof. Dr. med. M. W. Sereda

Prof. Dr. med. Thomas Dresbach

Prof. Dr. mult. Thomas Meyer

Datum der mündlichen Prüfung: 27.01.2022 
Hiermit erkläre ich, die Dissertation mit dem Titel "Der Einfluss von Lithium auf die Myelinisierung im peripheren Nervensystem“ eigenständig angefertigt und keine anderen als die von mir angegebenen Quellen und Hilfsmittel verwendet zu haben.

Mannheim, den .............. 


\section{Inhaltsverzeichnis}

Abbildungsverzeichnis ................................................................................. III

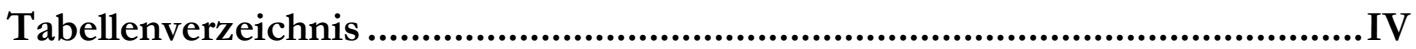

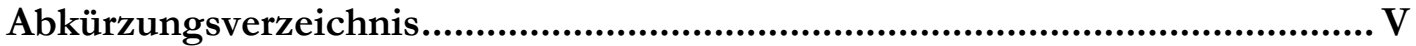

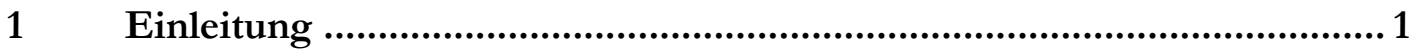

1.1 Myelinisierung im peripheren Nervensystem ..................................................................2

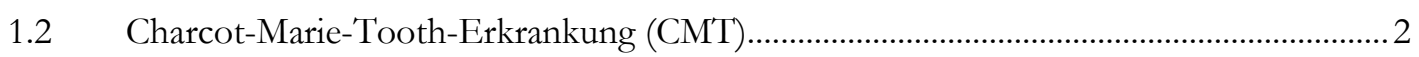

1.2.1 Charcot-Marie-Tooth-Erkrankung Typ 1A (CMT1A)...................................................... 4

1.2.2 Peripheres Myelinpotein 22 (PMP22) ........................................................................... 5

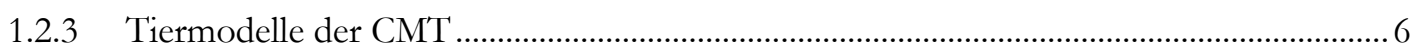

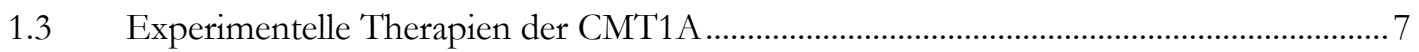

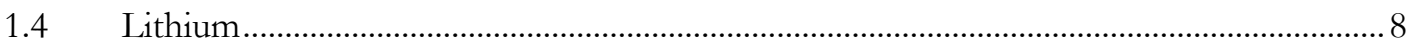

1.4.1 Einsatz von Lithium in der Medizin............................................................................. 8

1.4.2 Einfluss von Lithium auf die Myelinisierung im peripheren und zentralen

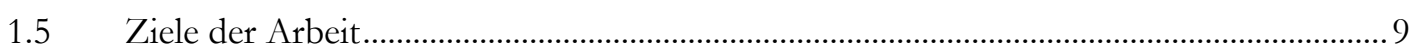

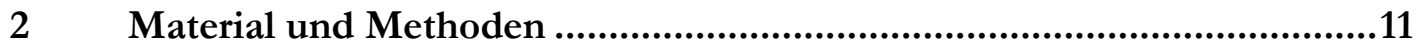

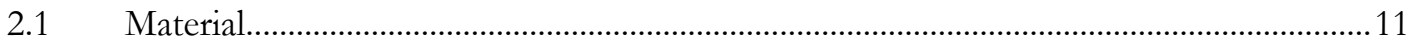

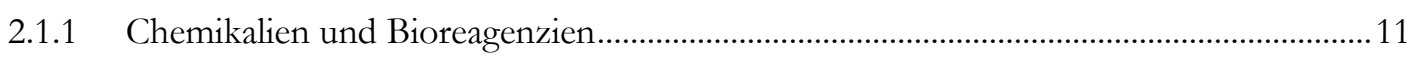

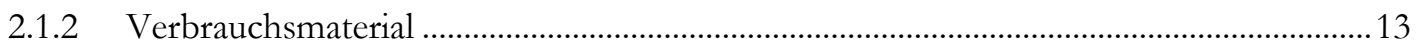

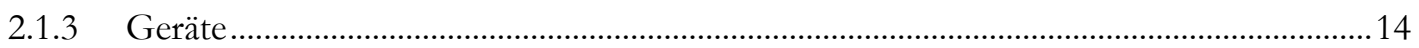

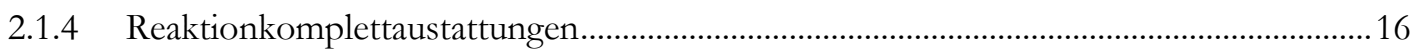

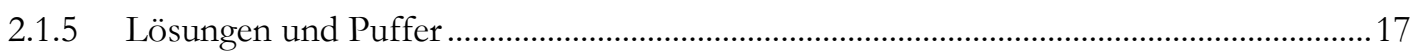

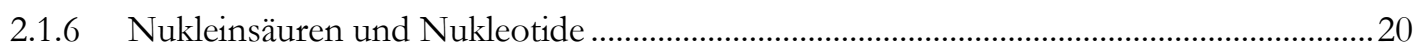

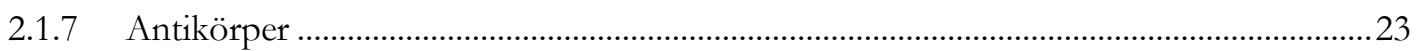

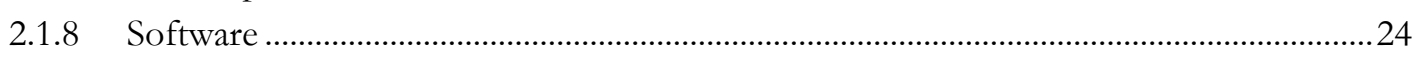

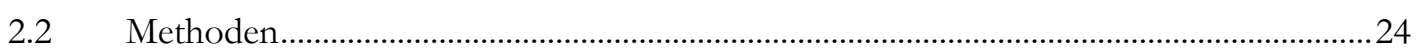

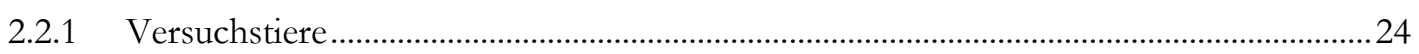

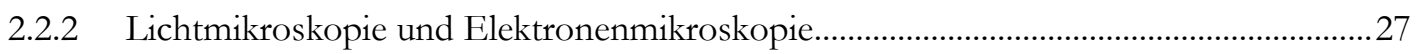

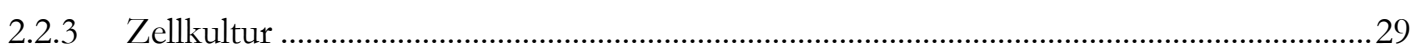

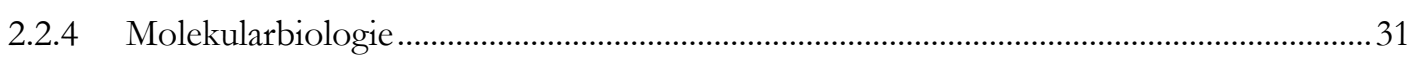

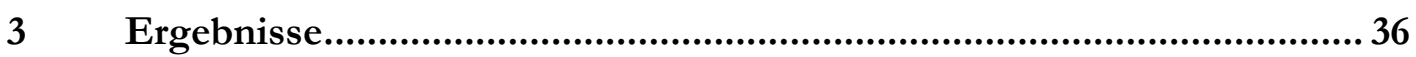

3.1 Einfluss von Lithium auf die Myelinisierung im peripheren Nervensystem von Wildtyp-

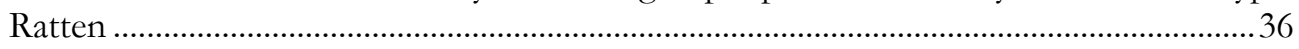

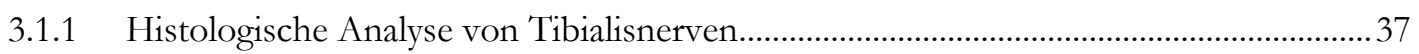

3.1.2 Genexpressionsanalysen aus RNA-Isolaten von Ischiasnerven ......................................39

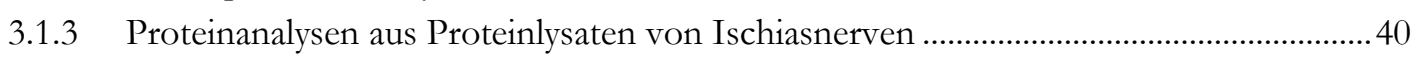

3.2 Einfluss von Lithium auf die Schwannzell-Differenzierung und Myelinisierung in vitro.. 
3.2.1 Genexpressionsanalysen aus primären Schwannzell-Kulturen .........................................43

3.2.2 Myelinisierung in Schwannzell-DRG-Neuron-Co-Kulturen...............................................45

3.3 Therapieversuch mit Lithium im transgenen Rattenmodell der CMT1A ........................47

3.3.1 Phänotypische Untersuchung Pmp22-transgener Ratten...................................................4

3.3.2 Elektrophysiologische Untersuchung an Schwanznerven Pmp22-transgener Ratten....49

3.3.3 Histologische Untersuchung von Tibialisnerven Pmp22-transgener Ratten ....................51

3.3.4 Genexpressionsanalysen aus RNA-Isolaten von Ischiasnerven Pmp22-transgener

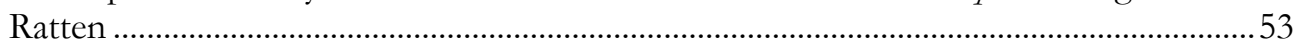

3.3.5 Proteinanalyse aus Proteinlysaten von Ischiasnerven Pmp22-transgener Ratten ............55

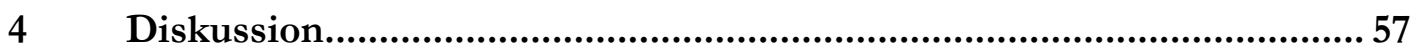

4.1 Einfluss von Lithium auf die Myelinisierung in Wildtyp-Ratten ......................................57

4.2 Einfluss von Lithium auf den Phänotyp und die Myelinisierung in einem transgenen Rattenmodell der CMT1A ...............................................................................................61

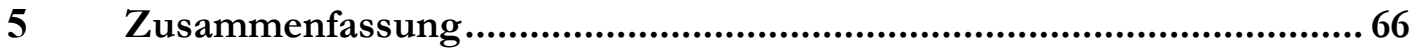

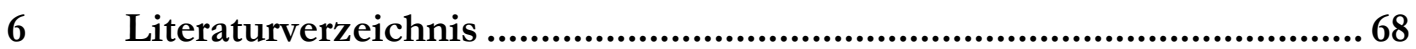




\section{Abbildungsverzeichnis}

Abbildung 1: Schematische Darstellung der Behandlung von Wildtyp-Ratten mit Lithium.....36

Abbildung 2: Gewicht und Serum-Lithiumkonzentration in Wildtyp-Ratten nach Lithiumbehandlung.

Abbildung 3: Histologische Analyse der relativen Myelindicke (g-ratio) in Tibialisnerven von Wildtyp-Ratten nach Lithiumbehandlung.

Abbildung 4: Histologische Analyse der Myelinkompaktierung in Tibialisnerven von Wildtyp-

Ratten nach Lithiumbehandlung.

Abbildung 5: Genexpressionsanalysen aus Ischiasnerven von Wildtyp-Ratten nach Lithiumbehandlung.

Abbildung 6: Proteinanalyse aus Ischiasnerven von adulten Wildtyp-Ratten nach Lithiumbehandlung.

Abbildung 7: Genexpressionsanalysen aus primären Schwannzell-Kulturen unter dem Einfluss von $1 \mathrm{mM}$ Lithiumcarbonat und Forskolin.

Abbildung 8: Genexpressionsanalysen aus primären Schwannzell-Kulturen unter dem Einfluss von $1 \mathrm{mM}$ und $5 \mathrm{mM}$ Lithiumcarbonat und Forskolin.......................................................4

Abbildung 9: Histologische Analyse der Myelinisierung von Schwannzell-DRG-Neuron-CoKulturen nach Lithiumbehandlung.

Abbildung 10: Schematische Darstellung der Lithiumbehandlung von Pmp22-transgenen Ratten.

Abbildung 11: Gewichtsverlauf bei Pmp22-transgenen Ratten nach Lithiumbehandlung. .........48

Abbildung 12: Verlauf der Griffstärke von Vorder- und Hinterläufen bei Pmp22-transgenen Ratten nach Lithiumbehandlung.

Abbildung 13: Messung der motorischen und sensiblen NLG bei Pmp22-transgenen Ratten nach Lithiumbehandlung.

Abbildung 14: Histologische Analyse der Anzahl myelinisierter und demyelinisierter Axone in Tibialisnerven von Pmp22-transgenen Ratten nach Lithiumbehandlung.

Abbildung 15: Histologische Analyse der relativen Myelindicke (g-ratio) in Tibialisnerven von Pmp22-transgenen Ratten nach Lithiumbehandlung..

Abbildung 16: Genexpressionsanalysen aus Ischiasnerven von Pmp22-transgenen Ratten nach Lithiumbehandlung.

Abbildung 17: Proteinanalyse aus Ischiasnerven von Pmp22-transgenen Ratten nach 


\section{Tabellenverzeichnis}

Tabelle 1: Einteilung der CMT nach Lupski et al. (2010) .............................................................3

Tabelle 2: Unterteilung der CMT/HSMN1 modifiziert nach Suter und Scherer (2003) ............. 4

Tabelle 3: Chemikalien und Bioreagenzien ................................................................................... 11

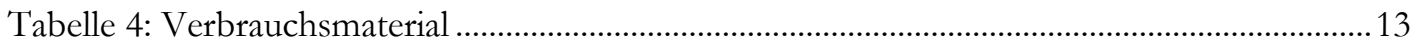

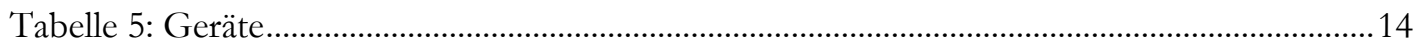

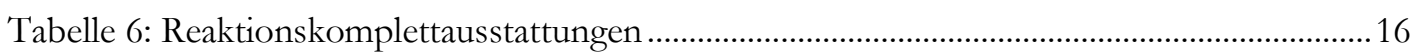

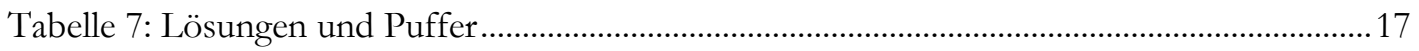

Tabelle 8: Primer zur Genotypisierung transgener Ratten.............................................................20

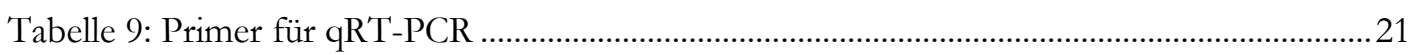

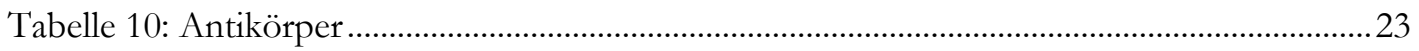

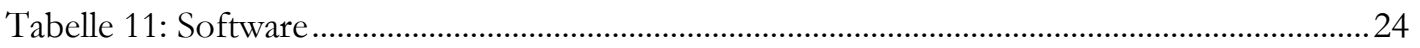

Tabelle 12: Protokoll Epon-Einbettung von Gewebe zur Licht- und Elektronenmikroskopie 27

Tabelle 13: Protokoll Genotypisierungs-PCR für Pmp22-transgene Tiere ...................................32

Tabelle 14: Protokoll qRT-PCR für Genexpressionsanalysen .......................................................34 


\section{Abkürzungsverzeichnis}

\begin{tabular}{|c|c|}
\hline BDNF & brain-derived neurotrophic factor \\
\hline BSA & bovines Serumalbumin \\
\hline cAMP & zyklisches Adenosin-Monophosphat \\
\hline cDNA & komplementäre Desoxyribonukleinsäure \\
\hline CMT & Charcot-Marie-Tooth-Erkrankung \\
\hline $\mathrm{Cx} 43$ & Connexin 43 \\
\hline $\mathrm{ddH}_{2} \mathrm{O}$ & doppelt destilliertes Wasser \\
\hline DDSA & 2-Duodecenyl-succinicacidanhydrid \\
\hline DMEM & Dulbecco's Modified Eagle's Medium \\
\hline DNA & Desoxyribonukleinsäure \\
\hline dNTP & Desoxynukleosidtriphosphat \\
\hline DTT & Dithiothreitol \\
\hline ECL & enhanced chemoluminescence \\
\hline EDTA & Ethylendiamintetraacetat \\
\hline Egr2 & Early growth response 2 \\
\hline ERK & extracellular signal regulated kinase \\
\hline FCS & fetal calf serum \\
\hline Gas3 & growth arrest specific gene 3 \\
\hline Gsk3b & Glykogensynthasekinase 3 beta \\
\hline HMNS1A & Hereditäre motorisch sensible Neuropathie Typ 1A \\
\hline HNPP & bereditary neuropathy with liability to pressure palsies \\
\hline HRP & horse radish peroxidase \\
\hline KG & Körpergewicht \\
\hline MAPK & mitogen-activated protein kinase \\
\hline MBP & basisches Myelinprotein \\
\hline MGB & modifizierter Gitschier Puffer \\
\hline MOPS & 3-Morpholino-1-propansulfonsäure \\
\hline MPZ & Myelinprotein 0 \\
\hline mRNA & messenger RNA \\
\hline MSAP & Muskelsummenaktionspotential \\
\hline NLG & Nervenleitgeschwindigkeit \\
\hline Nrg1 Typ III & Neuregulin 1 Typ III \\
\hline ns & nicht signifikant \\
\hline Oaz1 & ornithine decarboxylase antizyme 1 \\
\hline $\mathrm{p}$ & postnataler Tag \\
\hline PBS & phosphate-buffered saline \\
\hline PCR & Polymerase-Kettenreaktion \\
\hline PFA & Paraformaldehyd \\
\hline PI3K & Phosphatidylinositol 3-Kinase \\
\hline PLL & Poly-L-Lysin \\
\hline
\end{tabular}


PMP22 peripheres Myelinprotein $22 \mathrm{kDa}$

POU3F1 POU domain, class 3, transcription factor 1

Prx Periaxin

PVDF Polyvinylidenfluorid

p75NTR p75 neurotrophin receptor

qRT-PCR semiquantitative Real-Time-PCR

RNA Ribonukleinsäure

Rplp0 $\quad 605$ acidic ribosomal protein PO

Scap Sterol regulatory element-binding protein cleavage activating protein

SDS Natrium-Dodecyl-Sulfat

Stdabw. Standardabweichung

TAE Tris-Acetat Puffer

TBS Tris-Base-Salzpuffer

TrkB tropomyosin-related kinase receptor $B$

Tuj1 neuron-specific class III $\beta$-tubulin 


\section{$1 \quad$ Einleitung}

Das Nervensystem von Lebewesen ist ein komplexes Organ, dass zur Reizwahrnehmung, Weiterleitung und Verarbeitung dient. Es besteht aus untereinander vernetzten Nervenzellen und Gliazellen. Während in primitiveren Lebensformen wie Nesseltieren oder Fadenwürmern homogene Nervennetze oder strangförmige Nervensysteme bestehen, kommt es bei höheren Lebensformen zu einer zunehmenden Spezialisierung von bestimmten Nervenzellen mit Ausbildung übergeordneter Zentren. Gliederfüßer bilden z. B. bereits ein metameres (strickleiterartiges) Nervensystem mit Cerebralganglien als zentrale Steuereinheiten. Mit der Evolution fand eine zunehmende Cephalisation mit Ausbildung eines Gehirns statt. Bei höher entwickelten Lebensformen wie den Kopffüßern kommt es zu einer Trennung in zentrales Nervensystem, bestehend aus Gehirn und Rückenmark, und peripheres Nervensystem, wobei eine starre Trennung nach topographischer Lage nicht immer sinnvoll ist. So haben die motorischen Neurone ihr Soma im Rückenmark, ihre Axone ziehen jedoch in die Peripherie und gehören damit zum peripheren Nervensystem. Umgekehrt haben die sensiblen Neurone ihr Soma im peripheren Nervensystem, ihre Axone bilden unter anderem die Vorder- und Seitenstrangbahnen des Rückenmarks und gehören damit zum zentralen Nervensystem. Histologisch teilt sich das Nervensystem in Nervenzellen, die Neurone, sowie in die Gliazellen. Die Neurone bilden die funktionellen Einheiten des Nervensystems. Sie bestehen aus einem Zellkörper, dem Soma sowie Nervenzellfortsätzen. Im Soma finden fast alle wichtigen Stoffwechselprozesse statt. Stoffwechselprodukte werden aus dem Soma in die Nervenzellfortsätze transportiert. Die Nervenzellfortsätze lassen sich in das Axon sowie in Dendriten aufteilen. Dabei kann jedes Neuron mehrere Dendriten, jedoch nur ein Axon besitzen. Die Dendriten dienen dabei als Afferenz, nehmen also Signale auf oder wirken modulierend, die Axone bilden die Efferenz und dienen damit der Reizweiterleitung. An ihrem Ende befinden sich die synaptischen Endknöpfe, die zusammen mit der Zellmembran der nachfolgenden Zelle die Synapse, den Ort der Signalübertragung, bilden (Trepel 2004). Die axonalen Fortsätze einer Nervenzelle werden vom Nervenzellkörper bis hin zur Synapse von Gliazellen eingehüllt. Während kleine Axone nur von dem glialen Zytoplasma sowie der Zellmembran umgeben sind, bildet sich um größere Axone eine so genannte Myelinscheide. Hierbei handelt es sich um eine mehrschichtige Membranhülle, die ebenfalls von Gliazellen gebildet wird. Diese Gliazellen sind im zentralen Nervensystem die Oligodendrozyten, im peripheren Nervensystem wird diese Aufgabe von den Schwannzellen übernommen. Die Myelinscheide ist zum einen die Grundlage der schnellen saltatorischen Erregungsleitung in myelinisierten Nerven, zum anderen trägt die Myelinscheide zur Beibehaltung der axonalen Integrität bei und induziert über Signale der myelinisierenden Gliazellen z. B. die Verteilung von Ionenkanälen in der Zellwand des Axons (Schafer und Rasband 2006). 


\subsection{Myelinisierung im peripheren Nervensystem}

Myelin ist eine spezialisierte Zellmembran, die von den myelinisierenden Gliazellen, im peripheren Nervensystem den Schwannzellen, produziert wird. Während der Entwicklung des peripheren Nervensystems bilden sich aus Zellen der Neuralleiste Schwannzell-Vorläuferzellen, die sich wiederrum zu unreifen Schwannzellen entwickeln (Jessen und Mirsky 2005). Abhängig vom Durchmesser des Axons, mit dem die unreife Schwannzelle assoziiert ist, und der damit verbundenen Menge an axonal präsentiertem Neuregulin 1 Typ III (Nrg1 Typ III), werden Schwannzellen, die ein großes Axon umhüllen (Axone $>1 \mu \mathrm{m}$ ), zu myelinisierenden Schwannzellen, während Schwannzellen die mehrere Axone $<1 \mu \mathrm{m}$ Durchmesser in sogenannten Remak-Bündeln umgeben, in einem nicht-myelinisierenden Stadium verbleiben (Taveggia et al. 2005). Im Rahmen des sogenannten radial sorting gehen die myelinisierenden Schwannzellen ein 1:1 Verhältnis mit den Axonen des peripheren Nervensystems ein. Diese Schwannzellen erhalten unter Ausbildung einer Basalmembran sowie in der Interaktion mit dem Axon eine radiale und longitudinale Polarität, die für den Beginn der Myelinisierung essentiell ist (Salzer 2003; Simons und Trotter 2007). Die Schwannzellen produzieren große Mengen von spezifischen Myelinproteinen wie basisches Myelinprotein (MBP), Myelinprotein 0 (MPZ) und peripheres Myelinprotein $22 \mathrm{kDa}$ (PMP22) sowie von Phospholipiden, Glycosphingolipiden und Cholesterol die mit 70 \% einen hohen Teil der Myelinmasse ausmachen. Myelinproteine und Lipide werden an die Zelloberfläche transportiert, interagieren in einer einzigartigen Weise miteinander und werden in die Zellmembran eingebaut. Bunge et al. konnten bereits 1989 zeigen, dass es zu einem Wachstum des inneren axonnahen Schwannzell-Fortsatz kommt, der das Axon spiralförmig umgibt. Dabei wird die Zellmembran viele Male um das Axon gewickelt und bildet so die Myelinscheide (Simons und Trotter 2007).

\subsection{Charcot-Marie-Tooth-Erkrankung (CMT)}

Neuropathien sind eine uneinheitliche Gruppe von Erkrankungen des peripheren Nervensystems. Diese können entweder an einem einzelnen Nerven (Mononeuropathie) oder an mehreren Nerven (Polyneuropathie) auftreten. Klinisch können sich periphere Neuropathien durch Sensibilitätsstörungen und Störungen der Motorik sowie Beeinträchtigung der Muskeleigenreflexe äußern. Neurographisch zeigen sich eine Einschränkung der Nervenleitgeschwindigkeit (NLG) oder der Muskelsummenaktionspotentiale (MSAP). Die peripheren Neuropathien können in Axonopathien, das heißt Schädigungen des Axons bei erhaltener Nervenscheide und Myelinopathien, Störungen der Myelinscheide bei zunächst erhaltenem Axon, unterschieden werden. Neben der Einteilung nach Lokalisation der Schädigung ist auch eine Einteilung nach der Ätiologie der Schädigung möglich. So können die peripheren Neuropathien nach ihrer Ursache in primäre und sekundäre Neuropathien eingeteilt werden. Während die primären Neuropathien in der Regel genetisch bedingt sind, können die sekundären Neuropathien eine große Zahl an Ursachen haben. Die häufigsten Gründe für eine 
sekundäre Neuropathie sind metabolische Erkrankungen wie Diabetes mellitus, neurotoxische Substanzen wie Ethanol, zyklische Kohlenwasserstoffe oder Chemotherapeutika sowie autoimmunologische Erkrankungen wie das Guillain-Barré-Syndrom.

Die Charcot-Marie-Tooth (CMT)-Erkrankungen oder hereditäre motorisch sensible Neuropathie (HMSN) ist ein Oberbegriff für eine genetisch und klinisch heterogene Gruppe erblich bedingter Neuropathien. Mit einer Inzidenz von 1:2500 (Skre 1974; Krajewski et al. 2000) ist sie die häufigste genetisch bedingte Erkrankung des peripheren Nervensystems. Das Krankheitsbild wurde nach den Erstbeschreibern im Jahr 1886, dem französischen Pathologen Jean-Martin Charcot und dem Neurologen Pierre Marie, sowie dem britischen Neurologen Howard Henry Tooth benannt. CMT kann nach dem betroffenen Gen in verschiedene Typen und Untertypen eingeteilt werden (Lupski et al. 2010).

Tabelle 1: Einteilung der CMT nach Lupski et al. (2010)

\begin{tabular}{ll}
\hline \hline Typ & Name \\
\hline CMT/HMSN1 & demyelinisierende Form \\
CMT/HMSN2 & axonale Form \\
CMT/HMSN3 & Déjerine-Sottas-Syndrom \\
CMT/HMSN4 & Morbus Refsum \\
CMT/HMSN5 & spastische Paraplegie mit Amyotrophie \\
CMT/HMSN6 & hereditäre motorisch sensible Neuropathie mit optischer Atrophie \\
CMT/HMSN7 & hereditäre motorisch sensible Neuropathie mit Retinitis pigmentosa \\
\hline \hline
\end{tabular}

Klassifikation der wichtigsten demyelinisierenden, hereditären Neuropathien. Abkürzungen: CMT CharcotMarie-Tooth-Erkrankung. HMSN Hereditäre motorisch sensible Neuropathie. Modifiziert nach Lupski et al. (2010). 
Die CMT/HSMN1 lässt sich weiterhin einteilen:

Tabelle 2: Unterteilung der CMT/HSMN1 modifiziert nach Suter und Scherer (2003)

\begin{tabular}{llll}
\hline \hline Name & Merkmal & Gen & Lokus \\
\hline CMT1A & $\begin{array}{l}\text { häufigste Form der CMT, symmetri- } \\
\text { sche, distal betonte Muskelatrophie }\end{array}$ & PMP22-Duplikation & 17p11.2-12 \\
CMT1B & $\begin{array}{l}\text { ähnliche Symptomatik wie bei der } \\
\text { CMT1A }\end{array}$ & MPZ/PO & $1 \mathrm{q} 22$ \\
CMT1C & $\begin{array}{l}\text { ähnliche Symptomatik wie bei der } \\
\text { CMT1A }\end{array}$ & LITAF & $16 \mathrm{p} 13.3-\mathrm{p} 12$ \\
CMT1D & $\begin{array}{l}\text { ähnlich wie CMT1A jedoch breite klini- } \\
\text { sche Ausprägung }\end{array}$ & EGR2 & $10 \mathrm{q} 21.1-\mathrm{q} 22.1$ \\
HNPP & $\begin{array}{l}\text { Rezidivierende Drucklähmungen, histo- } \\
\text { logisch Ausbildung von Tomaculae }\end{array}$ & PMP22-Deletion & $17 \mathrm{p} 11.2$ \\
\hline \hline
\end{tabular}

Untertypen der CMT1. Die CMT1A ist mit ca. 50-60 \% aller CMT-Formen die hereditäre Neuropathie mit der größten klinischen Relevanz (Schenone et al. 2011). Abkürzungen: HNPP hereditary neuropatby with liability to pressure palsies; PMP22 peripheral myelin protein 22; MPZ/P0 myelin protein zero; LITAF lipopolysaccharide-induced tumor necrosis factor- $\alpha$; EGR2 early growth response protein 2. Tabelle modifiziert nach Suter und Scherer (2003)

\subsubsection{Charcot-Marie-Tooth-Erkrankung Typ 1A (CMT1A)}

Die Charcot-Marie-Tooth-Erkrankung Typ 1A (CMT1A) ist die häufigste Unterform der hereditären Neuropathien. Synonym wird im klinischen Kontext auch der Begriff hereditäre motorische sensible Neuropathie 1A (HMNS1A) verwendet (Schenone et al. 2011). Sie wird durch eine Duplikation des Gens für das periphere Myelinprotein 22 kDa (PMP22) auf Chromosom 17p11.2-12 (Lupski et al. 1991) verursacht und unterliegt einem autosomal dominanten Erbgang, kann jedoch auch durch ein ungleiches Crossing-over neu entstehen (Palau et al. 1993; Patzkó und Shy 2011). Die Erkrankung wird in der Regel im jungen Erwachsenenalter diagnostiziert. In vielen Fällen haben Patienten jedoch anamnestisch bereits länger Beschwerden wie mangelnde Leistungsfähigkeit beim Laufen. Die Ausprägung der Erkrankung sowie das Alter des Patienten beim Auftreten der ersten Krankheitssymptome sind sehr variabel. Die Ursache hierfür ist bisher noch nicht abschließend geklärt. Diskutiert werden hier unter anderem epigenetische Faktoren (Pareyson und Marchesi 2009; Reilly et al. 2011). Klinisch zeichnet sich die CMT1A-Erkrankung insbesondere durch eine symmetrische, distal betonte Muskelschwäche mit einer Betonung der unteren Extremität aus (Birouk et al. 1997b). Durch die neurogene Muskelatrophie kommt es im langsam progredienten Verlauf der Erkrankung zu einer Hohlfuß- und Krallenzehenausbildung mit einem charakteristischem Steppergang (Dyck et al. 1993). Hinzu kommen sensible Defizite wie mangelnde Propriozeption oder gestörte Schmerzwahrnehmung. Das Zusammenspiel aus motorischer 
Schwäche und verminderter Propriozeption kann bis zur Bindung an den Rollstuhl führen. Eine Minderung der Lebenserwartung ist üblicherweise mit der Erkrankung nicht verbunden. Elektrophysiologisch zeigt sich in der Regel eine Minderung der NLG $<40 \mathrm{~m} / \mathrm{s}$ sowie ein reduziertes MSAP. Histologisch zeigt sich in peripheren Nerven das Bild einer segmentalen Demyelinisierung mit axonalem Verlust. Außerdem lassen sich so genannte onion-bulbFormationen als Zeichen einer gleichzeitig ablaufenden De- und Remyelinisierung nachweisen (Gabreëls-Festen und Wetering 1999). Die Elektrophysiologie und die histologische Untersuchung an Nervenbiopsien aus dem Suralisnerv waren lange Zeit der Goldstandard zur Diagnostik einer CMT-Erkrankung. Dies wurde in den vergangenen Jahren durch den genetischen Nachweis der PMP22-Duplikation ergänzt (Slater et al. 2004).

Der genaue Pathomechanismus von der Duplikation des PMP22-Gens zum Phänotyp der CMT1A ist noch nicht abschließend geklärt. Die Wichtigkeit der genauen Gendosis wird durch die Tatsache bestärkt, dass das Fehlen einer Kopie des Gens zu einer milderen Form der CMT, der hereditären Neuropathie mit Neigung zu Drucklähmungen (HNPP) führt. Mutationen mit mehr als drei Kopien führen wiederum zur Ausbildung eines sehr schweren Phänotyps. In-vitro-Experimente haben gezeigt, dass eine erhöhte PMP22-Gendosis in Schwannzellen zu einer geringeren Proliferationsrate und zu einem späteren Eintritt in die S-Phase der Mitose führt. Dies zeigt, dass PMP22 eine Rolle im Zellzyklus und Zellwachstum spielt (Zoidl et al. 1995). Neuere Studien zeigen zudem, dass Schwannzellen in Pmp22-transgenen Ratten einen Differenzierungsdefekt und eine Imbalance im PI3K-AKT und MAPKERK-Signalweg aufweisen (Fledrich et al. 2014). Andere Autoren beschreiben einen Zusammenhang zwischen der PMP22-Überexpression und einer abnormal hohen Konzentration von intrazellulärem $\mathrm{Ca}^{2+}$ durch eine Überexpression des P2X-Kalziumkanals in Schwannzellen (Nobbio et al. 2009).

\subsubsection{Peripheres Myelinpotein 22 (PMP22)}

PMP22 wurde erstmalig aus Maus-Fibroblasten als growth arrest specific gene 3 (GAS3) isoliert (Schneider et al. 1988). Nachfolgend wurde das Gen SR13 in Rattennerven identifiziert. Dieses zeigte sich homolog zu dem vorher isolierten GAS3 (Manfioletti et al. 1990). Im weiteren Verlauf erkannte man, dass das Protein GAS3/SR13 in kompaktem Myelin lokalisiert ist und ein Molekulargewicht von $22 \mathrm{kDa}$ aufweist (Snipes et al. 1992). Es wurde daher in peripheres Myelinprotein 22 (PMP22) umbenannt. PMP22 ist ein hydrophobes Protein, das vom PMP22-Gen enkodiert wird. Das Protein enthält vier Transmembrandomänen, zwei extrazelluläre Schleifen und eine intrazelluläre Schleife. Es macht etwa 3 - $5 \%$ der Gesamtmasse des Proteins im peripheren Myelin aus und ist im kompakten Myelin lokalisiert (Suter und Scherer 2003). PMP22 wird im peripheren Nervensystem von Myelin-bildenden Schwannzellen exprimiert (Snipes et al. 1992). Während der Embryogenese gibt es auch eine transiente Expression in anderen Geweben. So wurde PMP22-Expression unter anderem in Neuronen der dorsalen Hinterwurzelganglien, dem Hirnstamm, Cortex und dem Rückenmark (Parmantier et al. 1995; Taylor et al. 1995) sowie in Geweben außerhalb des Nervensystems 
(Baechner et al. 1995) nachgewiesen. Beim Menschen befindet sich das Gen auf dem Chromosom 17p11.2 (15,13 - 15,17 Mb) und umfasst etwa $40 \mathrm{~kb}$. Es besteht aus sechs Exons und ist zwischen den verschiedenen Spezies hoch konserviert (Patel et al. 1992; Jetten und Suter 2000). Das erste Exon umfasst zwei verschiedene Transkripte (Exon 1a und Exon 1b), die sich nicht in ihrer codierenden Sequenz, sondern nur in ihrem untranslatierten 5' Ende unterscheiden (Suter und Patel 1994). Die codierende Region von PMP22 umfasst die Exons 2 bis 5. In vitro wurde gezeigt, dass PMP22 zunächst als $18 \mathrm{kDa}$ Vorläuferprotein synthetisiert und, wie andere Membranproteine auch, vorübergehend im endoplasmatischen Retikulum und Golgi-Apparat verbleibt, dort posttranslational durch N-Glykosylierung zu einem $22 \mathrm{kDa}$ Protein modifiziert wird und erst danach die Zellmembran erreicht (Pareek et al. 1993). PMP22 scheint eine maßgebliche Rolle in der Bildung und Aufrechterhaltung des kompakten Myelins zu haben. Zum aktuellen Zeitpunkt ist die Funktion von PMP22 noch nicht vollständig verstanden (Watila und Balarabe 2015).

\subsubsection{Tiermodelle der CMT}

Die Entwicklung neuer Behandlungsmethoden und die Untersuchung von Krankheitsursachen sind aufwendige und kostenintensive Prozesse. Aus praktischen und ökonomischen, aber auch aus ethischen Gründen ist eine Untersuchung am Menschen häufig nicht möglich.

Transgene Tiermodelle hereditärer Erkrankungen können den Verlauf von Erkrankungen des Menschen widerspiegeln. In der medizinischen und grundlagenwissenschaftlichen Forschung dienen sie als Werkzeug zur Untersuchung von Pathomechanismen menschlicher Erkrankungen und können helfen die Wirksamkeit und Sicherheit neuer Therapien zu überprüfen. Für die verschiedenen Subtypen der CMT gibt es sowohl natürliche Mutanten, wie auch künstlich erzeugte transgene Tiere (Sereda und Nave 2006; Fledrich et al. 2012b). Ein Austausch von Leucin 16 mit Prolin in der ersten Transmembrandomäne von Pmp22 verursacht bei der natürlichen Trembler-J-Mausmutante eine periphere Neuropathie und im Menschen die schwere Neuropathie Déjerine-Sottas-Syndrom (Jetten und Suter 2000). Daneben wurden Pmp22-überexprimierende Mäuse- (Huxley et al. 1996; Magyar et al. 1996; Huxley et al. 1998) und Rattenlinien generiert (Sereda et al. 1996). Die Pmp22-transgene Ratte trägt ein $43 \mathrm{~kb}$ großes Restriktionsfragment, dass das gesamte Pmp22-Transkript enthält und aus einer genomischen Maus-Cosmid-Bibliothek kloniert wurde. Southern-Blot-Analysen ergaben, dass das Pmp22-Transgen aus drei Kopien besteht (Sereda et al. 1996). In verschiedenen Tiermodellen der CMT1A mit unterschiedlich starker Pmp22-Überexpression wurde eine Korrelation zwischen der Schwere der manifesten Erkrankung und der Anzahl ins Genom integrierter Transgen-Kopien dargestellt (Huxley et al. 1998). Eine stark erhöhte Gendosis (16 - 30 Transgen-Kopien) führten in einer transgenen Maus zu einem vollständigen Fehlen der Myelinscheiden (Magyar et al. 1996). Auch in homozygot Pmp22-transgenen Ratten sind die Schwannzellen von Geburt an nicht in der Lage, Myelin zu bilden (Niemann et al. 2000). Expressionsstudien in heterozygoten transgenen Ratten zeigen eine mäßige Überexpression von Pmp22 von etwa 1,6 gegenüber den Wildtyp-Tieren (Sereda et al. 2003). Insbesondere 
für die Pmp22-überexprimierende Ratte konnte in der Vergangenheit gezeigt werden, dass sie den Krankheitsverlauf der CMT1A im Menschen gut widerspiegelt. Diese Tiere entwickeln eine Muskelschwäche und eine Gangstörung. Elektrophysiologisch sind die NLG sowie die Muskelsummenaktionspotentiale reduziert. Histologisch lässt sich eine Demyelinisierung mit sekundärem axonalen Verlust und Ausbildung von onion-bulb-Formationen zeigen (Sereda et al. 1996; Niemann et al. 1999; Sereda und Nave 2006; Fledrich et al. 2019). Im Jahr 2012 konnte zudem gezeigt werden, dass die Pmp22-transgene Ratte die aus dem Menschen bekannte Variabilität in der Ausprägung der Erkrankung und dem Alter des Erkrankungsbeginns widerspiegelt (Fledrich et al. 2012a).

\subsection{Experimentelle Therapien der CMT1A}

In den vergangenen 20 Jahren gab es bereits große Bemühungen eine Therapiemöglichkeit für die CMT1A zu finden. Insbesondere die oben beschriebene Entwicklung von Tiermodellen, aber auch der bessere Einblick in die Pathomechanismen der CMT1A und das genauere Verständnis der Myelinisierung haben zu großen Fortschritten geführt. Eine wirkungsvolle Therapie steht in der Klinik nach wie vor jedoch nicht zur Verfügung.

Ein vielversprechender Therapieansatz ergab sich durch die Beobachtung, dass Ascorbinsäure die Myelinisierung in vitro unterstützt (Eldridge et al. 1987). Weitere Untersuchungen zeigten, dass Ascorbinsäure in der Lage ist, über eine Reduzierung der cAMP (zyklisches Adenosin-Monophosphat)-Level die Pmp22-Expression zu hemmen (Kaya et al. 2007). In einem Mausmodell der CMT1A führte eine Hochdosistherapie mit Ascorbinsäure zu einer signifikanten Verbesserung der motorischen Fähigkeiten. Die in diesem Experiment verwendete Pmp22-überexprimierende Mauslinie zeigte eine reduzierte Lebenserwartung gegenüber Wildtyp-Mäusen. Die Behandlung mit Ascorbinsäure konnte die Lebenserwartung der transgenen Tiere annähernd verdoppeln (Passage et al. 2004). Mehrere, randomisierte, doppelt geblindete Studien mit unterschiedlichen Dosierungen an Patienten verschiedener Altersgruppen konnten jedoch keinen signifikanten Effekt einer Therapie mit Ascorbinsäure zeigen (Burns et al. 2009; Micallef et al. 2009; Verhamme et al. 2009; Pareyson et al. 2011; Lewis et al. 2013).

Ein weiterer pharmakologischer Ansatz zur Behandlung der CMT1A ist die Verwendung eines Progesteronantagonisten. Der Progesteronrezeptor wird von Schwannzellen exprimiert (Jung-Testas et al. 1996) und Progesteron von Schwannzellen synthetisiert (Robert et al. 2001). Progesteron spielt eine wichtige Rolle in der Myelinisierung des peripheren Nervensystems (Schumacher et al. 2001) und führt zu einer gesteigerten Expression vom Pmp22 in Schwannzellen (Sereda et al. 2003). Die Behandlung transgener Ratten mit einem Progesteronantagonisten ist in der Lage die Überexpression von Pmp22 zu reduzieren und den Phänotyp der Tiere zu verbessern (Sereda et al. 2003; Meyer zu Horste et al. 2007). Eine Langzeittherapie mit dem verwendeten Progesteronrezeptorantagonisten Onapristone scheiterte jedoch bisher an den damit verbundenen Nebenwirkungen. 
In HeLa-Zellen wurde beobachtet, dass Pmp22-Protein mit der Trembler- oder Trembler-JMutation (Punktmutationen im Pmp22-Gen) im endoplasmatischen Retikulum akkumuliert und eine Apoptose der Zellen einleitet. Eine Behandlung der Zellen mit Curcumin, einem Gewürz- und Aromastoff aus der Wurzel der Kurkumapflanze, konnte die Apoptoserate der Zellen vermindern. Eine Behandlung von neugeborenen Trembler-J-Mäusen mit Curcumin konnte ebenfalls die Apoptose von Schwannzellen reduzieren, die motorischen Fähigkeiten verbessern sowie die Myelindicke erhöhen (Khajavi et al. 2007). Eine Therapiestudie in der Pmp22-transgenen Ratte konnte jedoch bisher keinen überzeugenden Effekt von Curcumin nachweisen (Weiss 2014).

\subsection{Lithium}

\subsubsection{Einsatz von Lithium in der Medizin}

Lithium ist ein chemisches Element mit der Ordnungszahl 3. Es ist das erste Alkalimetall im Periodensystem. Aufgrund seiner hohen Reaktivität kommt Lithium in der Natur nicht gediegen vor. Lithium wird in Form seiner Salze klinisch seit den 50er Jahren erfolgreich für die Behandlung psychiatrischer Erkrankungen eingesetzt. Der genaue Wirkmechanismus ist jedoch bisher weitgehend unverstanden. Zahlreiche Studien haben sich mit der Rolle von Lithium für verschiedene neurologische Erkrankungen befasst. Insbesondere sind neuroprotektive Eigenschaften von Lithium im Zusammenhang mit M. Alzheimer, Amyotropher Lateralsklerose, Chorea Huntington und traumatischen Hirnverletzungen beschrieben worden (Rowe und Chuang 2004; Aghdam und Barger 2007; Yu et al. 2012). Auch zeigt Lithium positive Effekte auf axonale, Chemotherapie-induzierte Neuropathien im Tiermodell (Alimoradi et al. 2012; Mo et al. 2012). Weiterhin wurden in mehreren Studien immunmodulatorische und antientzündliche Effekte von Lithium beschrieben. So reduziert Lithium die Immunantwort von Mäusen mit experimenteller autoimmuner Encephalomyelitis, dem Tiermodell für Multiple Sklerose, und verbessert den Krankheitsverlauf der Tiere (De Sarno et al. 2008; Rowse et al. 2012). Bei der Einnahme von Lithium besteht keine Abhängigkeitsgefahr und in richtiger Dosierung zeigt sich eine gute Verträglichkeit. Die therapeutische Breite von Lithium ist, vermutlich aufgrund der geringen Affinität zu Ionenpumpen und der resultierenden Gefahr einer intrazellulären Akkumulation, relativ schmal, so dass in der klinischen Praxis regelmäßige Kontrollen der Lithiumspiegel im Serum erfolgen müssen (Delva und Hawken 2001). Lithium-Intoxikationen können zu Neurotoxizität, Kardiotoxizität sowie Nephrotoxizität führen (Delva und Hawken 2001). Sehr selten können Lithium-Intoxikationen das periphere Nervensystem mit einer axonalen Affektion betreffen (Chan et al. 2012). Die neurologischen Symptome sind nach Absetzen der Medikation reversibel (Delva und Hawken 2001; Chan et al. 2012). Am häufigsten treten zu Beginn der Behandlung mit Lithium gastrointestinale Nebenwirkungen auf. 


\subsubsection{Einfluss von Lithium auf die Myelinisierung im peripheren und zentralen Nervensystem}

Ein Effekt von Lithium auf myelinbildende Zellen des Nervensystems wurde erstmals 1987 in In-vitro-Experimenten zur Schwannzell-Proliferation (Yoshino und DeVries 1987) beschrieben. Einen direkten Einfluss von Lithium auf die Remyelinisierung von Schwannzellen zeigten Analysen nach einer akuten peripheren Nervenschädigung. In experimentellen Nerventraumata des Facialis- sowie des Ischiasnerven in Ratten konnte nachgewiesen werden, dass eine Therapie mit Lithium die Remyelinisierung verletzter Nerven fördert und die funktionelle Wiederherstellung der betroffenen Nerven verbessert. Dabei induziert Lithium über eine Inhibition der Glykogensynthasekinase 3 beta (GSK3b) und konsekutive Aktivierung des Wnt/B-Catenin-Signalwegs die Expression der Myelingene Myelinprotein 0 (Mpz) und Pmp22 (Makoukji et al. 2012). Eine wichtige Rolle des Wnt/B-Catenin-Signalwegs für die Differenzierung und Myelinisierung wurde in den letzten Jahren sowohl für Schwannzellen als auch für Oligodendrozyten beschrieben (Tawk et al. 2011). Eine Dysregulation des Wnt/B-Catenin-Signalwegs wurde dabei als wichtige Komponente für die fehlende Remyelinisierung im zentralen Nervensystem beschrieben (Fancy et al. 2009). Lithium entfaltet seine Wirkung jedoch nicht nur über den Wnt/ß-Catenin-Signalweg. Weitere wichtige, durch Lithium aktivierte intrazelluläre Signalkaskaden sind der PI3K/AKT- sowie der MAPK/ERKSignalweg (Einat et al. 2003; Pardo et al. 2003; Sinha et al. 2005; Pasquali et al. 2010). Beide Transduktionswege sind für die Entwicklung des peripheren Nervensystems und die Myelinbildung essentiell (Taveggia et al. 2010; Salzer 2012). Der Effekt von Lithium auf die PI3K/AKT- und MAPK/ERK-Signalwege in Schwannzellen während der physiologischen Myelinisierung wie auch in demyelinisierenden Erkrankungen ist bisher nicht untersucht worden. Auch wurde die Bedeutung des Lithium-Wnt/B-Catenin-Signalwegs während der Entwicklung von Schwannzellen und in chronisch demyelinisierenden Neuropathien in vivo bisher nicht analysiert. Verschiedene Autoren konnten außerdem eine Erhöhung des brainderived neurotrophic factors (BDNF) durch eine Behandlung mit Lithium im Blut von Menschen (Leyhe et al. 2009) bzw. im Hirn von Ratten (Fukumoto et al. 2001) zeigen. BDNF hat wiederum zahlreiche Effekte auf Neurogenese und neuronale Plastizität (Foltran und Diaz 2016) sowie auf die Myelinisierung (Funakoshi et al. 1993; Chan et al. 2001; Cosgaya et al. 2002).

\subsection{Ziele der Arbeit}

Lithium kann vielfältige Einflüsse auf das zentrale und periphere Nervensystem haben. Verschiedene Studien konnten einen neuroprotektiven Effekt von Lithium zeigen. Im peripheren Nervensystem ist Lithium in der Lage die Remyelinisierung nach Nervenverletzungen zu verbessern oder eine Chemotherapie-induzierte Neuropathie abzumildern. Der Einfluss von Lithium auf zahlreiche, für die Myelinisierung wichtige Signalwege wurde bereits gezeigt (Gabreëls-Festen und Wetering 1999). Auch eine direkte Beeinflussung der Expression von Myelinproteinen durch Lithium wurde publiziert (Makoukji et al. 2012). 
In der vorliegenden Arbeit soll zunächst der Einfluss von Lithium auf die Myelinisierung in Wildtyp-Ratten untersucht werden. Dazu sollen Ratten mit Lithium behandelt und der Einfluss von Lithium auf das periphere Nervensystem zu zwei Zeitpunkten während der Myelinisierung sowie zu einem Zeitpunkt nach Abschluss der Myelinisierung histologisch und molekularbiologisch untersucht werden. In einem zweiten Schritt soll die Kultivierung von primären Schwannzellen und die Analyse des Einflusses von Lithium auf die Expression von ausgewählten Genen sowie die Aktivierung von myelinassoziierten Signalwegen erfolgen. Außerdem soll der Einfluss von Lithium auf die In-vitro-Myelinisierung in einer Co-Kultur aus primären Schwannzellen und Neuronen aus dorsalen Hinterwurzelganglien der Ratte untersucht werden. Im klinischen Alltag wird Lithium als zugelassenes Medikament regelhaft zur Behandlung der bipolaren Störung eingesetzt. Seine Verträglichkeit und Sicherheit sind bereits mehrfach gezeigt worden. Für die CMT1A ist trotz großer Fortschritte in der Forschung noch keine Therapie verfügbar. Um die Möglichkeit einer bereits verfügbaren und gut verträglichen medikamentösen Behandlung zu untersuchen, soll der Einfluss von Lithium auf den Krankheitsverlauf in einem Rattenmodell der CMT1A histologisch und molekularbiologisch untersucht werden. 


\section{Material und Methoden}

\subsection{Material}

\subsubsection{Chemikalien und Bioreagenzien}

Tabelle 3: Chemikalien und Bioreagenzien

\begin{tabular}{|c|c|c|}
\hline Chemikalien und Bioreagenzien & Hersteller & Stadt/Land \\
\hline Acrylamid & Sigma-Aldrich & Schnelldorf \\
\hline Agarose & Bio-Rad & Hercules, USA \\
\hline Ammoniumacetat & Merck & Darmstadt \\
\hline Ammoniumperoxiddisulfat (APS) & Merck & Darmstadt \\
\hline Ascorbinsäure & Sigma-Aldrich & Schnelldorf \\
\hline Aqua-Poly/Mount & Polysciences, Inc. & Eppelheim \\
\hline Azur-II-Farbstoff & Merck & Darmstadt \\
\hline \multirow[t]{2}{*}{ Bromphenolblau } & International & Eldersburg, USA \\
\hline & Biotechnology Inc. & \\
\hline Beta-Mercaptoethanol & Merck & Darmstadt \\
\hline Bleicitrat & Merck & Darmstadt \\
\hline Bovines Pituitary Extract (BPE) & Sigma-Aldrich & Schnelldorf \\
\hline Bovines Serumalbumin (BSA) & Sigma-Aldrich & Schnelldorf \\
\hline Chloroform & Merck & Darmstadt \\
\hline 3-3'-diaminobenzidin (DAB) & Zytomed & Berlin \\
\hline 4',6-Diamidin-2-phenylindol (DAPI) & Boehringer & Mannheim \\
\hline 2-Duodecenyl-succinicacidanhydrid (DDSA) & Serva & Heidelberg \\
\hline 1,4-Dithiotreitol (DTT) & GibcoBRL & Karlsruhe \\
\hline Essigsäure & Merck & Darmstadt \\
\hline Ethylendiamintetraacetat (EDTA) & Merck & Darmstadt \\
\hline Ethanol & Merck & Darmstadt \\
\hline Ethidiumbromid & Sigma-Aldrich & Schnelldorf \\
\hline Eukitt (Einbettmedium) & Kindler $\mathrm{GmbH}$ & Freiburg \\
\hline
\end{tabular}




\begin{tabular}{|c|c|c|}
\hline Chemikalien und Bioreagenzien & Hersteller & Stadt/Land \\
\hline Fetales Kälberserum (FCS) & PAN Biotech & Aidenbach \\
\hline Ficoll (Typ 400) & Sigma-Aldrich & Schnelldorf \\
\hline Formol & Merck & Darmstadt \\
\hline Formvar & Merck & Darmstadt \\
\hline Forskolin & Sigma-Aldrich & Schnelldorf \\
\hline Gelatine & Sigma-Aldrich & Schnelldorf \\
\hline Glutardialdehyd & Merck & Darmstadt \\
\hline GlutaMax & GibcoBRL & Karlsruhe \\
\hline Hanks Balanced Salts Solution (HBSS) & GibcoBRL & Karlsruhe \\
\hline Isopropanol & Merck & Darmstadt \\
\hline Kaliumchlorid (KCl) & Merck & Darmstadt \\
\hline Ketamin $($ Ketanest $\mathbb{R})$ & Parke-Davis & Berlin \\
\hline Lithiumcarbonat $\left(\mathrm{Li}_{2} \mathrm{CO}_{3}\right)$ & Merck & Darmstadt \\
\hline Magnesiumchlorid & Merck & Darmstadt \\
\hline Methanol & Merck & Darmstadt \\
\hline Modified Eagle's Medium (MEM) & Invitrogen & Darmstadt \\
\hline Methylenblau & Merck & Darmstadt \\
\hline Dinatriumhydrogenphosphat $\left(\mathrm{Na}_{2} \mathrm{HPO}_{4}\right)$ & Merck & Darmstadt \\
\hline $\begin{array}{l}\text { Dinatriumhydrogenphosphat-2-hydrat } \\
\left(\mathrm{Na}_{2} \mathrm{HPO}_{4} 2 \mathrm{H}_{2} \mathrm{O}\right)\end{array}$ & Merck & Darmstadt \\
\hline Natriumchlorid $(\mathrm{NaCl})$ & Merck & Darmstadt \\
\hline $\begin{array}{l}\text { Natriumdihydrogenphosphat-hydrat } \\
\left(\mathrm{NaH}_{2} \mathrm{PO}_{4} \mathrm{H}_{2} \mathrm{O}\right)\end{array}$ & Merck & Darmstadt \\
\hline Natriumhydroxid $(\mathrm{NaOH})$ & Merck & Darmstadt \\
\hline Nerve growth factor (NGF) & Alamone Labs & Jerusalem, Israel \\
\hline Osmiumtetroxid & Serva & Heidelberg \\
\hline Paraformaldehyd & Serva & Heidelberg \\
\hline Phosphatase Inhibitor PhosSTOP & Roche & Grenzach \\
\hline Proteinase Inhibitor & Roche & Grenzach \\
\hline
\end{tabular}




\begin{tabular}{lll}
\hline \hline Chemikalien und Bioreagenzien & Hersteller & Stadt/Land \\
\hline Salzsäure (HCl) & Serva & Heidelberg \\
Sodium-Dodecyl-Sulfat (SDS) & Sigma-Aldrich & Schnelldorf \\
Sucrose & Sigma-Aldrich & Schnelldorf \\
Taq-Polymerase Puffer & Promega & Walldorf \\
Tris-HCl Base & Sigma-Aldrich & Schnelldorf \\
Triton X 100 & Sigma-Aldrich & Schnelldorf \\
Trypsin & Merck & Darmstadt \\
Uranylacetat & Merck & Darmstadt \\
Xylol & Merck & Darmstadt \\
Xylazin $\left(\right.$ Rompun $\left.{ }^{\circledR}\right)$ & Bayer & Leverkusen \\
Ziegenserum & Invitrogen & Darmstadt \\
\hline \hline
\end{tabular}

\subsubsection{Verbrauchsmaterial}

Tabelle 4: Verbrauchsmaterial

\begin{tabular}{lll}
\hline \hline Verbrauchsmaterial & Hersteller & Stadt/Land \\
\hline CO2-Gas & Air Liquide & Ludwigshafen \\
Coverplates für Immunhistochemie & Dako Cytomation & Hamburg \\
Deckgläschen & Marienfeld & Lauda-Königshofen \\
Einmalhandschuhe & Hartmann & Heidenheim \\
Falcon Röhrchen & Becton \& Dickinson & Heidelberg \\
Injektionskanülen & Becton \& Dickinson & Freiburg \\
Kupfergrids für Elektronenmikroskopie & Plano & Wetzlar \\
Mikroreaktionsgefäße & Eppendorf & Hamburg \\
NuPage 4-12\% Bis-Tris Gele & Invitrogen & Darmstadt \\
Objektträger & Gerhard Menzel & Braunschweig \\
Objektträger & Marienfeld & Lauda-Königshofen \\
Papiertücher & Wepa Professional & Arnsberg \\
PCR-Mikrotiterplatten 96well & ABgene & Surrey, UK \\
\hline \hline
\end{tabular}




\begin{tabular}{lll}
\hline \hline Verbrauchsmaterial & Hersteller & Stadt/Land \\
\hline PCR-Mikrotiterplatten 384-well & Roche & Mannheim \\
PCR-Plattenfolie & ABgene & Surrey, UK \\
Pipettenspitzen & Molecular Bioproduct & San Diego, USA \\
Präparationsbesteck & Fine Science Tools & Heidelberg \\
PVDF-Membran Hybond-PTM & GE Healthcare & Freiburg \\
Spritzen & Henke Saas Wolf & Tuttlingen \\
Spritzen & Becton \& Dickinson & Freiburg \\
Sterilfiltrationseinheit & Corning & Amsterdam, NL \\
Stickstoff flüssig & Air Liquide & Ludwigshafen \\
Tierfutter & SSniff Spezialdiäten & Soest \\
Trockeneis & Air Liquide & Ludwigshafen \\
Zellkulturplatten & Becton \& Dickinson & Freiburg \\
Zellkulturplatten und -schalen & Thermo Fisher Scientific & Braunschweig \\
\hline \hline
\end{tabular}

\subsubsection{Geräte}

Tabelle 5: Geräte

\begin{tabular}{lll}
\hline \hline Geräte & Hersteller & Stadt/Land \\
\hline Agarose-Gelkammer mit Kämmen & Hauswerkstatt MPI exp. Med. Göttingen \\
Agarosegeldokumentation Image Master Amersham Pharmacia Biotech & Freiburg \\
VDS & & \\
Blotkammern für Western Blots & Invitrogen & Darmstadt \\
Binokular M125 & Zeiss & Jena \\
CCD Kamera für EM & TRS & Moorenweis \\
Diamantmesser Diatome Ultra 35 & Diatome & Biel, CH \\
Elektronenmikroskop EM900 & Zeiss & Hamburg \\
\hline \hline
\end{tabular}




\begin{tabular}{|c|c|c|}
\hline Geräte & Hersteller & Stadt/Land \\
\hline Elektrophysiologiegerät Neuroscreen & $\begin{array}{l}\text { Jaeger Toennies, Erich Jaeger } \\
\text { GmbH }\end{array}$ & Höchberg \\
\hline Feinwaage & Heraeus Instruments & Langenselbold \\
\hline Fräse für Epon-Präparate EM TRIM & Reichert & Wien, AT \\
\hline Gefrierschrank $-20^{\circ} \mathrm{C}$ & Liebherr & Ochsenhausen \\
\hline Gefrierschrank $-80^{\circ} \mathrm{C}$ & New Brunswick Scentific & Nürtingen \\
\hline Gewebe-Einbettautomat Lynx el & Vision BioSystems Inc & Norwell, USA \\
\hline Gewebe-Einbettautomat EM TP & Leica Microsystems & Wetzlar \\
\hline $\begin{array}{l}\text { Gewebehomogenisierer Ultraturrax } \\
\text { PT3000 }\end{array}$ & IKA Labortechnik & Staufen \\
\hline Gewebehomogenisator Precellys 24 & PEQLAB Biotechnologie & Erlangen \\
\hline Glaswaren & Schott & Mainz \\
\hline Griffstärkemesser & Hauswerkstatt MPI exp. Med. & Göttingen \\
\hline Kaffeemaschine Bar & Mellita & Minden \\
\hline Laborwaagen & Sartorius & Göttingen \\
\hline Lichtmikroskop Axio Imager Z1 & Zeiss & Jena \\
\hline Lichtmikroskop Observer Z & Zeiss & Jena \\
\hline Magnetrührer RCT basic Ikamag & Omnilab & Bremen \\
\hline NanoDrop200 Spectraphotometer & Thermo Fisher Scientific Inc. & Braunschweig \\
\hline Thermomax microplate reader & MWG-Biotech & Ebersberg \\
\hline Thermomixer 5436 & Eppendorf & Hamburg \\
\hline Pipettierhilfe Pipetboy & Integra Biosciences & Fernwald \\
\hline PCR-Thermocycler T3 & Biometra & Göttingen \\
\hline PCR Versiegler $4 \mathrm{~s}^{2}$ & 4titude & Berlin \\
\hline Pipettenspitzen & Gilson & Villiers-le-Bel, FR \\
\hline Probenmischgerät Vortexer & Bender \& Hobein & München \\
\hline $\begin{array}{l}\text { Real-Time-PCR-System LightCycler }{ }^{\circledR} \\
480\end{array}$ & Roche Applied Sciences & Mannheim \\
\hline Reinstwasseranlage & Sartorius & Göttingen \\
\hline
\end{tabular}




\begin{tabular}{lll}
\hline \hline Geräte & Hersteller & Stadt/Land \\
\hline Rotationsmikrotom Leica RM 2155 & Leica Microsystems & Wetzlar \\
SDS-Page Kammer X-cell sure lock & Invitrogen & Darmstadt \\
Wasserbad & Memmert & Schwabach \\
Western Blot Gel Imager & Intas & Göttingen \\
Zellkulturinkubator Function Line & Heraeus Instruments & Langenselbold \\
Zentrifuge Heraeus Biofuge 13 & Heraeus Instruments & Langenselbold \\
Zentrifuge Laboratory Centrifuge 4K15 & Sigma Laborzentrifugen & Osterode Harz \\
Zentrifuge Labofuge 400 & Heraeus Instruments & Langenselbold \\
Kühlzentrifuge 5415R & Eppendorf & Hamburg \\
Zentrifuge Optima TLX & Beckman & Krefeld \\
\hline \hline
\end{tabular}

\subsubsection{Reaktionkomplettaustattungen}

Tabelle 6: Reaktionskomplettausstattungen

\begin{tabular}{|c|c|c|}
\hline Reaktionskomplettausstattungen & Hersteller & Stadt/Land \\
\hline Chemilumineszenzkit (Western Blot) & Perkin Elmer & Rodgau \\
\hline $\begin{array}{l}\text { Desoxyribonukleosid-Triphosphate } \\
\text { (dNTPs) }\end{array}$ & Boehringer & Mannheim \\
\hline DNA-Größenmarker Lambda/HindIII & Promega & Mannheim \\
\hline DNA-Größenmarker PhiX174/HaeIII & Promega & Mannheim \\
\hline DNeasy 96 $96^{\mathrm{TM}}$ Kit für DNA-Isolation & Qiagen & Hilden \\
\hline GoTaq $^{\mathrm{TM}}$ DNS-Polymerase & Promega & Mannheim \\
\hline Lowry Assay & Bio-Rad & Hercules, USA \\
\hline nexttec $^{\mathrm{TM}}$ Genomic DNA Isolation Kit & nexttec Biotechnologie $\mathrm{GmbH}$ & Hilgertshausen \\
\hline Power Sybr ${ }^{\circledR}$ Green PCR Master Mix & Applied Biosystems & Waltham, USA \\
\hline $\begin{array}{l}\text { Precision Plus Protein }{ }^{\mathrm{TM}} \text { Standard Dual } \\
\text { Color }\end{array}$ & Bio-Rad & Hercules, USA \\
\hline Proteinase K & Boehringer & Mannheim \\
\hline randomisierte Nonamer-Primer & $\begin{array}{l}\text { DNA Core Facility MPI exp. } \\
\text { Med. }\end{array}$ & Göttingen \\
\hline
\end{tabular}




\begin{tabular}{lll}
\hline \hline Reaktionskomplettausstattungen & Hersteller & Stadt/Land \\
\hline RNeasy ${ }^{\text {TM}}$ Mini Kit für RNA-Isolation & Quiagen & Hilden \\
Superscript IIITM RT-Kit & Invitrogen & Darmstadt \\
Taq-Polymerase Puffer & Promega & Mannheim \\
Taq-DNA-Polymerase $(5 \mathrm{U} / \mu \mathrm{l})$ & Boehringer & Mannheim \\
QIAzol Lysis Reagent & Quiagen & Hilden \\
\hline \hline
\end{tabular}

\subsubsection{Lösungen und Puffer}

Tabelle 7: Lösungen und Puffer

DNA-Probenpuffer

Bromphenolblau

$0,25 \mathrm{~g}$

Xylenxyanol

$0,25 \mathrm{~g}$

Ficoll (Typ 400)

$5 \mathrm{~g}$ in $100 \mathrm{ml} \mathrm{H}_{2} \mathrm{O}$

Blocking-Lösung für Immunzytochemie

\begin{tabular}{lc}
\hline BSA & $2 \mathrm{~g}$ \\
Horse Serum & $2 \mathrm{~g}$ \\
Gelatine & $0,1 \mathrm{~g}$
\end{tabular}

In 100 ml d-PBS lösen.

TAE-Puffer (50x Lösung, 1000 ml)

$\begin{array}{lc}\text { Tris-HCl Base } & 242 \mathrm{~g} \\ \text { Essigsäure } 100 \% & 57,1 \mathrm{ml} \\ \text { EDTA }(0,5 \mathrm{M} ; \mathrm{pH} 8) & 100 \mathrm{ml}\end{array}$

auf $1000 \mathrm{ml}$ mit dd $\mathrm{H}_{2} \mathrm{O}$ auffüllen 
PBS (phosphat-gepufferte Salzlösung (10x Stammlösung, 1000 ml)

\begin{tabular}{lc}
\hline $\mathrm{NaCl}$ & $100 \mathrm{~g}$ \\
$\mathrm{KCl}$ & $2,5 \mathrm{~g}$ \\
$\mathrm{Na}_{2} \mathrm{HPO}_{4} 2 \mathrm{H}_{2} \mathrm{O}$ & $7,2 \mathrm{~g}$ \\
$\mathrm{KH}_{2} \mathrm{PO}_{4}$ & $2,5 \mathrm{~g}$
\end{tabular}

auf $900 \mathrm{ml}$ mit $\mathrm{H}_{2} \mathrm{O}$ auffüllen; pH 7,2 mit $10 \mathrm{~N} \mathrm{NaOH}$ einstellen; auf $1000 \mathrm{ml}$ mit $\mathrm{H}_{2} \mathrm{O}$ auffüllen; autoklavieren; zur Verwendung die Stammlösung 1:10 verdünnen (1x PBS)

TBS (1000 ml)

Tris-HCl 1 M, pH 8,8 $50 \mathrm{ml}(50 \mathrm{mM})$

$\mathrm{NaCl}(5 \mathrm{M})$ $30 \mathrm{ml}(150 \mathrm{mM})$

auf $1000 \mathrm{ml}$ mit dd $\mathrm{H}_{2} \mathrm{O}$ auffüllen, $\mathrm{pH}$ 7,4 mit $1 \mathrm{M} \mathrm{HCl}$ einstellen

Sucrosepuffer

Sucrose

Tris-HCl 1 M, pH 8,8

$\mathrm{NaHCO}_{3}$

$\mathrm{MgCl}_{2}$

6x Sample Buffer/Loading Buffer

0.5 M Tris (pH 6.8)

Glycerol

DT'T

$10 \%$ Brom Blue

$10 \%$ SDS
$320 \mathrm{mM}$

$10 \mathrm{mM}$

$1 \mathrm{mM}$

$1 \mathrm{mM}$
$7 \mathrm{ml}$

$2.6 \mathrm{ml}$

$1 \mathrm{~g}$

$60 \mu \mathrm{l}$

$400 \mu \mathrm{l}$ 
K\&S Fixans nach Karlsson und Schultz (1965) für Licht- und Elektronenmikroskopie

Natriumdihydrogenphosphat $\mathrm{x}_{2} \mathrm{O}$ $0,36 \mathrm{~g}$

Dinatriumhydrogenphosphat x $2 \mathrm{H}_{2} \mathrm{O}$

$\mathrm{NaCl}$ $1 \mathrm{~g}$

Glutardialdehydlösung $25 \%$ $20 \mathrm{ml}$

Paraformaldehyd (PFA)

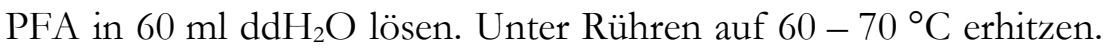
Mit $\mathrm{ddH}_{2} \mathrm{O}$ auf $80 \mathrm{ml}$ auffüllen. Langsam $1 \mathrm{M} \mathrm{NaOH}$ zugeben bis Lösung klar wird. Lösung steril filtrieren und mit $1 \mathrm{M} \mathrm{HCL}$ auf $\mathrm{pH}$

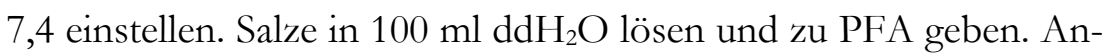
schließend $20 \mathrm{ml}$ Glutardialdehydlösung zugeben.

Kunstharzmischung Epon nach Luft (1961)

Epon Lösung A:

Glycidether $67,5 \mathrm{~g}$

Dodecenylsuccinicanhydrid (DDSA) $88,2 \mathrm{~g}$

eine Stunde mit Magnetrührer rühren

Epon Lösung B:

Glycidether $82,3 \mathrm{~g}$

Methylnadicanhydrid (MNA) $73,3 \mathrm{~g}$

eine Stunde mit Magnetrührer rühren

Gebrauchslösung Epon:

Epon Lösungen A und B im Verhältnis 1:1 mischen; 1,8 \% 2,4,6-

Trisdimethylaminomethylphenol (DMP 30) zufügen.

Laufpuffer für Polyacrylamidgele (20x):

MOPS

Tris Base

SDS

EDTA
$1 \mathrm{M}$

$1 \mathrm{M}$

69,3 mM

$20,5 \mathrm{mM}$ 
Lysepuffer für Proteinlysaten aus Ischiasnerven:

Sucrose

Tris

$\mathrm{NaHCO}_{3}$

$\mathrm{MgCl}_{2}$
$320 \mathrm{mM}$

$10 \mathrm{mM}$

$1 \mathrm{mM}$

$1 \mathrm{mM}$

Proteinase-Hemmer (Complete, Roche) und Phosphatase-Hemmer

(PhosSTOP, Roche), je eine Tablette für $10 \mathrm{ml}$ Lösung

Protein-Probenpuffer (2x):

Glyzerin

SDS

Bromphenolblau

Tris-Base
$20 \%$

$4,6 \%$

$0,4 \%$

$125 \mathrm{mM}$

auf $50 \mathrm{ml}$ mit dd $\mathrm{H}_{2} \mathrm{O}$ auffüllen. Mit HCL auf pH 6,8 einstellen. $\mathrm{Zu}$

$20 \mu \mathrm{l}$ Probenpuffer vor Probenzugabe $1 \mu \mathrm{l}$ ß-Mercaptoethanol (5 \%)

zugeben.

\subsubsection{Nukleinsäuren und Nukleotide}

\subsubsection{Primer zur Genotypisierung transgener Ratten}

Tabelle 8: Primer zur Genotypisierung transgener Ratten

\begin{tabular}{ll}
\hline \hline PMP22 & \\
\hline Sense: & 5'-GACAAACCCCAGACAGTTG-3' \\
Antisense: & 5'-CCAGAAAGCCAGGGAACTC-3' \\
\hline \hline
\end{tabular}

\subsubsection{Primer für semiquantitative Real-Time-PCR}

Primer für semiquantitative Real-Time-PCR (qRT-PCR) wurden mit Hilfe des Roche Universal ProbeLibrary Assay Design Center https://www.roche-applied-science.com/sis/rtpcr/upl/index.jsp?id=uplct_030000 (abgerufen 16.08.2020) designed. Dabei wurden Primer so gewählt, dass sie Introns umspannen, um die Gefahr der Amplifikation genomischer DNA zu vermindern. Die Primer wurden mit Hilfe der Software OligoAnalyzer auf Bildung von Hairpins und Self- oder Heterodimeren untersucht und soweit 
möglich Oligonukleotide mit einem $\Delta G>-3 \mathrm{kcal} / \mathrm{mol}$ ausgewählt. Anschließend wurden die Primer mit NCBI/ Primer-BLAST http://www.ncbi.nlm.nih.gov/tools/primerblast/ (abgerufen 16.08.2020) auf ihre Spezifität getestet. Die Oligonukleotide wurden durch die DNA Core Facility des MPI für experimentelle Medizin hergestellt.

Tabelle 9: Primer für qRT-PCR

\begin{tabular}{|c|c|}
\hline$B d n f$ & \\
\hline Sense: & 5'-GACAAACCCCAGACAGTTG-3' \\
\hline Antisense: & 5'-CCAGAAAGCCAGGGAACTC-3' \\
\hline \multicolumn{2}{|l|}{ Cyclophillin } \\
\hline Sense: & 5'-AGCACTGGGGAGAAAGGAT'T-3' \\
\hline Antisense: & 5'-AGCCACTCAGTCTTGGCAGT-3' \\
\hline \multicolumn{2}{|l|}{ Cx43/Gja1 } \\
\hline Sense: & 5'-TCCACTCTCGCCTATGTCT-3' \\
\hline Antisense: & 5'-GTAGTTCGCCCAGTTTTTGC-3' \\
\hline \multicolumn{2}{|l|}{ Gsk3b } \\
\hline Sense: & 5'-GCCACAGGAAGTCAGTTAC-3' \\
\hline Antisense: & 5'-GCAATCGGACTATGT'TACAG-3' \\
\hline \multicolumn{2}{|l|}{ Hmgcr } \\
\hline Sense: & 5'-CACAGTGCCACATACAATTCG-3' \\
\hline Antisense: & 5'-CACAGTGCCACATACAATTCG-3' \\
\hline \multicolumn{2}{|l|}{ Krox20/Egr2 } \\
\hline Sense: & 5'-CTACCCGGTGGAAGACCTC-3' \\
\hline Antisense: & 5'-TCAATGTTGATCATGCCATCTC-3' \\
\hline \multicolumn{2}{|l|}{$M b p$} \\
\hline Sense: & 5'-CCATGGGAGATCCAGAGC-3' \\
\hline Antisense: & 5'-GGCACGCT'TTCCAAAATCT-3' \\
\hline \multicolumn{2}{|l|}{ Mpr. } \\
\hline Sense: & 5'-TGCCCTGCTCTTCTCT'TCTT-3' \\
\hline Antisense: & 5'-TCССТGTCCGTGTAAACCAC-3' \\
\hline \multicolumn{2}{|l|}{ Oa:1 } \\
\hline Sense: & 5'-GCCTGAGGGCAGTAAGGAC-3' \\
\hline Antisense: & 5'-GGAGTAGGGCGGCTCTGT-3' \\
\hline
\end{tabular}


Oct6/Pou3f1

\begin{tabular}{ll}
\hline Sense: & 5'-GAGCGCAGACCCTCTCTG-3' \\
Antisense: & 5'-CAT'T'TTCGTTTCGT'TT'TACCC-3' \\
Periaxin & \\
\hline Sense: & 5'-AGAGCTATGGAGGCCAGGA-3' \\
Antisense: & 5'-CTCCACGATAATCTCCACCAA-3' \\
Pmp22 & \\
\hline Sense: & 5'-TGTACCACATCCGCCTTGG-3' \\
Antisense: & 5'-GAGCTGGCAGAAGAACAGGAAC-3' \\
Rphp0 & \\
\hline Sense: & 5'-GATGCCCAGGGAAGACAG-3' \\
Antisense: & 5'-CACAATGAAGCATTTTGGGTAG-3' \\
Scap & 5'-AAACAAGGAGAGCCCAGTGA-3' \\
\hline Sense: & 5'-CGAATATCTGCTGGATGTATGC-3' \\
Antisense: & \\
Ki67 & 5'-TGATGCTAAACTGGAAAATGGA-3' \\
\hline Sense: & 5'-CATCTGCTGCTGCTTCTCCT-3' \\
Antisense: & \\
\hline \hline
\end{tabular}




\subsubsection{Antikörper}

Tabelle 10: Antikörper

\begin{tabular}{llll}
\hline \hline Epitop & Verdünnung & Spezies & Hersteller und Artikelnummer \\
\hline Primärantikörper: & & & \\
Anti-Actin & $1: 5000$ & Maus & Sigma $\backslash \#$ A3853 \\
Anti-pAKT & $1: 1000$ & Kaninchen & Cell signaling \\
#3787 \\
Anti-AKT & $1: 1000$ & Kaninchen & Cell signaling \\
#4691 \\
Anti-GAPDH & $1: 5000$ & Maus & Stressgene $\backslash \#$ CSA-335 \\
Anti-pMAPK & $1: 1000$ & Kaninchen & Cell signaling \\
#9101 \\
Anti-MAPK & $1: 1000$ & Kaninchen & Cell signaling \\
#4695 \\
Anti-Tuj1 & $1: 400$ & Kaninchen & Covance \\
#PRB-435P \\
Anti-MBP & $1: 5000$ & Kaninchen & Dako \\
#A0623 \\
Sekundärantikörper: & & & \\
Maus-HRP & $1: 5000$ & Ziege & Dianova $\backslash \# 115035003$ \\
Kaninchen-HRP & $1: 5000$ & Ziege & Dianova $\backslash \# 111035003$ \\
Mouse-A488 & $1: 2000$ & Affe & Invitrogen \\
#A21202 \\
Mouse-A555 & $1: 2000$ & Affe & Invitrogen $\backslash \# A 31570$ \\
Rabbit-A488 & $1: 2000$ & Affe & Dianova $\backslash \# 711545152$ \\
Rabbit-A555 & $1: 2000$ & Affe & Dianova \\
#111545144 \\
\hline \hline
\end{tabular}




\subsubsection{Software}

Tabelle 11: Software

\begin{tabular}{llll}
\hline \hline Typ & Software & Hersteller & Stadt/Land \\
\hline Bildanalysesoftware & Fiji/ImageJ 1,5 & Wayne Rasband, NIH & Bethesda, USA \\
Bildbearbeitung & Gimp 2.8 & The GIMP Team & Berkeley, USA \\
$\begin{array}{l}\text { Mikroskopsoftware } \\
\text { Elektronenmikroskopie }\end{array}$ & ImageSP & TRS image SysProg & Moorenwies \\
$\begin{array}{l}\text { Mikroskopsoftware } \\
\text { Lichtmikroskopie }\end{array}$ & Zeiss ZEN 2.1 & Carl Zeiss Microscopy & Jena \\
Oligoanalyzer & OligoAnalyzer 3.1 & GmbH & \\
& & Integrated DNA Tech- Coralville, USA \\
Statistiksoftware & Graph Pad PRISM 6 & Graphpad Software, & La Jolla, USA \\
& & Inc. & \\
Text und Tabellenverar- & Microsoft Office für & Microsoft Corporation & Redmond, USA \\
beitung & Mac 16 & & \\
\hline \hline
\end{tabular}

\subsection{Methoden}

\subsubsection{Versuchstiere}

Die Haltung der Tiere erfolgte unter standardisierten Bedingungen und entsprechend der Empfehlungen der deutschen Gesellschaft für Versuchstierkunde im Tierhaus des MaxPlanck-Instituts für Experimentelle Medizin in Göttingen. Die Raumtemperatur lag für alle Tiere bei $22 \pm 1{ }^{\circ} \mathrm{C}$, die relative Luftfeuchtigkeit bei $55 \pm 10 \%$. Die Luftwechselrate lag bei 15-fach pro Stunde. Die Beleuchtung erfolgte mit Kunstlicht von 4:30 bis 16:30 Uhr MEZ mit einer Lichtintensität von 300 Lux, gemessen in einer Höhe von einem Meter über dem Fußboden in der Raummitte. Futter und Wasser waren zu jeder Zeit ad libitum verfügbar. Alle Versuche erfolgten entsprechend des Tierversuchsantrags 33.9.42502-04-017/09 beim Niedersächsischen Landesamt für Verbraucherschutz und Lebensmittelsicherheit.

\subsubsection{Identifikation der Tiere und Schwanzbiopsien}

Zur Genotypisierung der Versuchstiere wurde im Alter von drei Wochen beim Absetzen von der Mutter eine circa 0,5 cm lange Schwanzbiopsie entnommen und bis zur weiteren Verarbeitung bei $-20{ }^{\circ} \mathrm{C}$ gelagert. Gleichzeitig wurden die Tiere mit einer Ohrlochmarkierung zur späteren Identifikation versehen. Jede Ohrlochmarkierung wurde einem eindeutigen Identi- 
fikationscode, bestehend aus einer Kennziffer für die jeweilige Tierlinie und einer fortlaufenden Nummer, zugeordnet. Dieser Identifikationscode wurde zusammen mit dem Geburtsdatum, Geschlecht und der Tierlinie auf einer Karte vermerkt und diese am Käfig befestigt. Für den Zeitraum der Versuche wurden diese Karten durch handgeschriebene Karten ersetzt, die keine Zuordnung zu Genotyp oder Behandlungsgruppe ermöglichten.

\subsubsection{Einteilung der Versuchstiere}

In der vorliegenden Arbeit wurden zum einen Wildtyp-Ratten, zum anderen Pmp22-transgene Ratten verwendet. Wildtyp-Tiere wurden zu den Alterszeitpunkten postnataler Tag 0 bis postnataler Tag 6, postnataler Tag 0 bis postnataler Tag 21 und postnataler Tag 30 bis postnataler Tag 117 untersucht (im Folgenden p0 - p6 bzw. entsprechend genannt). Für die Behandlung der juvenilen Wildtyp-Tiere ( $\mathrm{p} 0$ - p6 und $\mathrm{p} 0$ - p21) wurden neugeborene Wildtyp-Ratten randomisiert in zwei Gruppen eingeteilt. Für die Gruppe der adulten Tiere von p30 - p117 wurden die Tiere gewogen und in jeweils zwei gleich schwere Gruppen eingeteilt. Diese Einteilungen wurden von Herrn Dr. Bernhard G. Weiss durchgeführt.

Vor Behandlung der Pmp22-transgenen Versuchstiere sowie deren Wildtyp-Kontrollen wurden im Alter von 28 Tagen der Griffstärketest und eine Bestimmung des Körpergewichts durchgeführt. Die Ergebnisse wurden durch Herrn Dr. Bernhard G. Weiss ausgewertet und transgene Tiere und Wildtyp-Kontrollen in jeweils zwei in Gewicht und Muskelkraft vergleichbare Gruppen eingeteilt.

\subsubsection{Kraftmessung/Griffstärke}

Mit Hilfe des Griffstärketests wurde die maximale Kraft der Versuchstiere untersucht. Die Messung der Griffstärke der vorderen und hinteren Extremität erfolgte im Alter von 3, 10, 13 und 16 Wochen. Alle Messungen wurden im Verlauf der Studie unter Blindung von Genotyp und Gruppenzugehörigkeit durchgeführt. Jede Messung wurde pro Extremität sieben Mal wiederholt. Der minimale und maximale Wert worden zur Vermeidung von Ausreißern eliminiert. Aus den verbleibenden fünf Werten wurde ein Mittelwert berechnet. Zur Messung der Griffstärke wurden die Tiere mit der Vorder- bzw. Hinterpfote auf eine horizontale, mit einem Kraftmesser verbundene Stange gesetzt. Nach dem Zugreifen der Tiere wurde ein horizontaler Zug auf den Schwanz ausgeübt und die maximale Kraft bis zum Loslassen des Tieres durch den Kraftmesser registriert (siehe Meyer zu Horste et al. 2007).

\subsubsection{Elektrophysiologische Analyse}

Die elektrophysiologische Analyse der Lithium-behandelten Pmp22-transgenen Ratten und Kontrolltiere erfolgte geblindet für Genotyp und Gruppenzugehörigkeit im Alter von 16 Wochen. Die Tiere wurden durch eine intraperitoneale Injektion mit Ketaminhydrochlorid $(100 \mathrm{mg} / \mathrm{kg} / \mathrm{KG})$ und Xylazinhydrochlorid $(8 \mathrm{mg} / \mathrm{kg} / \mathrm{KG})$ anästhesiert. Zur Aufrechterhaltung der Körpertemperatur wurden die Tiere umgehend auf eine $37^{\circ} \mathrm{C}$ temperierte 
Wärmematte gelegt. Die Messung der Muskelsummenaktionspotentiale (MSAP) und der Nervenleitgeschwindigkeit (NLG) wurde am Schwanz durchgeführt.

Zur Bestimmung der motorischen NLG wurden zwei Stahlelektroden zur Stimulation an der Basis des Schwanzes (proximale Stimulation), sowie $2 \mathrm{~cm}$ distal davon (distale Stimulation) subkutan eingebracht. Die Ableitung erfolgte durch zwei weitere, $3 \mathrm{~cm}$ distal der Schwanzbasis eingebrachte Stahlelektroden. Die Stimulation durch supramaximale, $100 \mu$ s dauernde Reize, sowie die Aufzeichnung erfolgte mittels eines Toennis Neuroscreen Elektrophysiologie-Geräts. Als Amplitude wurde die Differenz zwischen maximalem und minimalem Ausschlag definiert. Die NLG wurde automatisch aus der Differenz der Latenzen von proximaler und distaler Stimulation und der Strecke zwischen distaler und proximaler Stimulation berechnet.

Die Messung der sensiblen NLG erfolgte wiederum mittels des Toennis Neuroscreen Elektrophysiologie-Geräts in orthodromer Technik. Es wurden zwei Ableitungselektroden an der Schwanzbasis subkutan eingestochen. Eine Erdungselektrode wurde subkutan in der Haut des Rückens eingebracht. Die Stimulation erfolgte $2 \mathrm{~cm}$ distal durch zwei weitere Stahlelektroden. Zur Ableitung wurden die Summennervenaktionspotentiale aus 20 - 30 Stimulationen gemittelt. Die sensible NLG wurde aus der Distanz zwischen Stimulations- und Ableitungselektroden und der Latenz errechnet.

\subsubsection{Tötung von Versuchstieren und Präparation von Gewebe}

Zur Gewinnung von Proben wurden die Tiere durch Einleiten von $\mathrm{CO}_{2}$-Gas in einen gasundurchlässigen Käfig getötet. Direkt nach Tötung der Tiere wurde durch Punktion des rechten Herzventrikels Blut zur Messung des Lithiumspiegels gewonnen. Für histologische und molekularbiologische Untersuchungen wurden Ischias- und Tibialisnerven entnommen. Nervenpräparate für molekularbiologische Untersuchungen wurden von Bindegewebe und Perineurium befreit, in flüssigen Stickstoff überführt und bis zur weiteren Verwendung bei $-80{ }^{\circ} \mathrm{C}$ gelagert. Biopsien zur histologischen Analyse wurden bis zur Einbettung in Fixativ nach Karlsson und Schultz fixiert.

\subsubsection{Bestimmung des Lithium-Serumspiegels}

Die Bestimmung des Lithium-Serumspiegels wurde durch ein kommerzielles Labor (Labor Lademannbogen, Dr. med. Lämmel, Hamburg) für den Untersucher geblindet durchgeführt. Die Bestimmung erfolgte nach dem Verfahren der ionenselektiven Elektrode (Potentiometrie). 


\subsubsection{Lichtmikroskopie und Elektronenmikroskopie}

2.2.2.1 Einbettung und Schneiden von Gewebe zur histologischen Untersuchung Zur Anfertigung von Semi- oder Ultradünnschnitten wurden die fixierten Nerven in das Epoxydharz Epon eingebettet. Das Epon wurde aus 21,4 ml Glycidether 100, 14,4 ml DDSA, 11,3 ml MNA und 0,84 ml DMP-30 nach der Methode nach Luft (1961) hergestellt. Es erfolgte eine Vorkontrastierung mit Osmiumtetraoxid, sowie die Entwässerung und Eponinfiltration mit Hilfe der automatischen Einbettmaschine Leica EM TP entsprechend des folgenden Schemas:

Tabelle 12: Protokoll Epon-Einbettung von Gewebe zur Licht- und Elektronenmikroskopie

\begin{tabular}{|c|c|c|}
\hline Lösung: & Dauer: & Temperatur: \\
\hline Phosphatpuffer 0,1 M & 15 Minuten & $4^{\circ} \mathrm{C}$ \\
\hline $1 \% \mathrm{OsO}_{4}$ & 2 Stunden & $4^{\circ} \mathrm{C}$ \\
\hline Phosphatpuffer 0,1 M & 20 Minuten & $20{ }^{\circ} \mathrm{C}$ \\
\hline Phosphatpuffer 0,1 M & 20 Minuten & $20{ }^{\circ} \mathrm{C}$ \\
\hline Phosphatpuffer 0,1 M & 20 Minuten & $20{ }^{\circ} \mathrm{C}$ \\
\hline $30 \%$ Ethanol & 30 Minuten & $20{ }^{\circ} \mathrm{C}$ \\
\hline $50 \%$ Ethanol & 30 Minuten & $20{ }^{\circ} \mathrm{C}$ \\
\hline $70 \%$ Ethanol & 30 Minuten & $20{ }^{\circ} \mathrm{C}$ \\
\hline $90 \%$ Ethanol & 30 Minuten & $20{ }^{\circ} \mathrm{C}$ \\
\hline $100 \%$ Ethanol & 15 Minuten & $20{ }^{\circ} \mathrm{C}$ \\
\hline $100 \%$ Ethanol & 15 Minuten & $20{ }^{\circ} \mathrm{C}$ \\
\hline $100 \%$ Ethanol & 15 Minuten & $20{ }^{\circ} \mathrm{C}$ \\
\hline $100 \%$ Ethanol & 15 Minuten & $20{ }^{\circ} \mathrm{C}$ \\
\hline Isopropanol & 15 Minuten & $20{ }^{\circ} \mathrm{C}$ \\
\hline Propylenoxid & 15 Minuten & $20{ }^{\circ} \mathrm{C}$ \\
\hline Propylenoxid & 15 Minuten & $20{ }^{\circ} \mathrm{C}$ \\
\hline Propylenoxid: Epon 2:1 & 2 Stunden & $20{ }^{\circ} \mathrm{C}$ \\
\hline Propylenoxid: Epon 1:1 & 2 Stunden & $20{ }^{\circ} \mathrm{C}$ \\
\hline Propylenoxid: Epon 1:2 & 4 Stunden & $20{ }^{\circ} \mathrm{C}$ \\
\hline Epon & 4 Stunden & $20{ }^{\circ} \mathrm{C}$ \\
\hline
\end{tabular}


Im Anschluss wurden die infiltrierten Nerven in Epon eingegossen und zur Polymerisation für $24 \mathrm{~h}$ auf $60^{\circ} \mathrm{C}$ erhitzt. Die Epon-Blöckchen wurden mit Hilfe einer Leica EM TRIM Fräse in Form gefräst und mit einem Reichert Ultracut S Rotationsmikrotom und einem Diatome Ultra $35^{\circ}$ Diamantmesser $0,5 \mu \mathrm{m}$ Semidünnschnitte für Lichtmikroskopie angefertigt. Diese wurden auf einen Objekträger transferiert und bei $60{ }^{\circ} \mathrm{C}$ auf einer Wärmeplatte getrocknet. Zur elektronenmikroskopischen Analyse wurden Ultradünnschnitte in einer Dicke von $50 \mathrm{~nm}$ angefertigt. Diese wurde auf Formvar-befilmte Kupfergrids überführt und getrocknet.

\subsubsection{Färbung der Semidünnschnitte}

Die Färbung der Semidünnschnitte erfolgte mit der Methylen-Azur-II-Färbung (Richardson et al. 1960). Die Methylenblau-Lösung und Azur-II-Lösung wurden im Verhältnis 1:1 gemischt und filtriert. Die fertige Lösung wurde auf die Schnitte gegeben und für 1 min bei $60{ }^{\circ} \mathrm{C}$ inkubiert und mit destilliertem Wasser abgespült. Die gefärbten Schnitte wurden 10 min bei $60^{\circ} \mathrm{C}$ getrocknet und anschließend mit dem histologischen Einschlussmittel Eukitt ${ }^{\circledR}$ mit einem Deckglas verklebt.

\subsubsection{Lichtmikroskopie und Auswertung der Semidünnschnitte}

Zur histologischen Auswertung und Beurteilung von axonalem Verlust und Demyelinisierung wurden mikroskopische Bilder der Semidünnschnitte angefertigt. Die mikroskopischen Aufnahmen wurden mit einem Zeiss Axiophot Lichtmikroskop mit einer Videomikroskopie-Kamera und der Software Zeiss Zen angefertigt. Dabei wurde der Nerv in einer VergröBerung von 100x überlappend abfotografiert und von der Zeiss Bildverarbeitungssoftware zu einem Bild zusammengefügt. Die Quantifizierung der myelinisierten Axone erfolgte mit Hilfe der Software Fiji/ImageJ 1.5 (http://rsb.info.nih.gov/ij/) und dem Cell-Counter Plugin.

\subsubsection{Befilmen von Kupfergrids für Elektronenmikroskopie}

Vorgeputzte Objektträger wurden in einer speziellen Glasküvette mit Ablaufvorrichtung mit 0,25 \% Formvar-Lösung benetzt. Das Ventil der Küvette wurde geöffnet, sodass die Formvar-Lösung in einem gleichmäßigen Tempo an dem Objektträger entlanglief. Nach kurzem Trocknen wurde der so entstandene Formvar-Film an allen vier Seiten des Objektträgers mit einer Rasierklinge abgeschnitten. Schließlich wurde der Film durch Eintauchen im Winkel von ca. $25^{\circ}$ mit der Schmalseite in eine bis zum Rand mit destilliertem Wasser gefüllte Küvette vom Objektträger abgelöst. Nach Abschwimmen der Formvar-Folie wurden die Kupfergrids mit der Unterseite nach oben auf den schwimmenden Film gelegt. Anschließend wurde der Film mit den Grids durch zügiges Eintauchen eines mit Papier beklebten Objektträgers von der Wasseroberfläche aufgenommen und zum Trocknen auf ein Papiertuch gestellt. 


\subsubsection{Kontrastierung von Ultradünnschnitten für Elektronenmikroskopie}

Biologische Gewebe streuen die vom Elektronenmikroskop auftreffenden Elektronen nur leicht. Daraus resultieren ein unzureichender Kontrast und ein flaues Bild. Zur Steigerung des Kontrastes können die Gewebe mit Schwermetallen behandelt werden. Die Kontrastierung der Ultradünnschnitte erfolgte für $30 \mathrm{~min}$ mit Uranylacetat und für 6 min mit Bleicitrat nach Reynolds (1963).

\subsubsection{Elektronenmikroskopie}

Die elektronenmikroskopischen Aufnahmen erfolgten mit einem Zeiss EM 900 Transmissions-Elektronenmikroskop mit einer wide-angle dual speed 2K-CCD-Kamera (TRS, Moorenweis) und der ImageSP Software (TRS, SysProg). Pro Nerv wurden 20 - 30 repräsentative Bilder über die gesamte Fläche des Nervens verteilt in einer Vergrößerung von 3000x aufgenommen. Zur Analyse der Kompaktierung des Myelins bzw. Messung der Abstände der Myelin-Hauptlinien (major dense lines) wurden zusätzlich Aufnahmen von myelinisierten Axonen mit einer Vergrößerung von 12000x angefertigt.

\subsubsection{7 g-ratio}

Die g-ratio ist das Verhältnis zwischen Axondurchmesser und Myelindicke und ein Maß für die Myelinisierung der Axone (Quotient aus dem Durchmesser des Axons und der gesamten Faser). Als Standardwert für die g-ratio in gemischten Nerven der Ratte gilt ein Wert von ca. 0,68 (Fahrenkamp und Friede 1987). Pro Tier wurde auf elektronenmikroskopischen Aufnahmen des Tibialisnerven mit der Software ImageJ 1.5 der Umfang und die Fläche von 150 bis 200 Axonen pro Versuchstier gemessen und daraus die g-ratio berechnet.

\subsubsection{Messung Abstände der Myelin-Hauptlinien (major dense lines)/Kompaktierung des Myelins}

Zur Bestimmung der Dicke der einzelnen Myelinschichten wurde in elektronenmikroskopischen Aufnahmen von myelinisierten Nerven in einer Vergrößerung von 12000x die Dicke der Myelinschicht gemessen und durch Zählung der major dense lines die Anzahl der Myelinschichten bestimmt. Aus der Myelindicke und der Schichtanzahl wurde die durchschnittliche Dicke einer Myelinschicht bestimmt.

\subsubsection{Zellkultur}

\subsubsection{Kultivierung primärer Schwannzellen aus Ratten}

Ratten im Alter von zwei Tagen wurden durch Dekapitation getötet. Anschließend wurde der Körper mit $70 \%$ Ethanol desinfiziert und beide Ischiasnerven präpariert und in eine Zellkulturschale mit DMEM überführt. Die Nerven wurden mit 0,03 \% Collagenase und 0,25 \% Trypsin für 30 min bei $37^{\circ} \mathrm{C}$ lysiert. Die Lyse wurde durch Zugabe von fetalem Kälberserum 
(FCS) gestoppt und die Zellen durch Zentrifugation für 5 min bei $800 \mathrm{rpm}$ pelletiert. Anschließend wurden die Zellen in DMEM mit 10 \% FCS resuspendiert und auf Poly-L-Lysin beschichtete Zellkulturplatten oder Schalen ausplattiert. Da die Schwannzellen im Gegensatz zu Fibroblasten ohne Stimulation nur sehr langsam proliferieren, wurde nach $24 \mathrm{~h}$ für drei Tage auf DMEM mit 10\% FCS und 0,01 mM Cytarabin als Mitosegift gewechselt, um Fibroblasten zu entfernen. Im Anschluss wurden dieZellen mitPBS gewaschen, um noch vorhandenes Cytarabin zu entfernen und auf das Expansionsmedium (DMEM, $10 \%$ FCS, $0,77 \%$ Rinder-Hypophysenextrakt und $4 \mu \mathrm{M}$ Forskolin) gewechselt. Zur Behandlung der Rattenschwannzellen mit Lithium wurde in konfluenten Kulturen dem Medium für $72 \mathrm{~h}$ entweder $1 \mathrm{mM} / 1 \mathrm{Li}_{2} \mathrm{CO}_{3}, 1 \mathrm{mM} / 1 \mathrm{Li}_{2} \mathrm{CO}_{3}$ und Forskolin oder nur Forskolin zugegeben. Forskolin ist ein Aktivator der Adenylatcyclasen und führt zu einer Erhöhung des intrazellulären cyclischen Adenosinmonophosphats (cAMP). Ein erhöhter intrazellulärer cAMP-Spiegel führt in Schwannzellen zu Proliferation (Sobue et al. 1986), Differenzierung (Morgan et al. 1991) sowie zur Expression von Myelingenen (LeBlanc et al. 1992).

\subsubsection{Einfrieren, Auftauen und Passagieren von Ratten-Schwannzellen}

Konfluente Zellkulturschalen wurden mit PBS gewaschen und für 5 min bei $37^{\circ} \mathrm{C}$ mit Trypsinlösung inkubiert. Die Lyse wurde durch Zugabe von DMEM mit FCS gestoppt, die Zellen resuspendiert und durch Zentrifugation für 5 min bei $800 \mathrm{rpm}$ pelletiert. Danach wurden die Zellen in Medium resuspendiert und in der gewünschten Dichte auf Zellkulturplatten oder -schalen ausplattiert. Zum Einfrieren der Zellen wurden diese in DMEM mit $10 \%$ DMSO und $12,5 \% \mathrm{FCS}$ resuspendiert und bei $-80{ }^{\circ} \mathrm{C}$, bzw. $-196{ }^{\circ} \mathrm{C}$ für längere Lagerzeiten, eingefroren. Zum Auftauen wurden gefrorene Zellen zügig in warmem Medium resuspendiert, durch Zentrifugation pelletiert, in frischem Medium resuspendiert und auf Zellkulturplatten ausplattiert. Zur Vermehrung der Schwannzellen wurden diese maximal dreimal passagiert.

\subsubsection{Präparation von DRG-Neuron-Schwannzell-Co-Kulturen aus Ratten}

Co-Kulturen aus Schwannzellen und DRG-Neuronen wurden nach einer modifizierten Methode nach Kleitman et al. (1998) präpariert. Trächtige E18 Rattenweibchen wurden durch Einleiten von $\mathrm{CO}_{2}$ in einen gasundurchlässigen Käfig getötet, der Uterus entfernt und in gekühltes MEM überführt. Die E18 Rattenembryonen wurden vorsichtig aus dem Uterus entfernt und die dorsalen Hinterwurzelganglien präpariert und für 45 min bei $37^{\circ} \mathrm{C}$ in $5 \%$ Trypsin lysiert. Die Lyse wurde durch Zugabe von FCS gestoppt und $10 \mu$ l Suspension zur Zählung in einer Neubauer Zählkammer entnommen. Die Zellen wurden durch Zentrifugation bei $800 \mathrm{rpm}$ für 8 min pelletiert und in MEM mit $10 \% \mathrm{FCS}$ und $50 \mathrm{ng} / \mathrm{ml} \mathrm{NGF}$ resuspendiert. Es wurden 200000 Zellen in $40 \mu \mathrm{l}$ Medium pro Deckglas ausplattiert. Nach $24 \mathrm{~h}$ wurde $1 \mathrm{ml}$ Medium pro Deckglas aufgefüllt und für sieben Tage wachsen gelassen. Nach einer Woche wurde die Myelinisierung in vitro durch Wechsel auf MEM mit $10 \%$ 
FCS, $50 \mathrm{ng} / \mathrm{ml} \mathrm{NGF}$ und $50 \mu \mathrm{g} / \mathrm{ml}$ Ascorbinsäure induziert. Während der Induktion der Myelinisierung wurde das Medium dreimal pro Woche gewechselt.

\subsubsection{Immunzytochemie von DRG-Neuron-Schwannzell-Co-Kulturen aus Ratten}

16 Tage nach Induktion der Myelinisierung wurden die Zellen für 10 min bei Raumtemperatur mit $4 \%$ PFA fixiert und dreimal mit PBS gewaschen. Anschließend wurden die Zellen durch 10 min Inkubation bei $-20{ }^{\circ} \mathrm{C}$ in $95 \%$ Methanol und $5 \%$ Azeton permeabilisiert, erneut mit PBS gewaschen und unspezifische Antikörperbindungen durch zweistündige Inkubation mit $2 \%$ Pferdeserum, $2 \%$ BSA und 0,1\% Gelatine in PBS abgesättigt. Zur Darstellung von myelinisierten Segmenten erfolgte die Inkubation mit den Primärantikörpern anti-MBP, polyclonal rabbit (DAKO) 1:500 und Tuj-1, monoclonal mouse (Babco) 1:250 in $2 \%$ Pferdeserum, $2 \%$ BSA und 0,1\% Gelatine in PBS über Nacht bei Raumtemperatur. Als Sekundärantikörper kamen Alexa-488-goat-anti-rabbit (Invitrogen) 1:400 und Cy3-goatanti-mouse (Jackson Immuno Research) 1:1000 für 45 min zum Einsatz. Gleichzeitig erfolgte eine Kernfärbung mit 4',6-Diamidin-2- phenylindol (DAPI) 1:20000. Die myelinisierten Segmente wurden mit Hilfe eines Zeiss Observer Z Mikroskop gezählt.

\subsubsection{Molekularbiologie}

\subsubsection{Isolierung von genomischer DNA}

Zur Genotypisierung der Versuchstiere wurde genomische DNA aus Schwanzbiopsien gewonnen. Die DNA-Extraktion erfolgte mit Hilfe des nexttec ${ }^{\mathrm{TM}}$ „DNA Isolation Kit for Tissue and Cells cleanPlates96“ entsprechend des Herstellerprotokolls. Dazu wurden die gefrorenen Biopsien aufgetaut und durch Proteinase K in dem Kit beiliegendem Puffer für 30 Minuten bei $56^{\circ} \mathrm{C}$ und $200 \mathrm{rpm}$ auf dem Schüttelinkubator verdaut. Das Lysat wurde auf die nexttec ${ }^{\mathrm{TM}}$ cleanPlate überführt und die DNA nach einer Inkubationszeit von drei Minuten per Zentrifugation eluiert

\subsubsection{Genotypisierungs-Polymerasekettenreaktion aus genomischer DNA}

Die Genotypisierung der Versuchstiere erfolgte durch Polymerasekettenreaktion (PCR) nach Mullis et al. (1986). Hierfür wurde das GoTaq-Reaktionssystem von Promega verwendet. Zur Anwendung kamen Primer, die spezifisch ein 495 Nukleotide langes Produkt des transgenen Maus-Pmp22 amplifizieren, jedoch an keine komplementären Bereiche innerhalb des Rattengenoms binden. Auf diese Weise konnte sicher zwischen transgenen und WildtypTieren unterschieden werden. Für die PCR wurde ein Reaktionsvolumen von $20 \mu$ l verwendet: 
Tabelle 13: Protokoll Genotypisierungs-PCR für Pmp22-transgene Tiere

\begin{tabular}{|c|c|c|c|}
\hline \multicolumn{3}{|l|}{ DNA } & $1 \mu \mathrm{l}$ \\
\hline \multicolumn{3}{|c|}{$5^{\prime}$-Primer $(5 \mathrm{pmol} / \mu \mathrm{l})$} & $1 \mu \mathrm{l}$ \\
\hline \multicolumn{3}{|c|}{ 3'-Primer (5 pmol/ $\mu \mathrm{l})$} & $1 \mu \mathrm{l}$ \\
\hline \multicolumn{3}{|c|}{ dNTPs (je Nukleotid 2,5 mM) } & $1 \mu \mathrm{l}$ \\
\hline \multicolumn{3}{|c|}{$5 x$ Buffer } & $4 \mu \mathrm{l}$ \\
\hline \multicolumn{3}{|l|}{ GoTaq } & $0,1 \mu l$ \\
\hline \multicolumn{3}{|l|}{$\mathrm{dd}_{2} \mathrm{O}$} & $11,9 \mu \mathrm{l}$ \\
\hline \multicolumn{4}{|c|}{ Die Amplifikation der DNA erfolgte nach folgendem Schema } \\
\hline \multicolumn{4}{|c|}{$3 \min @ 95^{\circ} \mathrm{C}$} \\
\hline \multicolumn{4}{|c|}{ @ $56^{\circ} \mathrm{C}$} \\
\hline \multicolumn{2}{|r|}{ (a) $72{ }^{\circ} \mathrm{C}$} & \multicolumn{2}{|l|}{32 Zyklen } \\
\hline $30 \mathrm{~s}$ & (a) $95^{\circ} \mathrm{C}$ & & \\
\hline \multicolumn{2}{|r|}{ (a) $55^{\circ} \mathrm{C}$} & & \\
\hline \multicolumn{2}{|r|}{ (a) $72{ }^{\circ} \mathrm{C}$} & & \\
\hline
\end{tabular}

\subsubsection{Agarosegelelektrophorese und Detektion zur Genotypisierung}

Zur Detektion der amplifizierten DNA wurde eine Agarosegelelektrophorese durchgeführt. Zur Verwendung kamen 1,5\%ige Gele. Es wurde TAE-Puffer in der Mikrowelle erwärmt und die Agarose gelöst. Nach dem Zugeben von Ethidiumbromid $(1 \mu \mathrm{g} / \mathrm{ml})$ wurde die Agarose in eine Gelkammer gegossen und Gelkämme zur Herstellung von Probentaschen eingesetzt. Nach dem Erstarren der Agarose wurde das Gel mit TAE-Puffer übergossen und die PCR-Proben in die Taschen pipettiert. Zur späteren Identifizierung der Banden wurde zusätzlich ein Größenmarker verwendet (Promega 1 kb DNA Ladder). Nach dem Anlegen einer Spannung wandern die negativ geladenen Nukleinsäure-Moleküle im elektrischen Feld zur Kathode. Unterschiedlich lange Moleküle haben eine unterschiedliche Wanderungsgeschwindigkeit und lassen sich auf diese Weise nach ihrer Größe auftrennen. Durch Interkalierung des Ethidiumbromids in die DNA konnte diese unter UV-Licht sichtbar gemacht und abfotografiert werden. Alternativ zu Ethidiumbromid wurde der nicht mutagene Fluoreszenzfarbstoff GelRed ${ }^{\mathrm{TM}}$ (Biotium) verwendet.

\subsubsection{Präparation von RNA}

Die Isolierung von RNA erfolgte mit Hilfe des RNeasy Mini Kit von Quiagen entsprechend des Herstellerprotokolls. Zur Isolierung von RNA aus bei $-80{ }^{\circ} \mathrm{C}$ gelagerten Ischiasnerven wurden diese in einem $2 \mathrm{ml}$ Eppendorf Reaktionsgefäß in $1 \mathrm{ml}$ Quiazol Lysis Reagenz mit einem Ultra-Turrax Homogenisator zerkleinert. Der Homogenisator wurde nach jeder Probe dreimal mit destilliertem Wasser zur Vermeidung von Kontamination gereinigt. AnschlieBend wurden die Proben für 5 min bei Raumtemperatur inkubiert und mit $200 \mu$ l Chloroform versetzt. Nach Mischen mit dem Vortex und einer weiteren Inkubation von 3 min bei 
Raumtemperatur erfolgte die Zentrifugation für 15 min bei $12000 \mathrm{~g}$ und $4{ }^{\circ} \mathrm{C}$ mittels Kühlzentrifuge. Anschließend wurde die wässrige, RNA-haltige Phase in ein neues Gefäß überführt, mit derselben Menge $70 \%$ Ethanol versetzt, gemischt und auf die Silikat-Membran einer RNeasy-Säule pipettiert. Die RNA bindet an die Silikat-Membran der Säule, während die Lösung mit Hilfe des QuiVac24 Vakuumsystems durch die Säule gesaugt wurde. Es folgten Waschschritte mit den mitgelieferten Puffern RW1 und RPE. Anschließend wurde die Säule in ein $2 \mathrm{ml}$ Gefäß überführt, durch Zentrifugation bei $8000 \mathrm{~g}$ getrocknet, in ein neues 1,5 ml Gefäß überführt und die RNA mit $50 \mu \mathrm{l}$ RNAse freiem Wasser eluiert. Zur Isolierung von RNA aus kultivierten Schwannzellen wurde das Medium abgesaugt und die Zellen mit PBS gewaschen. Danach erfolgte die Lyse der Zellen mit RLT-Puffer und B-Mercaptoethanol $(10 \mu \mathrm{l} / \mathrm{ml}$ RLT). Das Lysat wurde in ein neues $2 \mathrm{ml}$ Gefäß überführt und mit derselben Menge $70 \%$ Ethanol versetzt. Diese Lösung wurde auf die Membran einer RNeasy Säule pipettiert. Anschließend wurde wie vorher beschrieben fortgefahren.

\subsubsection{Reverse Transkription von RNA}

Die Konzentrationsbestimmung der RNA erfolgte photometrisch anhand der OD260 mit Hilfe des NanoDrop 2000 Spectrophotometers (Thermo Scientific). Zur Synthese von komplementärer DNA (cDNA) wurden 500 ng RNA eingesetzt. Die Synthese erfolgte mit dem Reaktionssystem Superscript-III ${ }^{\mathrm{TM}}$ RT (Invitrogen) entsprechend der Herstellerangaben. Zur spezifischen Transkription von messenger RNA (mRNA) wurden poly-Thymidin-Primer (dT-Primer 0,6 $\mu \mathrm{M}$ ) verwendet. Zusätzlich wurden random nonamer primer (N9-Primer $120 \mu \mathrm{M})$ zur Effizienzsteigerung der reversen Transkription verwendet. Das Annealing erfolgte für $2 \mathrm{~min}$ bei $70{ }^{\circ} \mathrm{C}$. Anschließend wurden $4 \mu \mathrm{l} 5 \mathrm{x}$ 1st strand buffer, $2 \mu$ l Dichlordiphenyltrichlorethan (DDT, $100 \mathrm{mM}), 1 \mu \mathrm{l}$ gemischte Nukleotide $(10 \mathrm{mM})$, sowie $1 \mu \mathrm{l}$ Superscript-III ${ }^{\mathrm{TM}} \mathrm{RT}$-Polymerase mit einer Aktivität von $200 \mathrm{U} / \mu \mathrm{l}$ zugefügt. Die Elongation erfolgte für $10 \mathrm{~min}$ bei $25^{\circ} \mathrm{C}, 45 \mathrm{~min}$ bei $45^{\circ} \mathrm{C}$ und $45 \min$ bei $55^{\circ} \mathrm{C}$.

\subsubsection{Semiquantitative Real-Time PCR (qRT-PCR)}

Die qRT-PCR dient der relativen Quantifizierung von mRNA eines Gens im Vergleich zu einem konstant exprimierten Gen (Housekeeping-Gen). Die qRT-PCR erfolgte dabei nach dem Prinzip der PCR nach Mullis et al. (1986). Die Detektion der entstandenen PCRProdukte erfolgte durch den asymmetrischen Cyanin-Farbstoff Sybr ${ }^{\circledR}$ Green, der in doppelsträngige Nukleinsäuren interkaliert und grünes Licht bei $\lambda \max =521 \mathrm{~nm}$ emittiert. Die Intensität der Fluoreszenz ist dabei proportional zur Menge der doppelsträngigen Nukleinsäuren (Rye et al. 1992). Die Registrierung erfolgte am Ende jeder Elongationsphase. Die Anzahl der PCR-Zyklen, bis zu der ein definierter Grenzwert der Fluoreszenz überschritten wird, wird als Ct (threshold cycle) definiert. Die Auswertung der PCR erfolgte nach der 2- $\Delta \Delta$ Ct-Methode (Livak und Schmittgen 2001). Dabei wird der Ct-Wert des Standardgens von dem Ct-Wert des untersuchten Gens abgezogen und der $\Delta \mathrm{Ct}$ eines Kalibrators von allen $\Delta$ Ct-Werten abgezogen. Dieser $\Delta \Delta$ Ct-Wert wird in die Formel „Expression $=2^{-\Delta \Delta C \text { t } ~}$ 
eingesetzt. Die Expression wird dabei als n-fache Expression des Kalibrators angegeben. In der Regel wurden die Werte auf die Kontrollgruppe normalisiert. Die qRT-PCR wurde mit einem LightCycler@ 480 von Roche im 384 well Format mit dem SYBR ${ }^{\circledR}$ Green PCR Master Mix (Applied Biosystems) durchgeführt. Pro Gen und Probe wurden vier technische Replikate erstellt und der Mittelwert gebildet. Es wurde der von Applied Biosystems empfohlene Reaktionsansatz verwendet:

Tabelle 14: Protokoll qRT-PCR für Genexpressionsanalysen

\begin{tabular}{ll}
\hline \hline cDNA & $2 \mu \mathrm{l}$ \\
5'-Primer $(50 \mathrm{pmol} / \mu \mathrm{l})$ & $0,2 \mu \mathrm{l}$ \\
3'-Primer $(50 \mathrm{pmol} / \mu \mathrm{l})$ & $0,2 \mu \mathrm{l}$ \\
SYBR@-Green Master Mix & $5 \mu \mathrm{l}$ \\
$\mathrm{H}_{2} \mathrm{O}$ & $2,6 \mu \mathrm{l}$
\end{tabular}

Die Amplifikation erfolgte nach folgendem Schema:

$\left.\begin{array}{ll}10 \mathrm{~min} & @ 95^{\circ} \mathrm{C} \\ 15 \mathrm{~s} & @ 56^{\circ} \\ 20 \mathrm{~s} & @ 72^{\circ} \\ 40 \mathrm{~s} & @ 95^{\circ}\end{array}\right\} 45$ Zyklen

2.2.4.7 Isolierung von Proteinen

Zur Durchführung von Western-Blot-Analysen wurden Proteine aus Ischiasnerven isoliert. Bei $-80{ }^{\circ} \mathrm{C}$ gefrorene Ischiasnerven wurden in $2 \mathrm{ml}$ Eppendorfgefäße mit $200 \mu \mathrm{l}$ Sucrosepuffer (Sucrose $320 \mathrm{mM}$, Tris $10 \mathrm{mM}, \mathrm{NaHCO}_{3} 1 \mathrm{mM}, \mathrm{MgCl}_{2} 1 \mathrm{mM}$, Proteinaseinhibitor und Phosphataseinhibitor) und $25 \mathrm{~mm}$ Keramikkugeln überführt und mit einem Precellys 24 Homogenisator (PeqLab) zweimal bei $3000 \mathrm{rpm}$ für $10 \mathrm{~s}$ homogenisiert. Die Homogenisate wurden für $10 \mathrm{~min}$ bei $15000 \mathrm{rpm}$ bei $4{ }^{\circ} \mathrm{C}$ in der Kühlzentrifuge zentrifugiert, der Überstand in ein 1,5 ml Eppendorfgefäß überführt und bis zur Verwendung bei $-20^{\circ} \mathrm{C}$ gelagert. Kultivierte Zellen wurden zweimal mit PBS gewaschen und anschließend mit einem Cell Scraper in $100 \mu \mathrm{l}$ Sucrosepuffer gescrapt. Die Zellsuspension wurde durch mehrfaches pipettieren mit einer $200 \mu \mathrm{l}$ Pipette homogenisiert und für $10 \mathrm{~min}$ bei $15000 \mathrm{rpm}$ und $4{ }^{\circ} \mathrm{C}$ in der Kühlzentrifuge zentrifugiert und der Überstand wiederum bei $-20^{\circ} \mathrm{C}$ gelagert.

\subsubsection{Konzentrationsbestimmung von Proteinen}

Die Konzentrationsbestimmung von Proteinen erfolgte mit Hilfe des Bio-Rad DC Protein Assay Kit nach der Methode von Lowry et al. (1951) entsprechend des Herstellerprotokolls. Die Proteinmessung erfolgte photometrisch mit einem Thermo-Max Microplate reader bei $\lambda=600 \mathrm{~nm}$ auf einer 96-well Mikrotiterplatte. Die Standardisierung erfolgte mit einer Standardreihe mit 0,1 $\mu \mathrm{g} / \mu \mathrm{l}, 0,2 \mu \mathrm{g} / \mu \mathrm{l}, 0,4 \mu \mathrm{g} / \mu \mathrm{l}, 0,8 \mu \mathrm{g} / \mu \mathrm{l}, 1,2 \mu \mathrm{g} / \mu \mathrm{l}, 1,6 \mu \mathrm{g} / \mu \mathrm{l}, 2,0 \mu \mathrm{g} / \mu \mathrm{l}$ und 3,0 $\mu \mathrm{g} / \mu \mathrm{l}$ bovines Serum-Albumin (BSA). Von der Standardreihe wurden zwei technische Replikate durchgeführt, von jeder Probe drei technische Replikate. 


\subsubsection{Western Blot}

Proteinextrakte wurden mit dem Probenpuffer versetzt und bei $80{ }^{\circ} \mathrm{C}$ für 10 min denaturiert. Es wurden $20 \mu \mathrm{g}$ einer denaturierten Probe mit jeweils $4 \mu \mathrm{l}$ B-Mercaptoethanol und $10 \mu \mathrm{l}$ Loading Dye für die Gelektrophorese eingesetzt. Für die SDS-PAGE-Gelektrophorese wurde das NuPAGE-Gelektrophoresesystem von Invitrogen mit dem Kammersystem Xcell SureLock und mit NuPAGE-Gelen mit zehn Taschen verwendet. Der Aufbau der Xcell SureLock Kammer erfolgte gemäß dem Herstellerprotokoll von Invitrogen. Die PVDFMembran wurde vor dem Einsatz für $30 \mathrm{~s}$ in $100 \%$ Methanol aktiviert und danach kurz in Transfer-Puffer gewaschen. Nach Anlegen der Spannung, wandern die Proteine von der Kathode zur Anode und werden auf der PVDF-Membran durch hydrophobe und elektrostatische Bindungen fixiert. Die gesamte Western-Blot-Apparatur wurde zur Kühlung in ein Eisbad gestellt. Bei $400 \mathrm{~mA}$ und $30 \mathrm{~V}$ wurden die Proteine für $2 \mathrm{~h}$ transferiert. Nach Beendigung des Blottes wurde die Membran für $1 \mathrm{~h}$ bei Raumtemperatur in Blocking-Puffer inaktiviert. Nun wurde die Membran mit dem primären Antikörper in entsprechender Verdünnung in Blocking-Puffer bei $4{ }^{\circ} \mathrm{C}$ über Nacht inkubiert, gefolgt von vier Waschschritten für je 10 min mit TBS-T. Folgend wurde der sekundäre HRP-konjugierte Antikörper (1:5000 verdünnt in TBS-T) für 60 bis 90 min appliziert. Nach erneutem Waschen mit TBS-T wurde die PVDF-Membran mit ECL-Lösung (Parkin-Elmer) für 1 min nach Angaben des Herstellers inkubiert und in einer Plastikschutzfolie verpackt. Unter Lichtabschluss wurde die Membran je nach Signalstärke für unterschiedliche Zeiten (10 s bis $30 \mathrm{~min}$ ) einem automatischen Western-Blot-System der Firma Intas exponiert. Zum erneuten Detektieren mit einem weiteren primären Antikörper, wurde die PVDF-Membran in einem Stripping-Puffer für $2 \mathrm{~h}$ bei $60{ }^{\circ} \mathrm{C}$ behandelt, zweimal $20 \mathrm{~min}$ mit TBS-T bei Raumtemperatur gewaschen. Die Auswertung der Western-Blot-Aufnahmen erfolgte mittels des Plug-in Gel-Analyser der Software ImageJ. 


\section{Ergebnisse}

\subsection{Einfluss von Lithium auf die Myelinisierung im peripheren Nervensystem von Wildtyp-Ratten}

Um den Einfluss von Lithium auf die Myelinisierung zu untersuchen wurden zwei Zeitpunkte während der Myelinisierung ( $\mathrm{p} 0-\mathrm{p} 6$ und $\mathrm{p} 0-\mathrm{p} 21)$ sowie ein späterer Zeitpunkt nach Abschluss der Myelinisierung (p30 - p117) gewählt. Männliche, neugeborene Ratten wurden nach Geburt randomisiert in Gruppen aufgeteilt. Aufgrund der altersabhängigen Ernährung der neugeborenen Ratten über die Muttermilch hätte sich bei oraler Applikation von Lithium an die Muttertiere eine sehr unsichere Dosis von Lithium in den untersuchten Tieren ergeben. Daher wurde sich zu einer intraperitonealen Gabe von Lithiumchlorid entschieden. Hierzu wurden die Tiere täglich gewogen und $1 \mathrm{mMol} \mathrm{LiCl} / \mathrm{kg} / \mathrm{KG}$ $(50 \mathrm{mg} / \mathrm{kg} / \mathrm{KG})$ intraperitoneal injiziert. Am 6. bzw. 21. Lebenstag wurden die Tiere getötet und Gewebe zur histologischen und molekularbiologischen Untersuchung entnommen. Männliche Ratten im Alter von 30 Tagen wurden in je zwei gleich schwere Behandlungsund Kontrollgruppen aufgeteilt und ab dem 30. Lebenstag entweder mit Standardfutter ( $\mathrm{n}=20$, Durchschnittsgewicht Tag $33=117 \mathrm{~g})$, mit $0,12 \%$ Lithiumcarbonat $\left(\mathrm{Li}_{2} \mathrm{CO}_{3}\right)$ $(\mathrm{n}=10$, Durchschnittsgewicht $=118 \mathrm{~g})$ oder $0,24 \% \mathrm{Li}_{2} \mathrm{CO}_{3} \quad(\mathrm{n}=10$, Durchschnittsgewicht $=117 \mathrm{~g})$ angereichertem Futter ernährt (Abbildung 1).

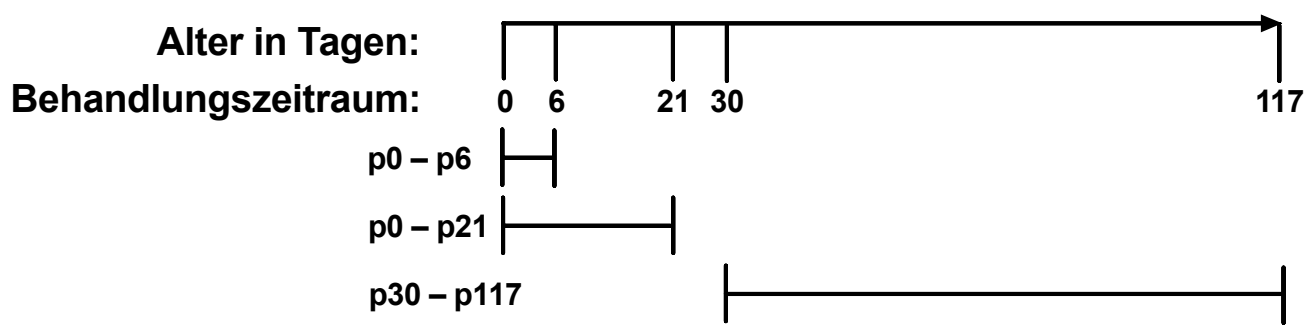

Abbildung 1: Schematische Darstellung der Behandlung von Wildtyp-Ratten mit Lithium. Behandlungszeiträume $\mathrm{p} 0-\mathrm{p} 6$ ( $\mathrm{n}=5$ je Gruppe) und $\mathrm{p} 0-\mathrm{p} 21$ ( $\mathrm{n}=8$ je Gruppe) während der Myelinisierung. Diese Tiere erhielten tägliche intraperitoneale Injektionen mit $1 \mathrm{mM} \mathrm{LiCl} / \mathrm{kg} / \mathrm{KG}(50 \mathrm{mg} / \mathrm{kg} / \mathrm{KG}) \mathrm{bzw}$. physiologische Kochsalzlösung in der Kontrollgruppe. Behandlungszeitraum p30 - p117 ( $\mathrm{n}=10$ je Gruppe) nach Abschluss der Myelinisierung. Diese Tiere erhielten Futter mit 0,12\% $\mathrm{Li}_{2} \mathrm{CO}_{3}$ bzw. 0,24\% $\mathrm{Li}_{2} \mathrm{CO}_{3} . \mathrm{Die}$ entsprechende Kontrollgruppe erhielt Standardfutter. Zum Abschluss des jeweiligen Behandlungszeitraums wurden die Tiere getötet und Gewebe zur histologischen und molekularbiologischen Analyse entnommen.

Die Tiere, die 0,24\% $\mathrm{Li}_{2} \mathrm{CO}_{3}$ erhielten, zeigten einen deutlichen Gewichtsverlust (Abbildung 2) sowie eine rapide Verschlechterung des Allgemeinzustandes. Das Gewicht der Tiere mit $0,24 \% \mathrm{Li}_{2} \mathrm{CO}_{3}$ betrug an Lebenstag 47 durchschnittlich nur $72 \mathrm{~g}$ (Tiere mit Standardfutter: $196 \mathrm{~g}$, Tiere mit $\left.0,12 \% \mathrm{Li}_{2} \mathrm{CO}_{3}: 156 \mathrm{~g}\right)$. Daher wurde beschlossen die Versuchsgruppe mit $0,24 \%$ zu beenden. Diese Tiere sowie die entsprechende Kontrollgruppe wurden getötet und Blut zur Bestimmung der Lithiumkonzentration entnommen. Aus technischen Gründen 
(geringe Blutmenge) war nur bei vier Tieren aus der 0,24\% $\% \mathrm{Li}_{2} \mathrm{CO}_{3}$-Gruppe eine Konzentrationsbestimmung von Lithium im Blut möglich. Auf eine weitere histologische und molekularbiologische Untersuchung der entnommenen Gewebe wurde aufgrund des Gewichtsverlustes und des schlechten Allgemeinzustandes der Tiere verzichtet. Am 117. Tag wurden die übrigen Ratten gewogen und nach dem Töten Blut aus dem rechten Ventrikel entnommen. Außerdem wurden Gewebe zur histologischen und molekularbiologischen Untersuchung gewonnen. In der Gruppe mit $0,12 \% \mathrm{Li}_{2} \mathrm{CO}_{3}$ zeigte sich an Tag $117 \mathrm{im}$ Durchschnitt ein Körpergewicht von 329 g (Standardfutter 351 g) und eine Serumkonzentration von $0,33 \mathrm{mmol} / 1$, in der Gruppe mit $0,24 \% \mathrm{Li}_{2} \mathrm{CO}_{3}$ eine Serumkonzentration von $1,57 \mathrm{mmol} / \mathrm{l}$ (Tag 47) (Abbildung 2).

a

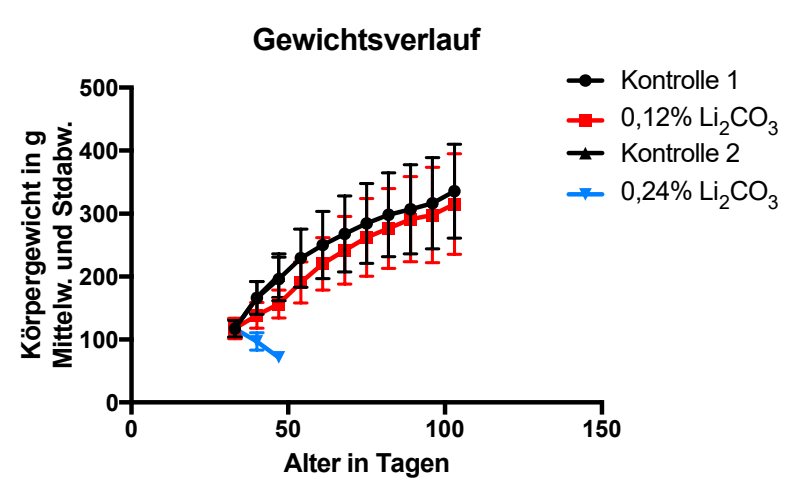

b

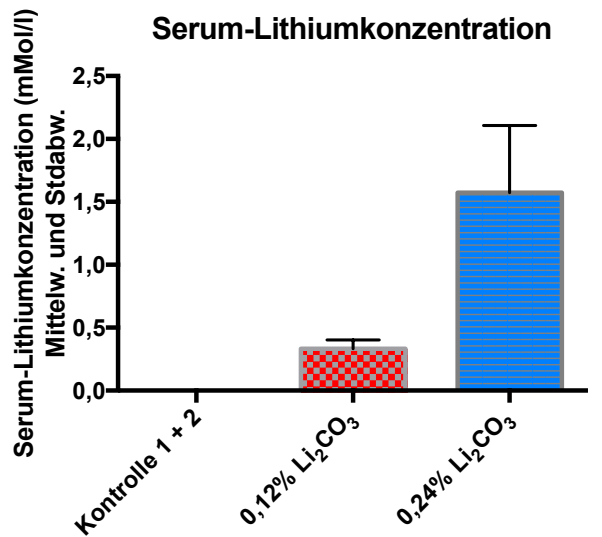

Abbildung 2: Gewicht und Serum-Lithiumkonzentration in Wildtyp-Ratten nach Lithiumbehandlung. a) Darstellung des Gewichtsverlaufs nach oraler Gabe von Lithiumcarbonat $\left(0,12 \%\right.$ und $0,24 \% \mathrm{Li}_{2} \mathrm{CO}_{3}$ sowie entsprechende Kontrollgruppen) über die Nahrung. Tiere aus der Gruppe mit $0,24 \% \mathrm{Li}_{2} \mathrm{C}_{3}$ zeigten einen deutlichen Gewichtsverlust im Vergleich zu den anderen Gruppen (Gewicht an Tag 47: Mittelwert Kontrolle $1=196 \mathrm{~g}, 0,12 \% \mathrm{Li}_{2} \mathrm{CO}_{3}=156 \mathrm{~g}$, Kontrolle $2=201 \mathrm{~g}, 0,24 \% \mathrm{Li}_{2} \mathrm{CO}_{3}=72 \mathrm{~g}, \mathrm{n}=10$ ) b) Bestimmung der Serum-Lithiumkonzentration mittels ionenselektiver Elektrode (durchgeführt durch Labor Lademannbogen, Hamburg). Kontrolle $\mathrm{n}=16$, Mittelwert Serum-Lithiumkonzentration $0,12 \% \mathrm{Li}_{2} \mathrm{C}_{3}=0,33 \mathrm{mmol} / \mathrm{l}(\mathrm{Tag}$ 117), $\mathrm{n}=10,0,24 \% \mathrm{Li}_{2} \mathrm{C}_{3}=1,57 \mathrm{mmol} / \mathrm{l}(\mathrm{Tag} 47), \mathrm{n}=4$.

\subsubsection{Histologische Analyse von Tibialisnerven}

Tibialisnerven wurden in Lösung nach Karlsson und Schultz (1965) fixiert, in Epoxidharz eingebettet und Schnitte für Elektronenmikroskopie angefertigt. Es wurden repräsentative Ausschnitte der Tibialisnerven mit dem Elektronenmikroskop in einer 3000x Vergrößerung abfotografiert, der Umfang von Axon und Myelinscheide gemessen und daraus die g-ratio als Maß für die relative Myelindicke (Fahrenkamp und Friede 1987) berechnet. Zu den beiden frühen Zeitpunkten während der Myelinisierung, $\mathrm{p} 0$ - p6 und $\mathrm{p} 0-\mathrm{p} 21$, zeigte sich kein Unterschied in der g-ratio zwischen behandelten Tieren und der Kontrollgruppe. Die Gruppe der langzeitbehandelten Tiere nach Abschluss der Myelinisierung, p30 - p117, zeigte eine statistisch signifikant kleinere g-ratio (Mittelwert Kontrolle 0,6428, Mittelwert Lithium 
0,5936, $\mathrm{p}<0,01)$ als Ausdruck einer dickeren Myelinscheide im Vergleich zur unbehandelten Kontrollgruppe (Abbildung 3).
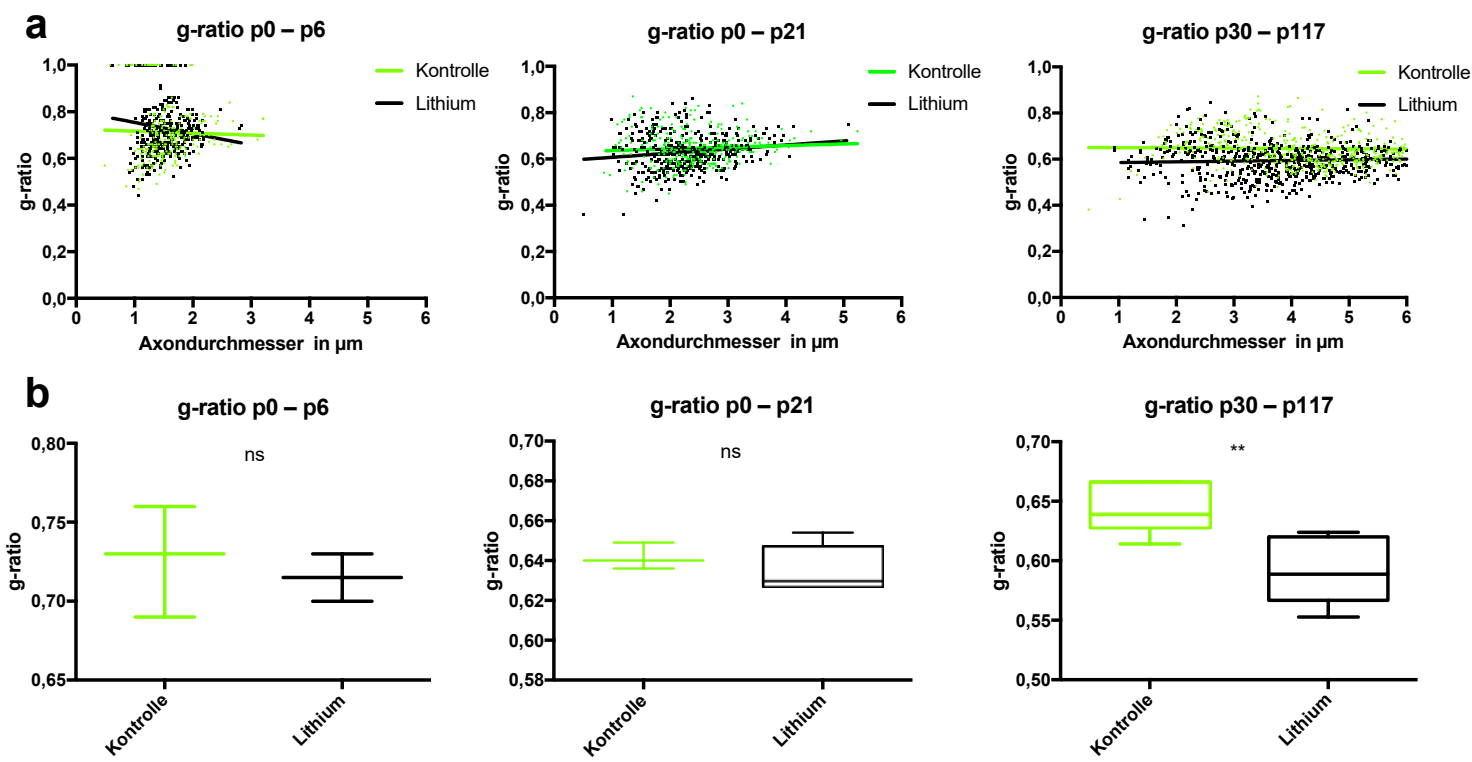

Abbildung 3: Histologische Analyse der relativen Myelindicke (g-ratio) in Tibialisnerven von WildtypRatten nach Lithiumbehandlung. grün: Wildtyp-Ratten ohne Lithiumbehandlung (Kontrolle), schwarz: Wildtyp-Ratten nach Lithiumbehandlung. a) Auftragung der Myelindicke (g-ratio) auf den Axondurchmesser. In den Altersgruppen p0 - p6 und p0 - p21 fand sich kein statistisch signifikanter Unterschied. In der Gruppe p30 - p117 zeigte sich ein statisch signifikanter Unterschied der Höhe der linearen Regression $(\mathrm{p}<0.0001)$. Die Steigung der linearen Regression unterschied sich nicht. b) In den Altersgruppen p0 - p6 bzw. p0 - p21 zeigte sich kein statistisch signifikanter Unterschied des mittleren g-ratios. In der Gruppe p30 - p117 zeigte sich nach Lithiumbehandlung ein statistisch signifikanter Unterschied des g-ratios, entsprechend einer Zunahme der Myelindicke nach Lithiumbehandlung. Boxplots mit Median, Quartil, Min./Max.. Mann-WhitneyU-Test ( $\left.{ }^{* *} \mathrm{p}<0,01\right) \cdot \mathrm{p} 0-\mathrm{p} 6 \mathrm{n}=3$ je Gruppe; $\mathrm{p} 0-\mathrm{p} 21$ Kontrolle $\mathrm{n}=3$, Lithium $\mathrm{n}=5$; p30 - p117 Kontrolle $\mathrm{n}=6$, Lithium $\mathrm{n}=7$.

Schwannzellen umgeben die Axone mit ihrer Zellmembran spiralförmig und bilden so das Myelin. Die direkt aneinander liegenden Zellmembranen ohne dazwischen befindliches Zytoplasma bilden das kompakte Myelin. Die gegenüberliegenden Anteile der intrazellulären Membran stellen dabei die sogenannte major dense line, die gegenüberliegenden extrazellulären Anteile die intraperiod line dar. Der Abstand zwischen zwei major dense lines beträgt im peripheren Nervensystem ca. $15 \mathrm{~nm}$ (Kirschner und Blaurock 1992). Um zu bestätigen, dass es sich bei der Abnahme der g-ratio um eine echte Zunahme der Myelindicke und nicht um eine Verbreiterung der einzelnen Schichten des Myelins bzw. eine Veränderung der Kompaktierung des Myelins handelte, wurden von Tieren aus der Gruppe p30 - p117 mikroskopische Aufnahmen der Myelinschicht von Tibialisnerven mit einer Vergrößerung von 12000x angefertigt. Die Dicke der Myelinschicht wurde gemessen und durch die Anzahl der major dense lines geteilt. Es zeigte sich ein durchschnittlicher Abstand der major dense lines von 14,23 nm in der Kontrollgruppe und 14,08 nm in der Lithiumgruppe (Mann-Whitney-U-Test, $\mathrm{p}=0,9$ ). Es gab also keinen Unterschied in dem durchschnittlichen Abstand zwischen zwei major dense 
lines zwischen behandelten und unbehandelten Tieren. Daraus lässt sich schließen, dass es sich um eine Zunahme der Myelindicke und nicht um eine Veränderung der Myelinkompaktierung handelte (Abbildung 4).
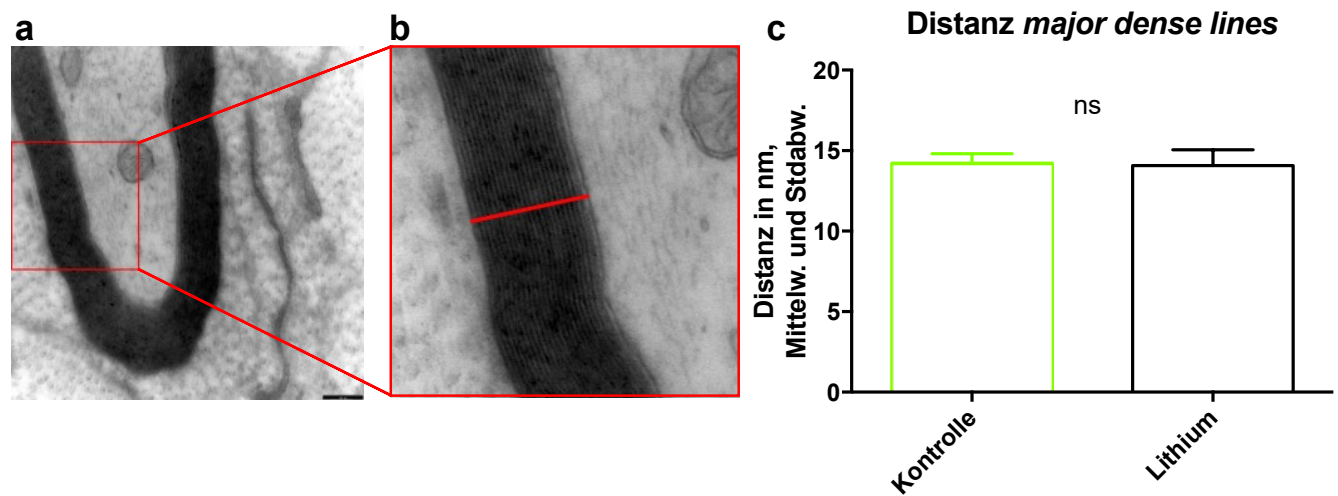

\begin{abstract}
Abbildung 4: Histologische Analyse der Myelinkompaktierung in Tibialisnerven von Wildtyp-Ratten nach Lithiumbehandlung. grün: Wildtyp-Ratten p30 - p117 ohne Lithiumbehandlung (Kontrolle), schwarz: Wildtyp-Ratten p30 - p117 nach Lithiumbehandlung. a) Repräsentative, elektronenmikroskopische Aufnahme eines Axons mit Myelinscheide aus dem Tibialisnerv einer 117 Tage alten Ratte. 12000x Vergrößerung. b) Vergrößerter Ausschnitt aus a). Die Dicke der Myelinschicht wurde gemessen und durch die Anzahl der major dense lines dividiert. c) Durchschnittlicher Abstand der major dense lines als Maß für die Dicke der einzelnen Myelinlamellen (Myelinkompaktierung). Ein Unterschied zwischen Lithium-behandelten- und Kontrolltieren ergab sich nicht. Mann-Whitney-U-Test, $n=3$ je Gruppe.
\end{abstract}

\title{
3.1.2 Genexpressionsanalysen aus RNA-Isolaten von Ischiasnerven
}

Aus entnommenen Ischiasnerven wurde RNA isoliert und nach erfolgter cDNA-Synthese die relative Expression verschiedener Gene normalisiert auf konstant exprimierte Gene mittels qRT-PCR in den Altersgruppen p0 - p21 und p30 - p117 gemessen. Hierbei wurde die Expression verschiedener Gene für Myelinproteine sowie der für die Cholesterinbiosynthese essentiellen Gene HMG-CoA-Reduktase (Hmgcr) und sterol regulatory element-binding protein cleavage-activating protein (Scap) untersucht. Außerdem wurde die relative Expression von Periaxin (Prx), der Transkriptionsfaktoren Oct6/Pou3f1 und Krox20/Egr sowie des Neurotrophins brain-derived neurotrophic factor (Bdnf) bestimmt. Es zeigte sich nach 21 Tagen Behandlung eine statistisch signifikant höhere Expression des Myelinproteins 0 ( $M p z$ ) (Abbildung 5c) sowie tendenziell eine erhöhte Expression des basischen Myelinproteins ( $M b p$ ) (Abbildung 5d) sowie der für die Cholesterinsynthese geschwindigkeitsbestimmenden HMG-CoAReduktase (Abbildung 5a). Die Expression von Bdnf war in der Gruppe p0 - p21 statistisch signifikant auf etwa $50 \%$ der Kontrollgruppe erniedrigt $(p=0,021)$ während sich in der Gruppe p30 - p117 kein Unterschied in der Bdnf-Expression verglichen mit der Kontrollgruppe fand (Abbildung 5h). Das periphere Myelinprotein Pmp22 (Abbildung 5e), der Transkriptionsfaktor Krox20/Egr (Abbildung 5i) sowie Connexin 43 (Cx43) (Abbildung 5j), als Indikator für eine Aktivierung des Wnt/B-Catenin-Signalwegs, waren lediglich zum Zeitpunkt p30 - p117 differentiell reguliert, während sich zu dem frühen Zeitpunkt kein signifikanter Unterschied fand. Die Expression von Scap, Prx, sowie des Transkriptionsfaktor 
Oct6/ Pou3f1 waren weder in der Altersgruppe p0 - p21 noch in der Gruppe p30 - p117 nach Behandlung der Wildtyp-Ratten mit Lithium signifikant differentiell reguliert (Abbildung $5 b, f, g)$.

a

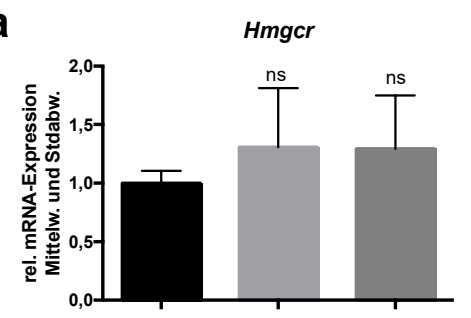

d

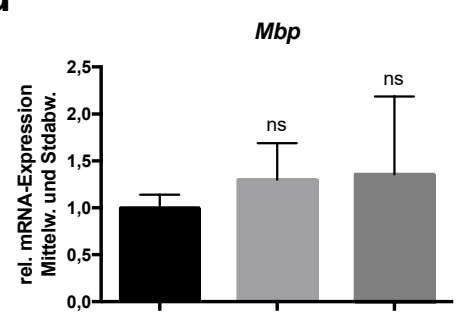

g

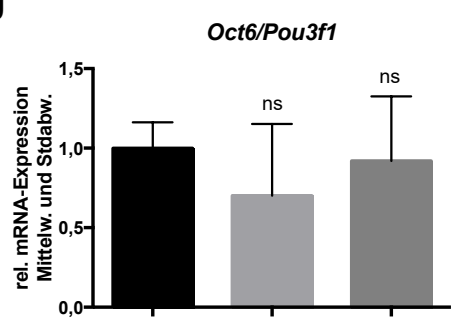

b

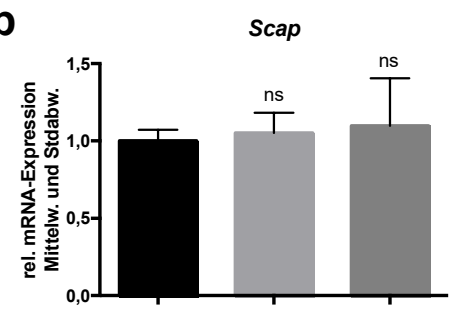

e

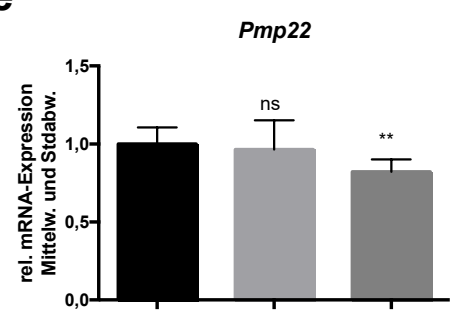

h

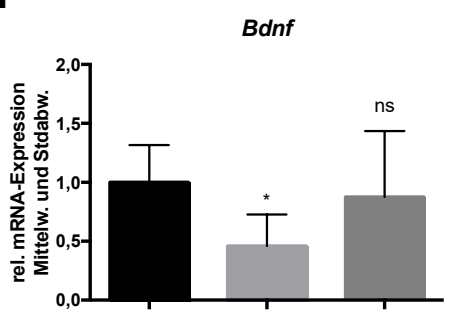

C

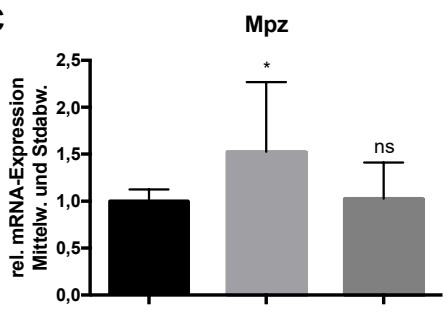

f

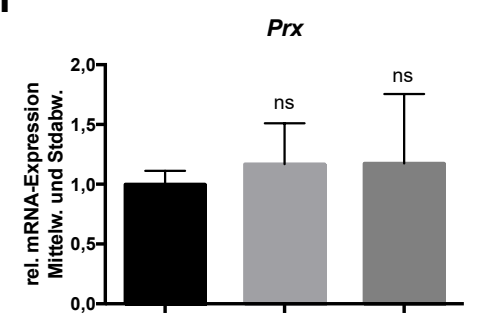

i

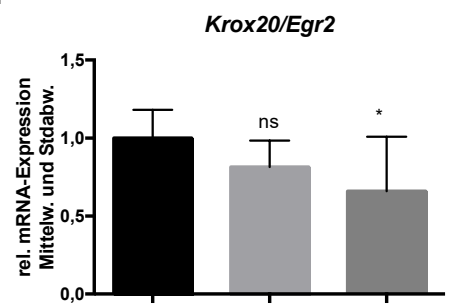

j

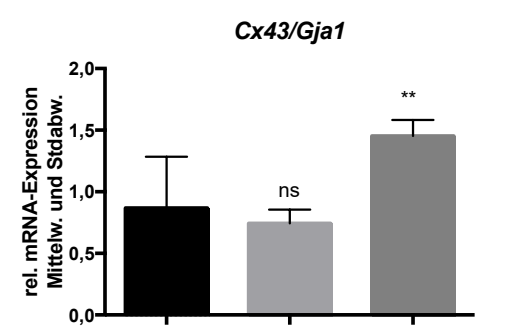

Wildtyp-Kontrolle

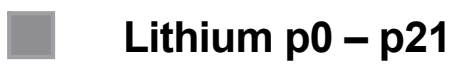

Lithium p30 - p117

Abbildung 5: Genexpressionsanalysen aus Ischiasnerven von Wildtyp-Ratten nach Lithiumbehandlung. Relative mRNA-Expression normalisiert auf unbehandelte Wildtyp-Ratten. Standardisiert auf die kon-

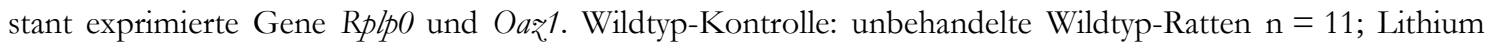
p0 - p21: Wildtyp-Ratten mit $1 \mathrm{mM} \mathrm{LiCl} / \mathrm{kg} / \mathrm{KG}$ intraperitoneal behandelt $\mathrm{n}=6$; Lithium p30 - p117: Wildtyp-Ratten mit $0,12 \% \mathrm{Li}_{2} \mathrm{CO}_{3}$ p. o. behandelt $\mathrm{n}=6$. Mittelwert und Standardabweichung, One-way-ANOVA mit Tukey post-hoc-Test $\left(* \mathrm{p}<0,05,{ }^{* *} \mathrm{p}<0,01\right)$.

\subsubsection{Proteinanalysen aus Proteinlysaten von Ischiasnerven}

Lithium ist in der Lage über die Inhibition von GSK3b den Abbau von $\beta$-Catenin zu hemmen (Phiel und Klein 2001). Der Wnt/ $\beta$-Catenin-Signalweg stimuliert die Myelingenexpression. Eine Hemmung des Wnt/ $\beta$-Catenin-Signalwegs führt zu einer Hypomyelinisierung (Tawk et al. 2011). Neben diesem bekannten Signalweg ist Lithium auch in der Lage den 
PI3K/AKT-Signalweg (Sinha et al. 2005) sowie den MAPK/ERK-Signalweg (Einat et al. 2003; Pardo et al. 2003) zu beeinflussen. Der PI3K/AKT-Signalweg spielt eine entscheidende Rolle in der Myelinisierung. So steuert der AKT-Signalweg die Umhüllung des Axons und reguliert die Dicke des Myelins im peripheren Nervensystem (Norrmén und Suter 2013; Domenech-Estevez et al. 2016). Bei einer Überaktivierung des PI3K/AKT-Signalwegs in Schwannzellen kommt es zu einer fokalen Hypermyelinisierung, Myelin outfoldings (zusätzliche Myelinschleifen, die sich innerhalb des Schwannzell-Zytoplasmas befinden oder das Axon außerhalb der normalen Myelinscheide umgeben) und Ausbildung von Tomaculas (abnormale, fokale Verdickungen des Myelins) (Goebbels et al. 2012). Der MAP/ERKSignalweg spielt eine wichtige Rolle in der Entwicklung des peripheren Nervensystems. Deletion von ERK1/2 in Schwannzell-Vorläuferzellen in Knock-Out-Mäusen führt zu einer Hypomyelinisierung (Newbern et al. 2011). Um zu überprüfen, inwiefern Lithum über einen dieser beiden Signalwege die Myelinisierung beeinflusst, wurden Western-Blot-Analysen aus Proteinlysaten von Ischiasnerven Lithium-behandelter Wildtyp-Ratten (p30-p117 mit $0,12 \% \mathrm{Li}_{2} \mathrm{CO}_{3}$ p. o.) auf $\mathrm{AKT} /$ phopho-AKT sowie auf die $42 \mathrm{kDa}$ und $44 \mathrm{kDa}$ Isoformen der MAPK/phospho-MAPK durchgeführt (Abbildung 6a). Um zu untersuchen, ob es zu einer Aktivierung der unterschiedlichen Signalwege kommt, wurde nach Normalisierung auf die Ladekontrolle Glycerinaldehyd-3-phosphat-Dehydrogenase der Quotient aus unphosphorylierter und phosphorylierter Form gebildet. Hier zeigte sich eine statistisch signifikante Aktivierung der p42MAPK als Ausdruck einer Aktivierung des MAPK/ERK-Signalwegs (Abbildung 6c). Es zeigte sich ebenfalls eine Aktivierung der p44MAPK-Isoform, aufgrund einer höheren Standardabweichung war der Unterschied jedoch statistisch nicht signifikant. Der Anteil des phospho-AKT war nach Lithiumbehandlung ebenfalls statistisch signifikant erhöht $(p=0,01)$, normalisiert auf das Gesamt-AKT zeigte sich jedoch nach Lithiumbehandlung kein statistisch signifikanter Unterschied (Abbildung 6b). 
a

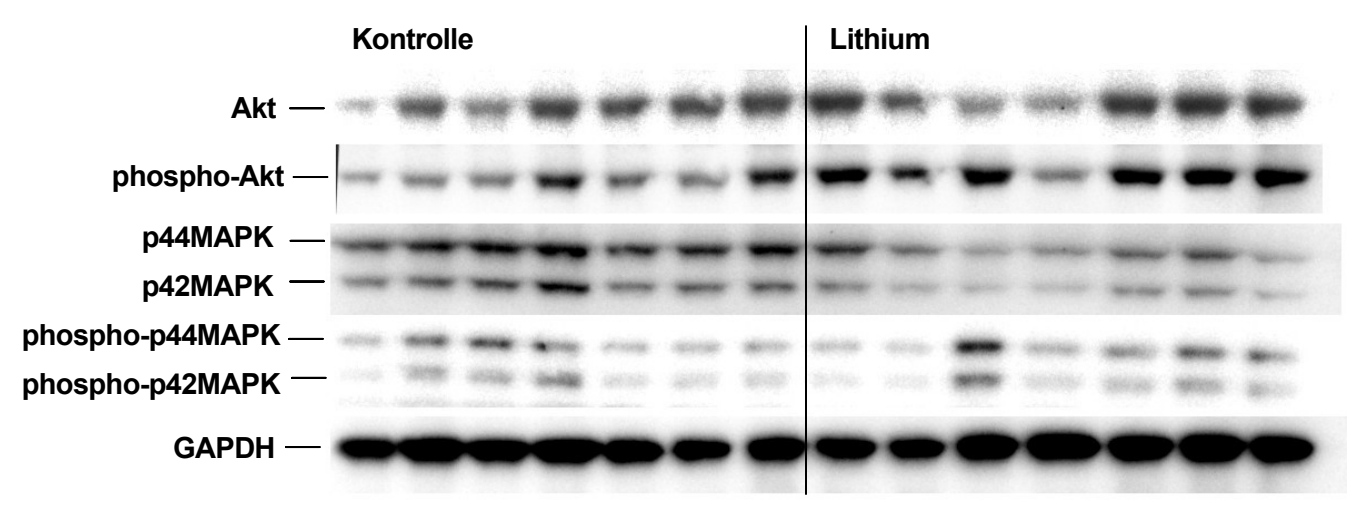

b
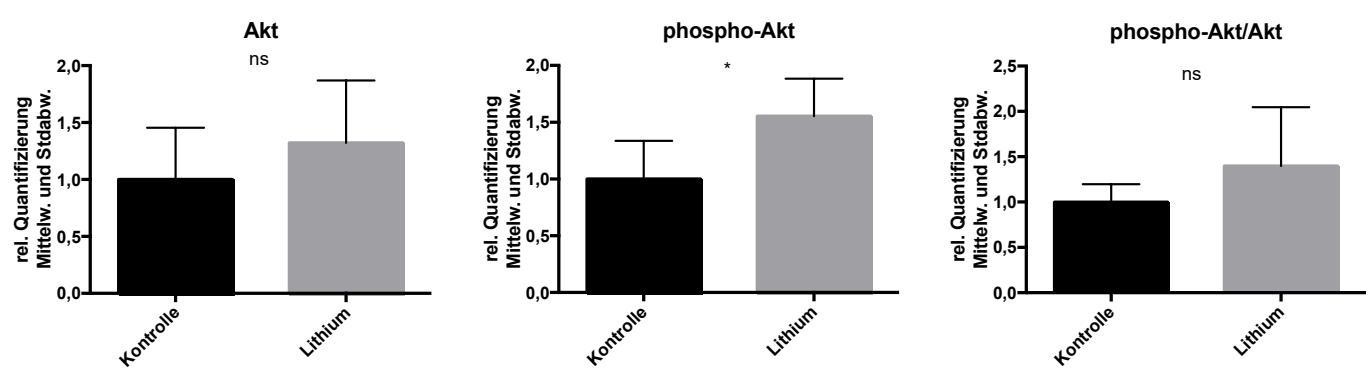

C

p42MAPK
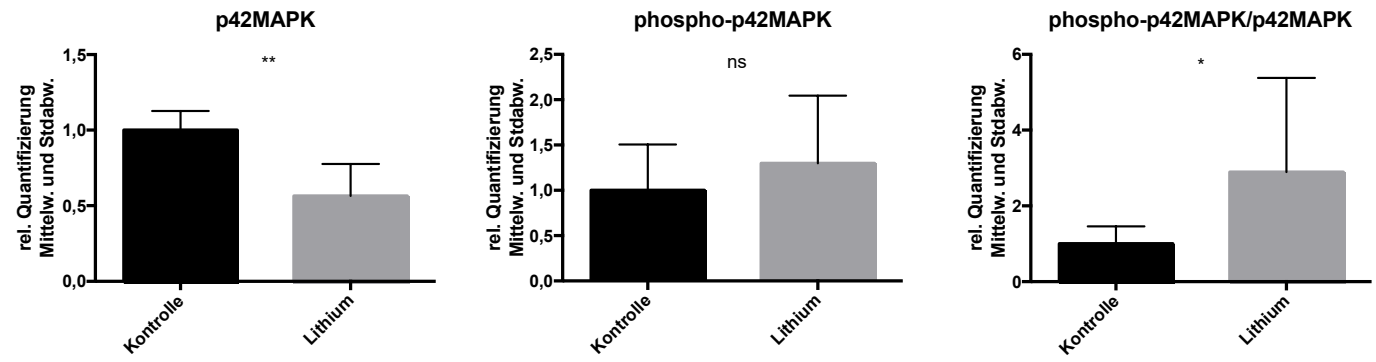

d
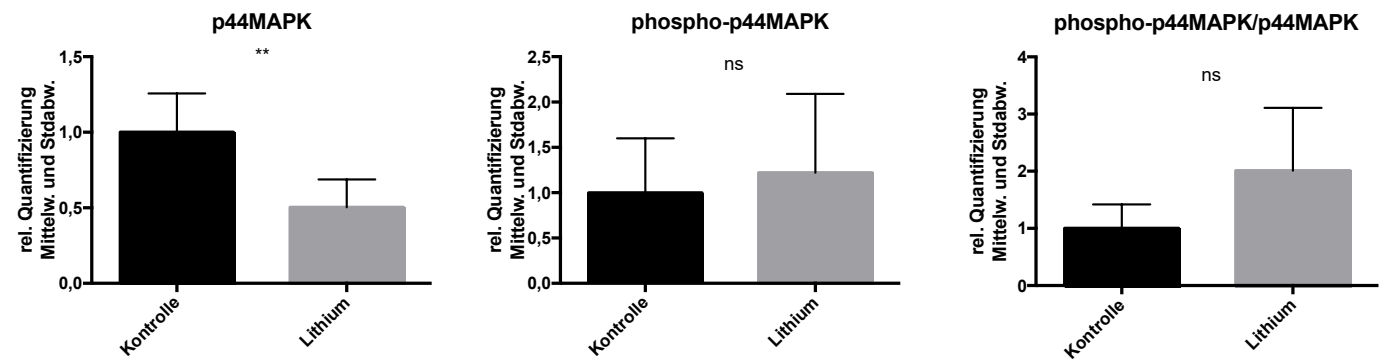

Abbildung 6: Proteinanalyse aus Ischiasnerven von adulten Wildtyp-Ratten nach Lithiumbehandlung. a) Repräsentative Western Blots mit Proteinlysaten aus Ischiasnerven adulter Wildtyp-Ratten mit Lithiumbehandlung ( $\mathrm{p} 30$ - p117, 0,12\% $\mathrm{Li}_{2} \mathrm{CO}_{3}$ ) und Kontrollgruppe ohne Lithiumbehandlung (p30 - p117). Alle Blots wurden auf GAPDH als Ladekontrolle normalisiert. Nach Lithiumbehandlung zeigte sich eine statistisch signifikante Aktivierung der p42-Isoform der MAPK sowie eine tendenzielle Aktivierung der p44-Isoform. $\mathrm{n}=7$ je Gruppe, Mann-Whitney-U-Test $\left(* \mathrm{p}<0,05,{ }^{* *} \mathrm{p}<0,01\right)$. 


\subsection{Einfluss von Lithium auf die Schwannzell-Differenzierung und Myelinisierung in vitro}

\subsubsection{Genexpressionsanalysen aus primären Schwannzell-Kulturen}

Primäre Schwannzell-Kulturen wurden aus Ischiasnerven zwei Tage alter Ratten präpariert. Nach Behandlung mit Cytarabin zur Elimination von Fibroblasten wurden die Zellen auf Zellkulturschalen ausplattiert und zur Vermehrung maximal dreimal passagiert. Forskolin ist ein Aktivator der Adenylatcyclasen und führt zu einer Erhöhung des intrazellulären cyclischen Adenosinmonophosphats (cAMP). Ein erhöhter intrazellulärer cAMP-Spiegel führt in Schwannzellen zu Proliferation (Sobue et al. 1986), Differenzierung (Morgan et al. 1991) sowie zur Expression von Myelingenen (LeBlanc et al. 1992). Um die Wirkung von Lithium auf Schwannzellen in vitro zu untersuchen, wurde in konfluenten Kulturen dem Medium für 72 Stunden entweder keine Zusätze, $1 \mathrm{mM} \mathrm{Li}_{2} \mathrm{CO}_{3}, 1 \mathrm{mM} \mathrm{Li}_{2} \mathrm{CO}_{3}$ und $4 \mu \mathrm{M}$ Forskolin oder nur $4 \mu \mathrm{M}$ Forskolin zugegeben. Nach 72 Stunden Behandlung der Zellen wurde gemäß Herstellerprotokoll RNA isoliert, cDNA synthetisiert und Genexpressionsanalysen mittel qRTPCRs durchgeführt.

Das Gap-Junction-Protein Connexin 43 (Cx43) ist ein bekanntes Target des Wnt/B-CateninSignalwegs (Van der Heyden et al. 1998) und ist selbst für die Aufrechterhaltung einer normalen Myelinscheide im peripheren Nervensystem notwendig (Anzini et al. 1997). Lithium wiederrum ist in der Lage über die Inhibition der Glykogensynthasekinase 3 beta (GSK3b) den Wnt-Signalweg zu aktivieren (Hedgepeth et al. 1997). Eine Behandlung mit Lithium $1 \mathrm{mM} / 1$ für $72 \mathrm{~h}$ führte nicht zu einer erhöhten Expression von $C \times 43$. Durch die Erhöhung des intrazellulären cAMP kam es zu einer etwa 5-fach erhöhten Expression von Cx43. Eine Kombination von Forskolin und Lithium führte zu keiner weiteren Erhöhung der $C \times 43$ Expression (Abbildung 7a). Die Expression von Gsk3b wurde weder durch die Gabe von Lithium noch durch Forskolin verändert (Abbildung 7i).

Untersuchungen haben wiederholt gezeigt, dass die Gabe von Lithium in der Lage ist die Expression von Myelingenen zu induzieren (Makoukji et al., 2012; Fang et al., 2016). Nach Behandlung der Schwannzellen mit $1 \mathrm{mM} \mathrm{Li}_{2} \mathrm{CO}_{3}$ zeigte sich eine signifikant erhöhte Expression von Pmp22 ( $\mathrm{p}=$ 0,0317, Abbildung 7b). Die Expression des Myelinproteins 0 (Mpz) wurde durch die Zugabe von $1 \mathrm{mM} \mathrm{Li}_{2} \mathrm{CO}_{3}$ nicht beeinflusst (Abbildung 7c). Erwartungsgemäß kam es durch die Erhöhung des intrazellulären cAMPs durch Forskolin zu einer erhöhten Expression beider Myelinproteine. Die Zugabe von $1 \mathrm{mM}$ Lithium und Forskolin zusammen führte nicht zu einer erhöhten Expression der Myelinproteine $M p$ z und $P m p 22$ gegenüber der alleinigen Gabe von Forskolin (Abbildung 7b,c). Die mRNA-Level der HMGCoA Reduktase (Hmgrr) sowie von Sterol regulatory element-binding protein cleavage activating protein (Scap), einem Schlüsseltranskriptionsfaktor der Cholesterinbiosynthese, sowie des Proliferationsmarkers Ki67, wurden weder durch die Gabe von $1 \mathrm{mM}$ Lithium noch durch Forskolin beeinflusst (Abbildung 7d,e,f). 
Die Expression der Schwannzell-Differenzierungsmarker Krox20/Egr1 und Oct6/Pou3f1 wurde durch die Gabe von Forskolin stimuliert. Die Gabe von $1 \mathrm{mM}$ Lithium führte weder in der Anwesenheit noch in der Abwesenheit von Forskolin zu einer Veränderung der Expression (Abbildung 7g,h).

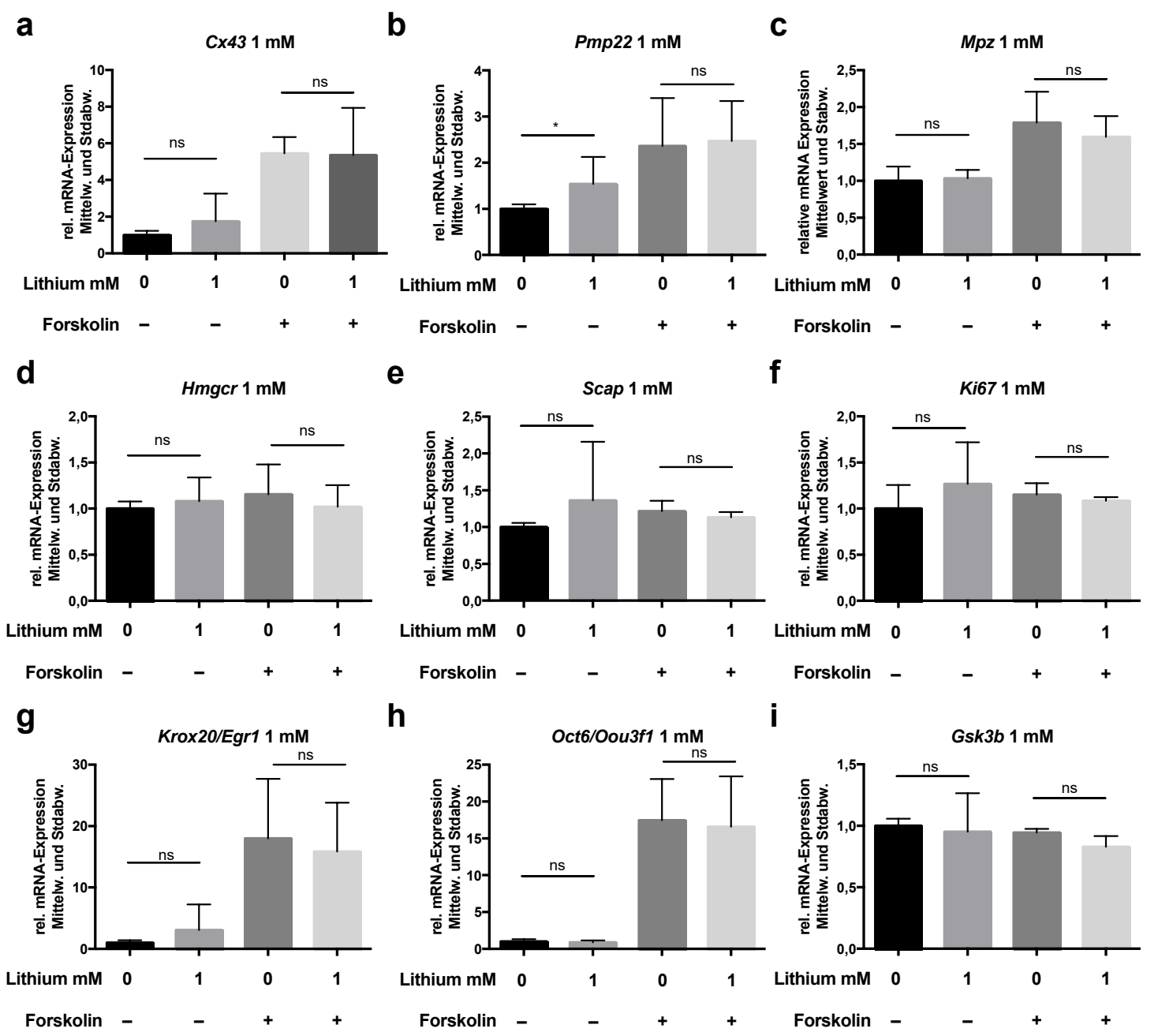

Abbildung 7: Genexpressionsanalysen aus primären Schwannzell-Kulturen unter dem Einfluss von $1 \mathrm{mM}$ Lithiumcarbonat und Forskolin. Relative mRNA-Expression normalisiert auf die Kontrollgruppe (Lithium 0/Forskolin-). Für 72 Stunden wurden dem Nährmedium entweder keine Zusätze (Lithium 0/Forskolin -), nur $1 \mathrm{mM} \mathrm{Li}_{2} \mathrm{CO}_{3}$ (Lithium 1/Forskolin-), $1 \mathrm{mM} \mathrm{Li}_{2} \mathrm{CO}_{3}$ und $4 \mu \mathrm{M}$ Forskolin (Lithium 1/ Forskolin + ) oder nur $4 \mu \mathrm{M}$ Forskolin (Lithium 0/Forskolin + ) zugegeben. Die Erhöhung des intrazellulären cAMPs mit Forskolin führte zu einer Induktion von Pmp22 (b), Mpz (c) sowie der Transkriptionsfaktoren Oct6/POU3F1 (g) und Krox20/Egr2 (h). Signifikante Induktion der Expression von Pmp22 nach Behandlung mit $1 \mathrm{mM} \mathrm{Li}_{2} \mathrm{CO}_{3}$ ohne Forskolin (b). Eine statistisch signifikante Änderung der Expression durch Gabe von $\mathrm{Li}_{2} \mathrm{CO}_{3}$ zeigte sich in keinem anderen der untersuchten Gene. $\mathrm{n}=6$ je Gruppe, One-way-ANOVA mit Tukey post-hoc-Test $\left(*_{p}<0,05\right)$.

Um zu überprüfen, inwieweit die Beeinflussung der Genexpression durch Lithium dosisabhängig war, wurden zusätzlich Schwannzell-Kulturen für 72 Stunden mit $5 \mathrm{mM} \mathrm{Li}_{2} \mathrm{CO}_{3}$ ( \pm Forskolin) behandelt. Hier zeigte sich gegenüber der Behandlung mit $1 \mathrm{mM}$ eine statistisch signifikant erhöhte Expression von Cx43 sowohl in Abwesenheit als auch Anwesenheit 
von Forskolin ( $p=0,0238-$ Forskolin bzw. $p=0,0067+$ Forskolin, Abbildung 8a). Die Expression von Pmp22 stieg nach Behandlung mit $5 \mathrm{mM}$ Lithium gegenüber der unbehandelten Kontrollgruppe um etwa den Faktor 4,5 bzw. 5 nach zusätzlicher Stimulation mit Forskolin. Der Unterschied war statistisch signifikant $(p=0,049$ - Forskolin bzw. $\mathrm{p}=0,0357+$ Forskolin, Abbildung 8b). Die Expression von Mpz war nach Behandlung der Schwannzell-Kulturen mit $5 \mathrm{mM} \mathrm{Li}_{2} \mathrm{CO}_{3}$ ohne zusätzliche Stimulation mit Forskolin nicht statistisch signifikant verändert. Nach Behandlung der Zellen mit $5 \mathrm{mM} \mathrm{Li}_{2} \mathrm{CO}_{3}$ und Forskolin zeigte sich eine statistisch signifikante Induktion der $M_{p} z_{-}$Expression um den Faktor 3 ( $p=0,0238$, Abbildung 8c).
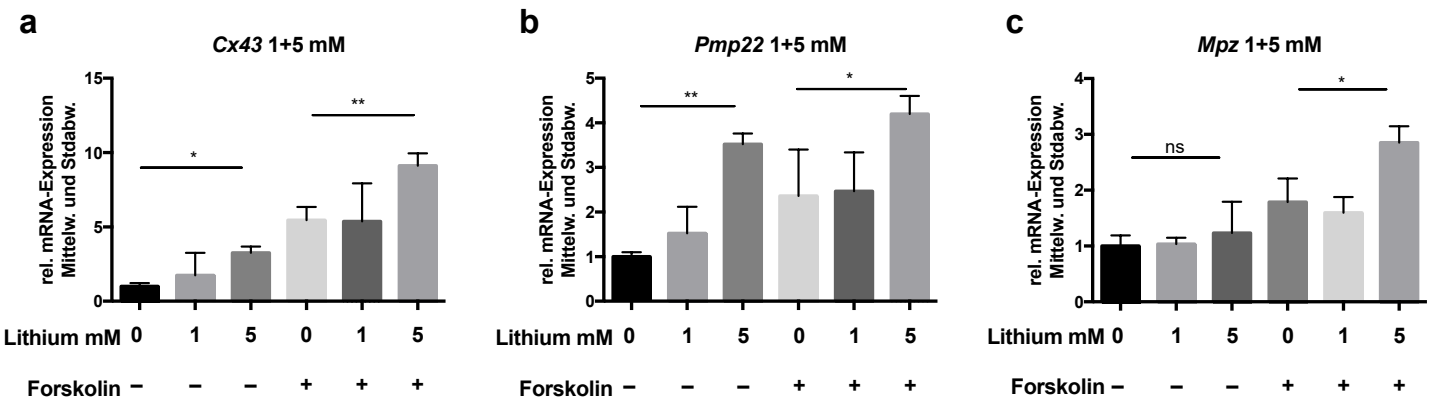

Abbildung 8: Genexpressionsanalysen aus primären Schwannzell-Kulturen unter dem Einfluss von $1 \mathrm{mM}$ und 5 mM Lithiumcarbonat und Forskolin. Für 72 Stunden wurden dem Nährmedium zusätzlich zur vorhergehenden Untersuchung der Genexpression in Schwannzellkulturen (vgl. Abbildung 7) zwei Dosierungsstufen hinzugefügt: nur $5 \mathrm{mM} \mathrm{Li}_{2} \mathrm{CO}_{3}$ (Lithium $5 /$ Forskolin -) und $5 \mathrm{mM} \mathrm{Li}_{2} \mathrm{CO}_{3}$ und $4 \mu \mathrm{M}$ Forskolin (Lithium 5/Forskolin + ). Es zeigte sich nach Gabe von $5 \mathrm{mM} \mathrm{Li}_{2} \mathrm{CO}_{3}$ eine dosisabhängige Lithium-bedingte Induktion von Cx43 (a), Pmp22 (b) und Mpz (c). Alle Werte normalisiert auf die Kontrollgruppe (Lithium 0/Forskolin -), $\mathrm{n}=3$ je Gruppe, One-way-ANOVA mit Tukey post-hoc-Test $\left({ }^{*} \mathrm{p}<0,05,{ }^{* *} \mathrm{p}<0,01\right)$.

\subsubsection{Myelinisierung in Schwannzell-DRG-Neuron-Co-Kulturen}

Co-Kulturen aus Neuronen der dorsalen Hinterwurzelganglien (DRG-Neurone) und Schwannzellen sind in vitro in der Lage Myelin zu bilden. Diese myelinisierenden Co-Kulturen bieten die Möglichkeit den Einfluss von Substanzen auf die Myelinisierung in vitro zu untersuchen. Es wurden Kulturen nach einer modifizierten Methode nach Kleitman et al. (1998) präpariert. Mit Initialisierung der Myelinisierung mittels Ascorbinsäure (Eldridge et al. 1987) an Tag 7 wurden dem Medium 0 mM, 1 mM oder 5 mM Li $\mathrm{CO}_{3}$ zugegeben. Nach 16 Tagen wurden die Kulturen fixiert und das neuron-specific class III $\beta$-tubulin (Tuj1) zur Darstellung der Axone sowie Mbp zur Darstellung des Myelins gefärbt. Das Experiment wurde an jeweils drei unabhängigen Kulturen durchgeführt. Auf jeweils drei Coverslips pro Gruppe wurde die Anzahl myelinisierter Segmente gezählt. Hier zeigte sich eine statistisch signifikante Zunahme der myelinisierten Segmente nach Behandlung mit $1 \mathrm{mM} \mathrm{Li}_{2} \mathrm{CO}_{3}$. Die Gruppe mit $5 \mathrm{mM} \mathrm{Li}_{2} \mathrm{CO}_{3}$ zeigte nahezu keine Myelinisierung sowie einen Untergang der DRG-Neurone (nicht quantifiziert) (Abbildung 9). 
a

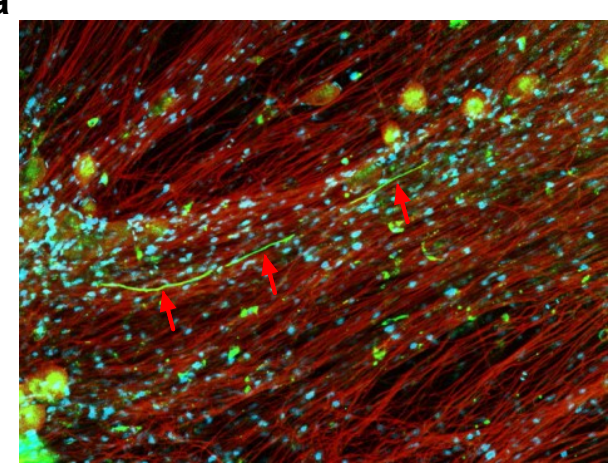

b

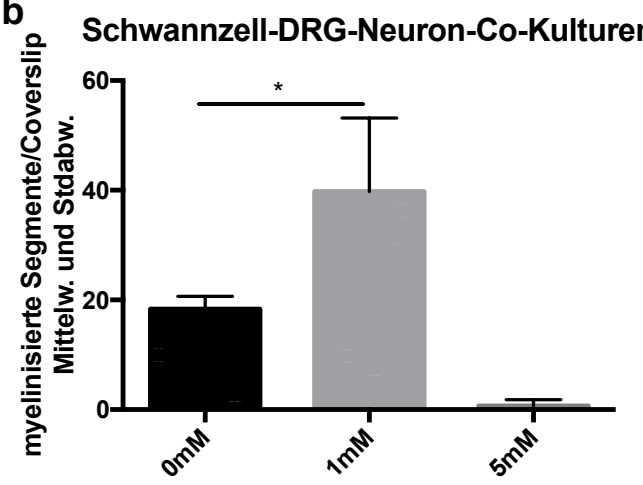

Abbildung 9: Histologische Analyse der Myelinisierung von Schwannzell-DRG-Neuron-Co-Kulturen nach Lithiumbehandlung. a) Immunfluoreszenzdreifachfärbung, rot: Tuj1 (Axone), grün: Mbp (Myelin), blau: DAPI-Kernfärbung. 1000x Vergrößerung. Repräsentativer Ausschnitt einer Schwannzell-DRG-NeuronCo-Kultur, rote Pfeile markieren myelinisierte Segmente. b) Quantifizierung der myelinisierten Segmente von Schwannzell-DRG-Neuron-Co-Kulturen pro Coverslip. Zugabe von 0mM, $1 \mathrm{mM}$ oder $5 \mathrm{mM} \mathrm{Li}_{2} \mathrm{C0}_{3}$ mit Initialisierung der Myelinisierung. Statistisch signifikante Zunahme der Anzahl myelinisierter Segmente nach Zugabe von $1 \mathrm{mM} \mathrm{Li}_{2} \mathrm{CO}_{3}$ ab Tag 7. $\mathrm{n}=3$ je Gruppe, One-way-ANOVA mit Tukey post-hoc-Test $\left({ }^{*} \mathrm{p}<0,05\right)$. 


\subsection{Therapieversuch mit Lithium im transgenen Rattenmodell der CMT1A}

In Nouri et al. (2009) und Makoukji et al. (2012) wurde der positive Einfluss von Lithium auf die Regeneration bzw. Remyelinisierung nach Nervenverletzungen im Rattenmodell dargestellt. Pourmohammadi et al. (2012) konnten eine Abmilderung einer Paclitaxel-induzierten Neuropathie durch eine Behandlung mit Lithium zeigen. Aufgrund der in der Literatur beschriebenen Einflüsse von Lithium auf Neuropathien und Nerventraumata sowie der vielversprechenden Ergebnisse aus der Voruntersuchung in Wildtyp-Tieren, entschlossen wir uns zu einem Therapieversuch im Rattenmodell der CMT1A (Pmp22-transgene Ratten; Sereda et al. 1996). Da sich in den Vorexperimenten bei Wildtyp-Ratten, während des Prozesses der Myelinisierung ( $00-\mathrm{p} 6$ und $\mathrm{p} 0-\mathrm{p} 21)$, keine Unterschiede zeigten, entschlossen wir uns im Alter von 30 Tagen mit der Behandlung zu beginnen (vgl. Abbildung 3). Es wurde ein Behandlungszeitraum von insgesamt zwölf Wochen bis zum Alter von 16 Wochen gewählt, da sich zu dem späteren Zeitpunkt ein stärker ausgeprägter Phänotyp der transgenen Ratten zeigt (Sereda et al. 1996; Fledrich et al. 2012a) (Abbildung 10). Hierzu wurden 30 Pmp22-transgene Ratten und 24 Wildtyp-Kontrolltiere im Alter von 28 Tagen gewogen und die Griffstärke der Vorder- und Hinterbeine gemessen. Danach wurden die transgenen Ratten und die Wildtyp-Tiere in jeweils zwei durchschnittlich gleich starke und schwere Gruppen eingeteilt. Ab dem Alter von 30 Tagen bekamen jeweils eine Gruppe transgene Ratten $(\mathrm{n}=15)$ und Wildtyp-Ratten $(\mathrm{n}=12)$ für insgesamt zwölf Wochen Futter mit $0,12 \% \mathrm{Li}_{2} \mathrm{CO}_{3}$. Als Placebo-Kontrollen erhielten je eine Gruppe transgene Tiere $(\mathrm{n}=15)$ und Wildtyp-Ratten ( $\mathrm{n}=12$ ) Standardfutter. Im Alter von 10, 13 und 16 Wochen wurde die Griffstärke an Vorder- und Hinterläufen getestet. Im Alter von 16 Wochen wurde zusätzlich eine elektrophysiologische Untersuchung der peripheren Nerven am Schwanz der Tiere durchgeführt. Im Anschluss wurden die Tiere durch Einleitung von $\mathrm{CO}_{2}$ Gas getötet und Gewebe zur histologischen und molekularbiologischen Untersuchung entnommen.

\section{a) Alter in Wochen}

b) Behandlungszeitraum

c) Messung Gewicht und Griffstärke

d) Elektrophysiologie, Töten der Tiere, Entnahme von Gewebe zur weiteren Analyse
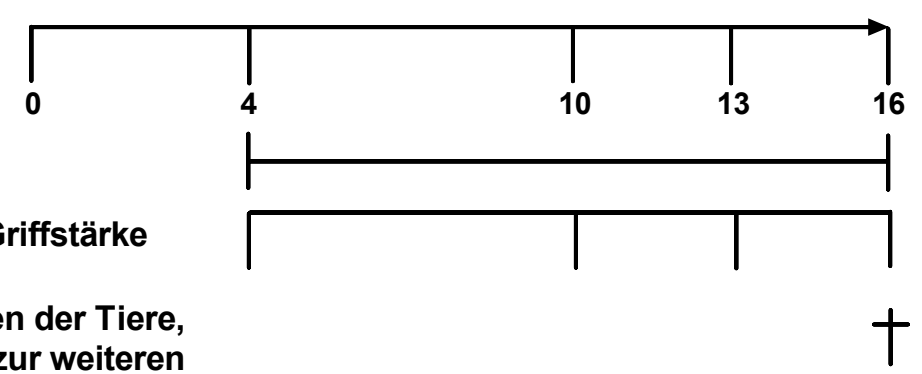

Abbildung 10: Schematische Darstellung der Lithiumbehandlung von Pmp22-transgenen Ratten. a) Einteilung im Alter von vier Wochen nach Gewicht und Griffstärke in jeweils zwei gleichwertige transgene $(\mathrm{n}=15)$ bzw. Wildtyp-Gruppen $(\mathrm{n}=12)$. b) Ab dem 30. Tag Behandlung der Tiere mit $\mathrm{Li}_{2} \mathrm{CO}_{3}$ bzw. Standardfutter. c) Messung von Griffstärke und Gewicht im Alter von 10 und 13 Wochen. d) Im Alter von 16 Wochen Messung von Griffstärke und NLG. Im Anschluss Tötung der Tiere und Entnahme von Gewebe zur weiteren Analyse. 


\subsubsection{Phänotypische Untersuchung Pmp22-transgener Ratten}

Wie auch bei Lithium-behandelten Wildtyp-Tieren (Abbildung 2) kam es bei den transgenen Tieren im Verlauf der Behandlung mittels Lithiumcarbonat zu einem Gewichtsverlust. Dieser war sowohl in der Gruppe der transgenen Ratten als auch bei den Wildtyp-Tieren zum Abschluss der Studie signifikant (transgene Ratten $\mathrm{p}=0,0237$, Wildtyp p $=0,0437$, Abbildung 11).

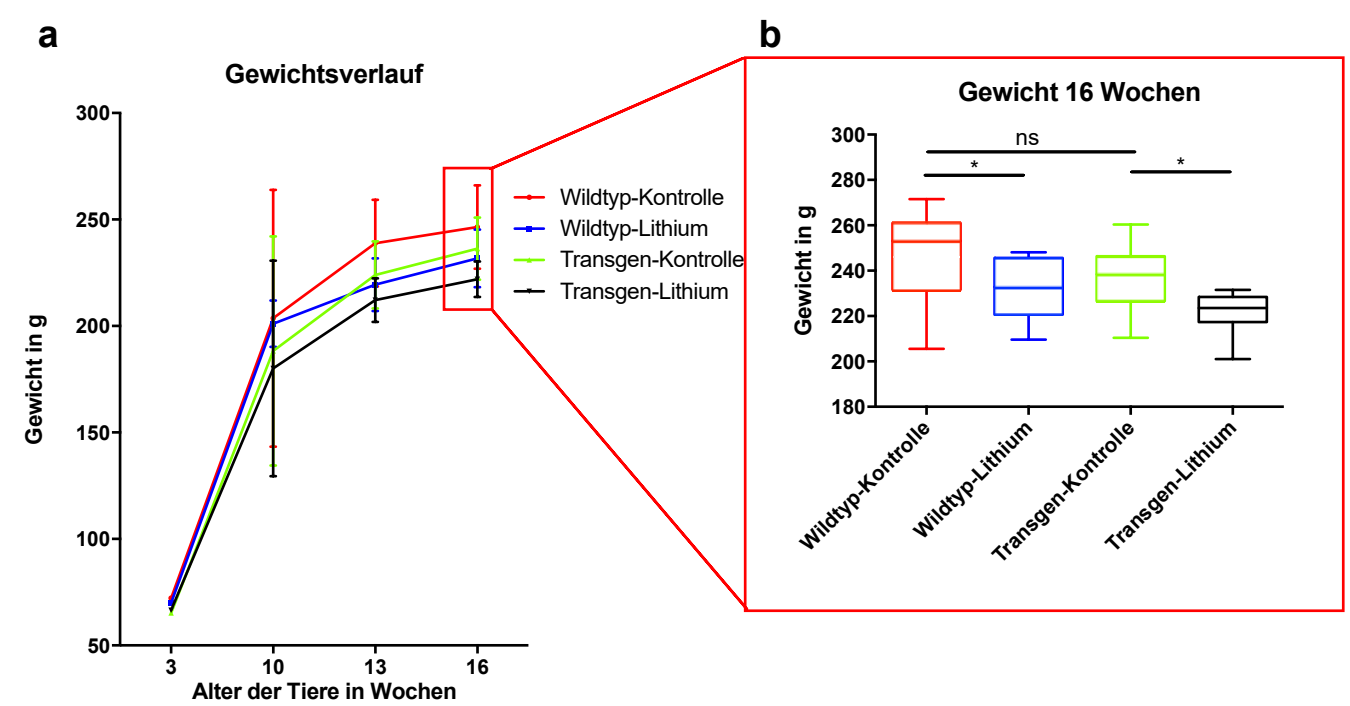

Abbildung 11: Gewichtsverlauf bei Pmp22-transgenen Ratten nach Lithiumbehandlung. a) Im Alter von drei Wochen erfolgte die Einteilung der Gruppen nach Griffstärke und Gewicht, sodass die einzelnen Gruppen hier keinen Unterschied zeigten. Im Verlauf zeigte sich ein zunehmender Gewichtsverlust bei den Lithium-behandelten Ratten im Vergleich zu den Kontrollgruppen. b) Zum Abschluss der Studie (Alter von 16 Wochen) statistisch signifikanter Gewichtverlust der Lithium-behandelten Ratten im Vergleich zu den Kontrollgruppen. Mittelwerte: Wildtyp-Kontrolle 246,5 g, Wildtyp-Lithium 231,7 g, Transgen-Kontrolle 236,4 g, Transgen-Lithium 221,9 g. Wildtyp-Kontrolle und Wildtyp-Lithium je $\mathrm{n}=12$, Transgen-Kontrolle und Transgen-Lithium je $n=15$. Boxplot mit Median, Quartil, Min./Max.. One-way-ANOVA mit Tukey post-hoc-Test $(* \mathrm{p}<0,05)$.

Im Alter von drei Wochen zeigte sich ein statistisch signifikanter Unterschied in der Griffstärke der Vorder- und Hinterläufe zwischen Pmp22-transgenen und Wildtyp-Ratten, der im weiteren Verlauf konstant war (Abbildung 12). Während die Messung der Vorderläufe allenfalls eine geringe Verbesserung der Griffstärke der Lithium-behandelten transgenen Tiere ergab, zeigte sich an den Hinterläufen ab der 13. Woche eine signifikante Zunahme der Griffstärke bei den Lithium-behandelten transgenen Ratten im Vergleich zu den unbehandelten transgenen Tieren. Zum Abschluss der Therapie im Alter von 16 Wochen war dieser Unterschied signifikant $(\mathrm{p}=0,0128)$. Die Griffstärke der Wildtyp-Ratten mit Standardfutter und mit Lithium-Futter unterschied sich während des gesamten Verlaufs nicht, trotz eines zum Abschluss der Untersuchung statistisch signifikanten Gewichtsverlustes der Lithium-behandelten Tiere (Abbildung 11). 
a

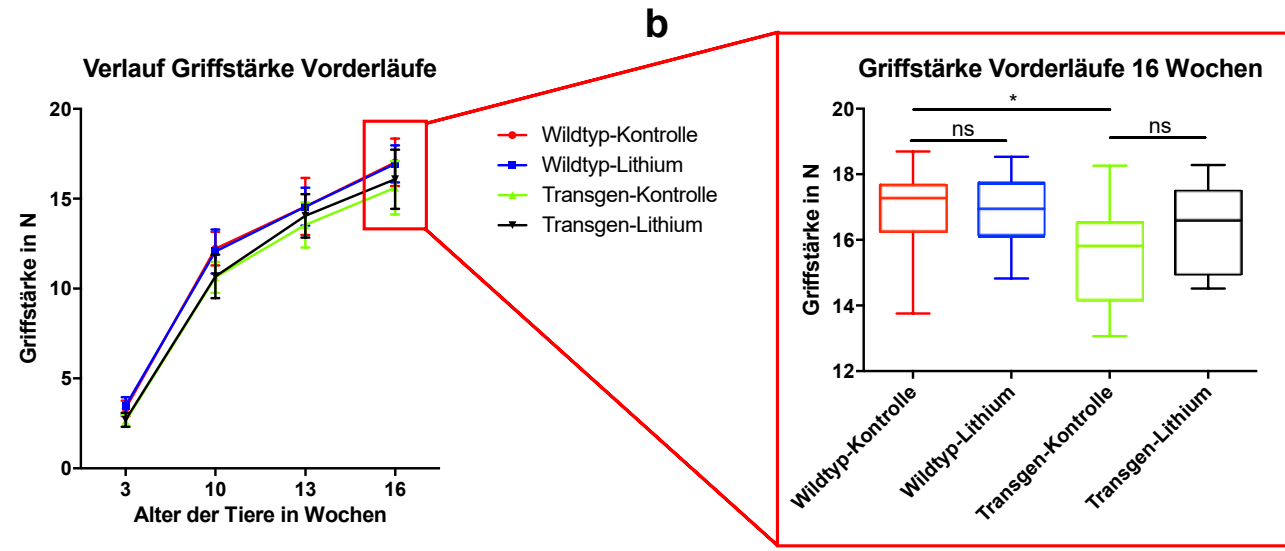

C

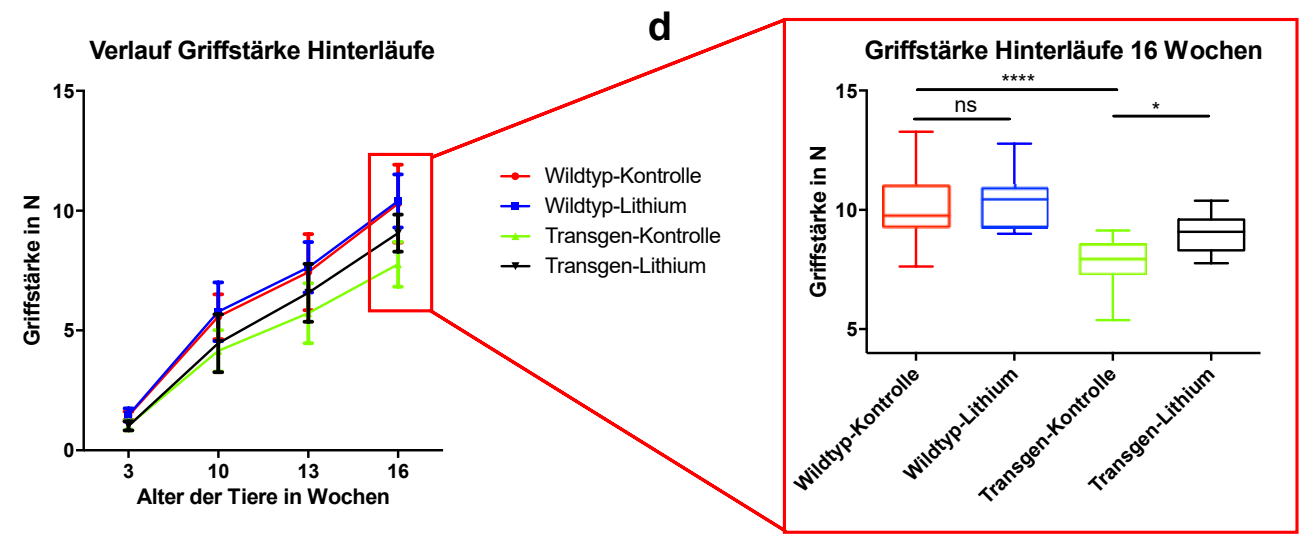

Abbildung 12: Verlauf der Griffstärke von Vorder- und Hinterläufen bei Pmp22-transgenen Ratten nach Lithiumbehandlung. $a+c)$ Im Alter von drei Wochen zeigte sich bereits ein Unterschied in der Griffstärke von Vorder- und Hinterläufen zwischen Pmp22-transgenen- und Wildtyp-Ratten. Im Verlauf zunehmender Kraftverlust an Vorder- und Hinterläufen. b + d) Zum Abschluss der Studie (Alter von 16 Wochen) zeigte sich ein signifikanter Unterschied zwischen Wildtyp- und Pmp22-transgenen Ratten. Nach Therapie mit $\mathrm{Li}_{2} \mathrm{CO}_{3}$ der Pmp22-transgenen Tiere statistisch signifikanter Unterschied der Kraft an den Hinterläufen (d) sowie statistisch nicht signifikanter Unterschied an den Vorderläufen im Vergleich zur transgenen Kontrollgruppe (b). Wildtyp-Kontrolle und Wildtyp-Lithium je $n=12$, Transgen-Kontrolle und Transgen-Lithium je $n=15$. Boxplot mit Median, Quartil, Min./Max.. One-way-ANOVA mit Tukey post-hoc-Test $\left({ }^{*} \mathrm{p}<0,05,{ }^{*} \mathrm{p}<0,01\right.$, $* * * * \mathrm{p}<0,001)$.

\subsubsection{Elektrophysiologische Untersuchung an Schwanznerven Pmp22-transgener Ratten}

Aus Untersuchungen an CMT1A-Patienten (Pareyson et al. 2006) sowie aus Experimenten am transgenen Rattenmodell der CMT1A (Sereda et al. 1996) ist eine Verringerung der Nervenleitgeschwindigkeit (NLG) sowie der Amplituden der Muskelsummenaktionspotentiale (MSAP) bei elektrophysiologischen Untersuchungen bekannt. Vor Abschluss der Therapie wurden die Tiere analgosediert, zur Erhaltung der Körpertemperatur auf einer Wärmematte gelagert und eine Messung der motorischen und sensiblen NLG an den Schwanznerven der Ratten durchgeführt. Erwartungsgemäß zeigte sich ein deutlicher Unterschied der NLG und der MSAP zwischen transgenen und Wildtyp-Ratten. Eine Verbesserung der MSAP zeigte sich zum Abschluss der Studie im Alter von 16 Wochen in den Lithium-behandelten Tieren 
im Vergleich zu der Kontrollgruppe nicht. Durch die Behandlung mit Lithium ließ sich jedoch im Alter von 16 Wochen eine statistisch signifikante Verbesserung der NLG bei den transgenen Tieren im Vergleich zur Kontrollgruppe erzielen (Abbildung 13a). In der Messung der sensiblen Neurographie in orthodromer Richtung zeigte sich ebenfalls ein hoch signifikanter Unterschied der NLG sowie der sensiblen Nervenaktionspotentiale (SNAP) zwischen Wildtyp-Kontrollen und Pmp22-transgenen Tieren. In der Gruppe der WildtypKontrollen zeigte sich kein Unterschied zwischen Lithium-behandelten Tieren und Tieren mit Standardfutter. In der Gruppe der transgenen Tiere ließ sich durch die Lithiumbehandlung eine leichte, statistisch nicht signifikante Verbesserung der sensiblen NLG erzielen. Ein Unterschied in der Amplitude des SNAP zeigte sich nicht (Abbildung 13b).

a

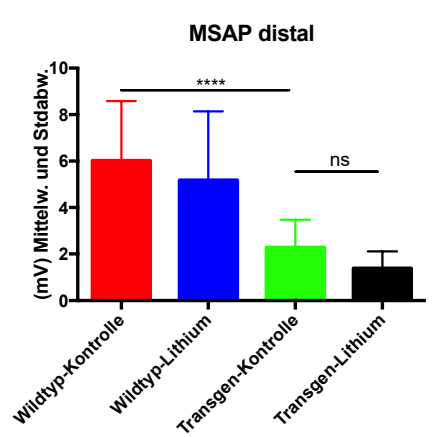

b

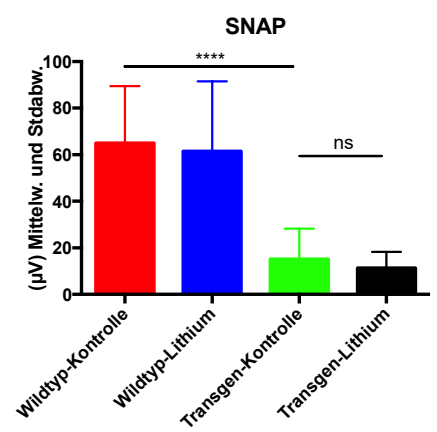

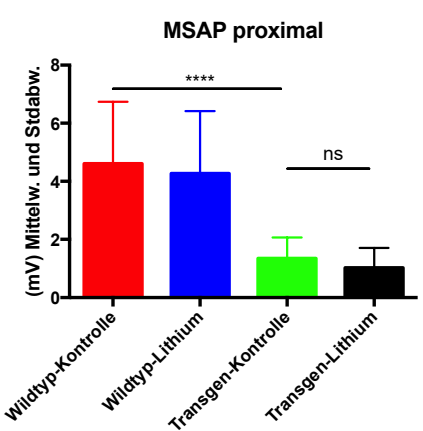

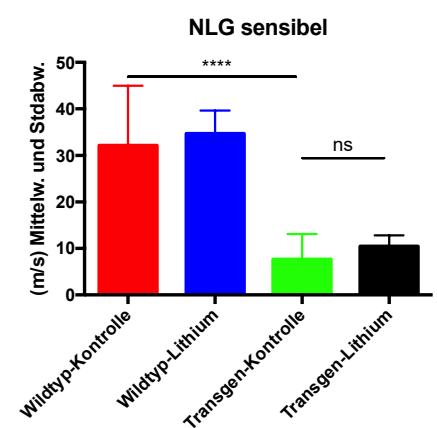

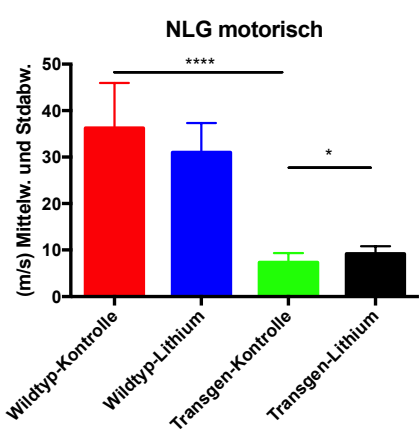

Wildtyp-Kontrolle

Wildtyp-Lithium

Transgen-Kontrolle

Transgen-Lithium

Abbildung 13: Messung der motorischen und sensiblen NLG bei Pmp22-transgenen Ratten nach Lithiumbehandlung. Zum Abschluss der Studie (Alter von 16 Wochen) erfolgte die Messungen der Muskelsummenaktionspotentiale (MSAP) und Nervenleitgeschwindigkeit (NLG) am Schwanz der transgenen und Wildtyp-Ratten mit und ohne Lithiumbehandlung $\left(0,12 \% \mathrm{Li}_{2} \mathrm{CO}_{3}\right)$. a) Statistisch signifikanter Unterschied der MSAP und NLG zwischen transgenen und Wildtyp-Ratten. Nach Behandlung mit $0,12 \% \mathrm{Li}_{2} \mathrm{C}_{3}$ ließ sich eine Verbesserung der NLG im Vergleich zu unbehandelten transgenen Ratten erzielen. In Wildtyp-Ratten veränderte die Lithiumbehandlung weder MSAP noch NLG. b) statistisch signifikanter Unterschied der sensiblen NLG und Summennervenaktionspotentiale (SNAP) zwischen unbehandelten transgenen und Wildtyp-Ratten. Kein signifikanter Unterschied durch Lithiumbehandlung sowohl in transgenen als auch in Wildtyp-Ratten. Wildtyp-Kontrolle und Wildtyp-Lithium je $n=12$, Transgen-Kontrolle und Transgen-Lithium je $n=15$. Oneway-ANOVA mit Tukey post-hoc-Test $(* \mathrm{p}<0,05$, **** $\mathrm{p}<0,0001)$. 


\subsubsection{Histologische Untersuchung von Tibialisnerven Pmp22-transgener Ratten}

Bei der CMT1 kommt es im Verlauf der Erkrankung zu einer Demyelinisierung und zu einem axonalen Verlust (Sereda et al. 1996; Meyer zu Horste et al. 2007). Daher wurden die nach Studienende entnommenen Tibialisnerven histologisch analysiert. Dazu wurden Tibialisnerven unter 100x Vergrößerung lichtmikroskopisch vollständig abfotografiert, mittels der Zeiss Mikroskopiesoftware zu einem vollständigen Bild des Nervens zusammengefügt und die Gesamtanzahl myelinisierter Axone quantifiziert. Hier zeigte sich nach Abschluss der Behandlung ein statistisch signifikanter Verlust myelinisierter Axone der transgenen Tiere im Vergleich mit Wildtyp-Tieren.

a

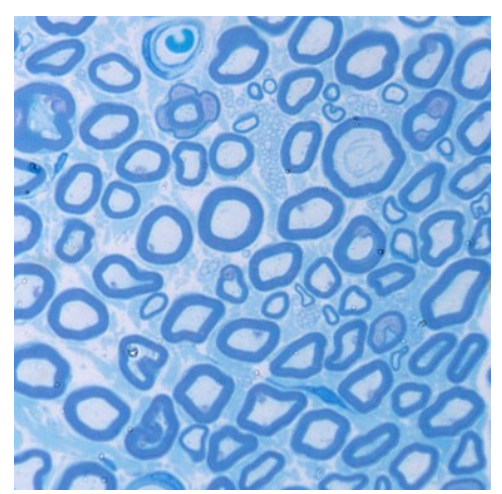

C

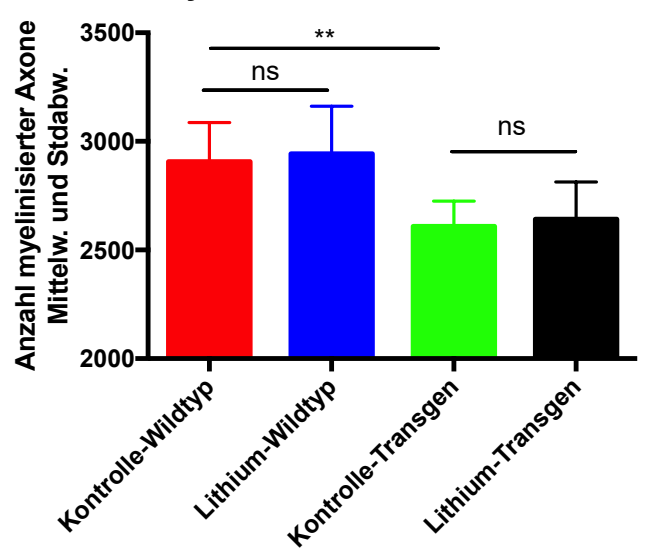

b

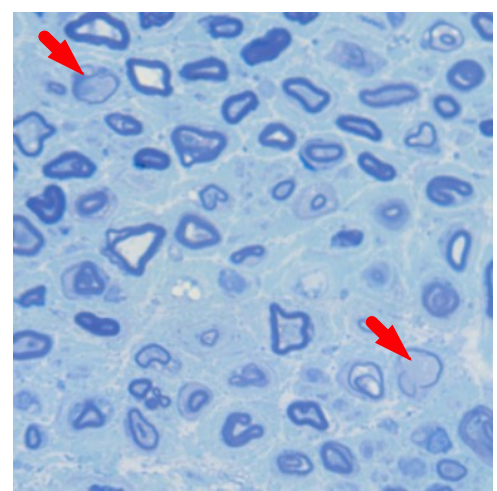

d

demyelinisierte Axone Tibialisnerv

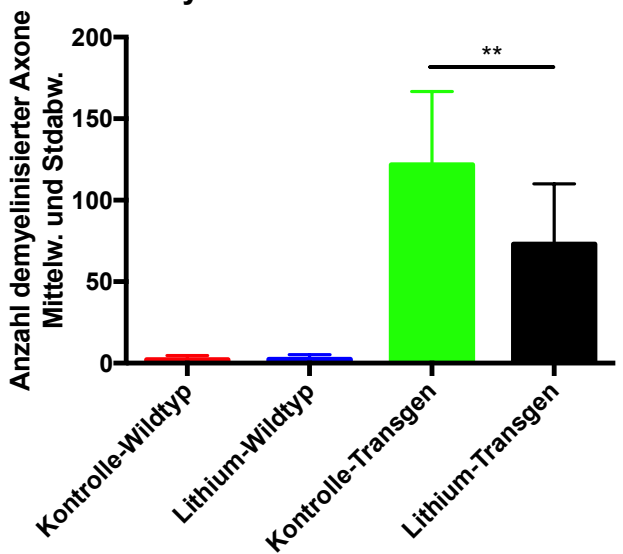

Abbildung 14: Histologische Analyse der Anzahl myelinisierter und demyelinisierter Axone in Tibialisnerven von Pmp22-transgenen Ratten nach Lithiumbehandlung. Repräsentative, lichtmikroskopische Aufnahmen von Tibialisnerven der Wildtyp-Ratte (a) und Pmp22-transgenen Ratte (b) 100x Vergrößerung. Hypomyelinisierung und axonaler Verlust als Zeichen der Neuropathie. Rote Pfeile zeigen Beispiele demyelinisierter Axone c) transgene Ratten zeigten einen statistisch signifikanten Verlust myelinisierter Axone im Vergleich zu Wildtyp-Ratten. Ein statistisch signifikanter Unterschied der Anzahl myelinisierter Axone zwischen den Gruppen mit Lithiumbehandlung und den Kontrollgruppen zeigte sich nicht. d) Nach Lithiumbehandlung zeigte sich eine verminderte Anzahl demyelinisierter Axone in Tibialisnerven von transgenen Ratten. WildtypRatten $n=12$ je Gruppe, transgene Ratten $n=10$ je Gruppe. One-way-ANOVA mit Tukey post-hoc-Test $(* * \mathrm{p}<0,01)$. 
In beiden Gruppen zeigte sich jedoch tendenziell eine erhöhte Anzahl myelinisierter Axone (Abbildung 14). In der gleichen Untersuchung wurden ebenfalls demyelinisierte Axone gezählt. Während sich in den Wildtyp-Gruppen erwartungsgemäß nahezu keine demyelinisierten Axone nachweisen ließen, zeigten Lithium-behandelte transgene Tiere jedoch eine verminderte Anzahl demyelinisierter Axone im Vergleich zu den unbehandelten transgenen Ratten ( $p=0,0026$, Abbildung 14d). Neben der Quantifizierung myelinisierter Axone in lichtmikroskopischen Aufnahmen erfolgten außerdem Messungen der relativen Myelindicke auf elektronenmikroskopischen Aufnahmen von Tibialisnerven mit einer Vergrößerung von 3000x. Hierzu wurden bei jeweils 100 - 200 Nervenfasern pro Tier der Quotient aus dem Umfang von Axon und Myelin bestimmt (g-ratio).

a

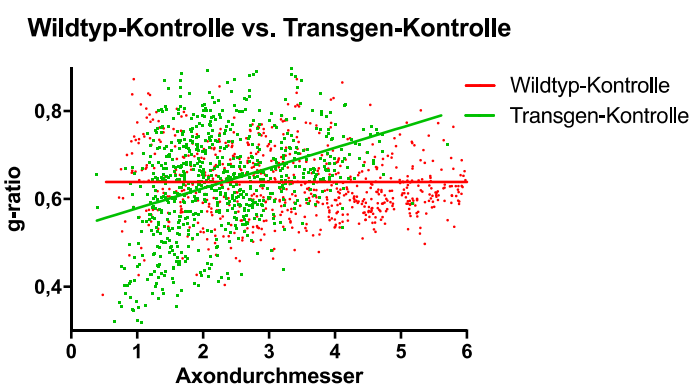

C

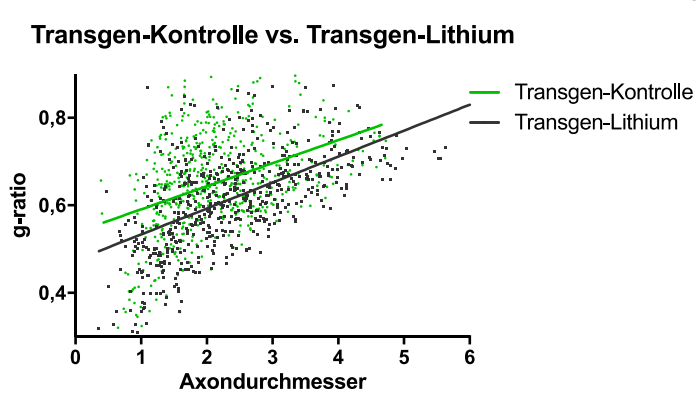

b

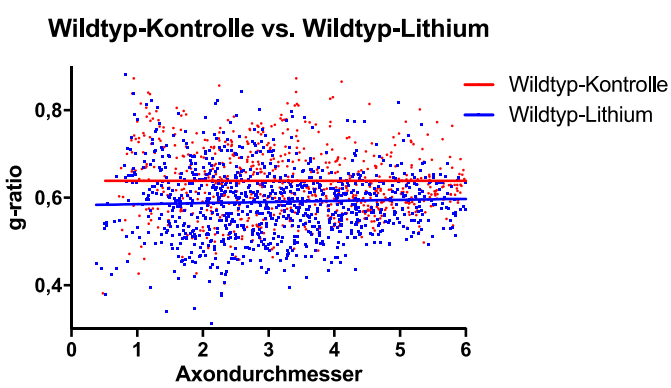

d

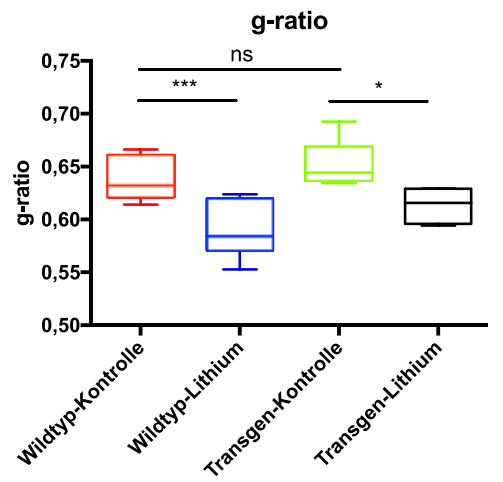

Abbildung 15: Histologische Analyse der relativen Myelindicke (g-ratio) in Tibialisnerven von Pmp22transgenen Ratten nach Lithiumbehandlung. Die Auswertung erfolgte an elektronenmikroskopischen Bildern in 3000x Vergrößerung. a-c) Auftragung der Myelindicke (g-ratio) auf den Axondurchmesser. a) Die Wildtyp-Kontrollgruppe (rot) zeigte eine physiologische Verteilung der Myelinschichtdicke. In der Gruppe der transgenen Kontrollen (grün) zeigte sich eine Hypomyelinisierung von großen und eine Hypermyelinisierung kleiner Axone. b) Lithium-behandelte Wildtyp-Ratten (blau) zeigten im Vergleich zur Kontrollgruppe (rot) eine Zunahme der Myelinschichtdicke. Zu einer Veränderung der Verteilung der Myelinschichtdicke kam es nicht. c) Lithium-behandelte transgene Ratten (schwarz) zeigten eine Zunahme der Myelinschichtdicke bei weiterhin unphysiologischer Hypomyelinisierung von großen und Hypermyelinisierung von kleinen Axonen. d) Mittelwerte der g-ratios aus a-c. Statistisch, signifikanter Unterschied des mittleren g-ratios nach Lithiumbehandlung sowohl in der Wildtyp- wie auch in der transgenen Gruppe. Kein Unterschied des mittleren g-ratios zwischen Wildtyp- und transgenen Kontrollratten. $\mathrm{n}=5-9$ je Gruppe, mind. 100 Axone pro Tier. Boxplot mit Median, Quartil, Min./Max.. One-way-ANOVA mit Tukey post-hoc-Test $\left(* \mathrm{p}<0,05,{ }^{* * *} \mathrm{p}<0,001\right)$. 
Hier zeigte sich in den Pmp22-transgenen Ratten insbesondere die von Meyer zu Horste et al. (2007) bekannte unphysiologische Hypermyelinisierung kleinerer Axone und Hypomyelinisierung größerer Axone im Vergleich zu Wildtyp-Kontrollen (Abbildung 15a). Ein statistisch signifikanter Unterschied in der gemittelten g-ratio zwischen transgenen- und WildtypKontrollen zeigte sich nicht (Abbildung 15d). Insgesamt zeigte jedoch die Gruppe der Lithium-behandelten Tiere, sowohl in dem Studienarm mit Wildtyp-Tieren als auch bei transgenen Tieren unabhängig von der Axongröße eine Zunahme der Myelindicke (Abbildung 15). Eine Änderung der unphysiologischen Verteilung der Myelindicke mit Hypermyelinisierung kleinerer Axone und Hypomyelinisierung größerer in Pmp22-transgenen Ratten ließ sich durch eine Behandlung mit Lithium nicht erzielen (Abbildung 15c).

\subsubsection{Genexpressionsanalysen aus RNA-Isolaten von Ischiasnerven Pmp22- transgener Ratten}

Aus entnommenen und bei $-80{ }^{\circ} \mathrm{C}$ gelagerten Ischiasnerven wurde RNA isoliert. Nach reverser Transkription wurden durch qRT-PCR mittels SYBR ${ }^{\circledR}$ Green Genexpressionsanalysen durchgeführt. Bestimmt wurden die relativen Expressionen von Connexin 43 (Cx43), der Myelinproteine Peripheres Myelinprotein 22 (Pmp22), Myelinprotein 0 (Mp₹), und Basisches Myelinprotein $(M b p)$. Außerdem wurden die relative Expression der Transkriptionsfaktoren Oct6/Pou3f1 und Krox20/Egr2, des Regulatorproteins der Cholesterinbiosynthese Scap, der HMG-CoA-Reduktase (Hmgcr), des Neurotrophins Bdnf und des Myelin-Stabilisierungsproteins Periaxin (Prx) durchgeführt. Die Werte wurden jeweils auf die konstant exprimierten Gene ornithine decarboxylase antisyme 1 (Oaz1), 605 acidic ribosomalprotein $\mathrm{PO}(\mathrm{R} p h 0)$ und Cyclophilin standardisiert und auf die Wildtyp-Kontrollgruppe normalisiert. Sobue et al. (1998) haben gezeigt, dass Bdnf nach Nervenverletzungen und bei peripheren Neuropathien differentiell reguliert ist. In den transgenen Tieren zeigte sich eine statistisch signifikante Erniedrigung der Bdnf-mRNA-Level. Durch die Behandlung mit Lithium ließen sich die mRNALevel in den transgenen Tieren auf Wildtyp-Level bringen (Abbildung 16h). Krox20/Egr ist ein für die Myelinisierung essentieller Transkriptionsfaktor. Er ist zusammen mit anderen Transkriptionsfaktoren für den Übergang von der pro-myelinisierenden Schwannzelle zur myelinisierenden Schwannzelle zuständig. Mutationen im Krox20/Egr2-Gen führen aufgrund der Differenzierungsstörung der Schwannzellen zu hereditären Myelinopathien (CMT1D) (Topilko et al. 1994; Warner et al. 1998). In den Pmp22-transgenen Tieren zeigte sich Krox20/Egr2 signifikant erniedrigt. Eine Behandlung mit Lithium führte zu einer Erhöhung der Krox20/Egr2-mRNA-Level in transgenen Tieren, welche jedoch statistisch nicht signifikant war (Abbildung 16i). Periaxin ist ein Myelinprotein und für die Aufrechterhaltung der Myelinscheide notwendig (Dytrych et al. 1998). Mutationen im Prx-Gen führen zu einer peripheren Neuropathie (Boerkoel et al. 2001). In den transgenen Ratten zeigte sich eine signifikante Verringerung der Prx-mRNA-Level. Die Behandlung mit Lithium hatte keinen Einfluss auf die Prx-Expression (Abbildung 16f). Oct6/Pou3f1 ist ein Transkripitionsfaktor 
der gemeinsam mit Krox20/Egr2 für den Übergang von der nicht myelinisierenden Schwannzelle zur myelinisierenden Schwannzelle notwendig ist (Jaegle et al. 1996). Eine veränderte Expression von Oct6/Pou3f1 ist damit Ausdruck einer Differenzierungsstörung der Schwannzellen. In den transgenen Ratten war die Expression von Oct6/Pou3f1 deutlich erhöht. Ein Unterschied durch die Therapie mit Lithium ließ sich nicht erzielen (Abbildung 16g). Aus Sereda et al. (2003) ist eine etwa 1,6-fache Pmp22-Überexpression in heterozygoten Pmp22-transgenen Ratten bekannt. Dies ließ sich in unserem Tierkollektiv ebenso darstellen. Eine signifikante Änderung der Pmp22-Expression ließ sich durch die Behandlung mit Lithium jedoch nicht erreichen (Abbildung 16e). Cholesterin ist mit ca. $25 \%$ das häufigste Lipid in der Myelinscheide. Die HMG-CoA-Reduktase ist der geschwindigkeitsbestimmende Schritt in der Cholesterinbiosynthese. In den transgenen Tieren war die mRNA-Expression der Hmgor signifikant reduziert. Die Behandlung mit Lithium hat in dieser Gruppe keinen Einfluss auf die Expression der Hmgcr (Abbildung 16a). Sterol regulatory element-binding protein cleavage-activating protein (Scap) bindet an sterol regulatory element binding-Proteine (Srebp) und ermöglicht so die Translokation in den Golgi-Apparat. Dort wird der Srebp-Komplex durch proteolytische Kaskaden gespalten. Das N-terminale Fragment kann anschließend in den Kern gelangen und aktiviert dort Lipidsynthese und Cholesterolmetabolismus. Während der Myelinisierung ist die mRNA-Expression von Scap stark hochreguliert (Leblanc et al. 2005). Mäuse mit einem Schwannzell-spezifischen Scap-Knock-Out zeigen eine kongenitale Hypomyelinisierung (Verheijen et al. 2009). Pmp22-transgene Ratten zeigten im Vergleich zu Wildtyp-Tieren eine verminderte Scap-Expression als Ausdruck der Myelinisierungsstörung. Nach Lithiumtherapie zeigte sich ein Anstieg der Scap-Expression, der jedoch statistisch nicht signifikant war (Abbildung 16b). Während das Myelinprotein 0 (Mpz) im zentralen Nervensystem nicht exprimiert wird, bildet es im peripheren Nervensystem eines der wichtigsten Strukturproteine. Es ist ein Glykoprotein und wird durch das $M_{p} z_{-}-\mathrm{Gen}$ codiert (Lemke et al. 1988). Mpz und Pmp22 interagieren miteinander und formen gemeinsam Komplexe in der Myelin-Membran (D’Urso et al. 1999; Sereda 1999). Sereda (1999) mutmaßte, dass es durch die Pmp22-Uberexpression zu einem gestörten Verhältnis von Pmp22 und Mpz kommt. In Proteinextrakten von Pmp22-transgenen Ratten sind im Alter von 30 Tagen und 2,5 Monaten die Proteinlevel von Mpz signifikant verringert (Sereda 1999). Außerdem zeigt sich eine Erniedrigung der $M p z-m R N A-E x p r e s s i o n$ (Sociali et al. 2016). Normalisiert auf die Expression der Wildtyp-Ratten ohne Behandlung zeigten die transgenen Tiere eine statistisch signifikante Verringerung der $M_{p} z$-Expression von etwa 0,29. Die mit Lithium behandelten Tiere zeigten eine erhöhte Expression von 0,47. Der Unterschied war statistisch signifikant (Abbildung 16c). Basische Myelinproteine (Mbp) machen etwa 15-20\% der Proteine des peripheren Nervensystems aus. Sie sind eine Gruppe von Proteinen, die durch unterschiedliches Splicing und posttranslationale Modifikation aus demselben Transkript entstehen. Mbp interagieren im Myelin mit Lipiden und stabilisieren die Struktur des Myelins (Deber und Reynolds 1991). Die Expression von Mbp war als Ausdruck einer Myelinisierungsstörung in den beiden transgenen Tiergruppen ebenfalls deutlich erniedrigt. Eine Behandlung 
mit Lithium konnte keinen statistisch signifikanten Unterschied verursachen. $C \times 43$ ist ein target gene des Wnt/B-Catenin-Signalwegs. Bei einer Lithium-bedingten Aktivierung des Wnt/B-Catenin-Signalwegs ist ein Anstieg der Cx43-Expression zu erwarten. Im vorliegenden Fall zeigte sich zwar ein leichter Anstieg um 39,5\%. Anders als in vitro (vgl. Abbildung 8a), war der Unterschied hier jedoch statistisch nicht signifikant (Abbildung 16j).

a

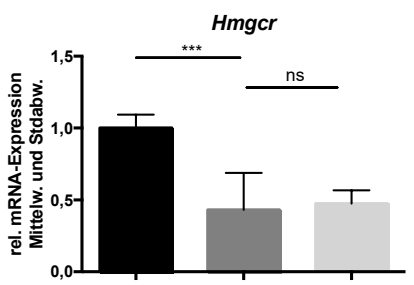

d

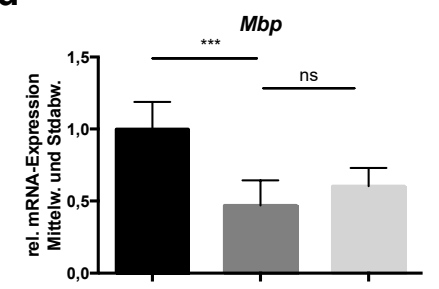

g

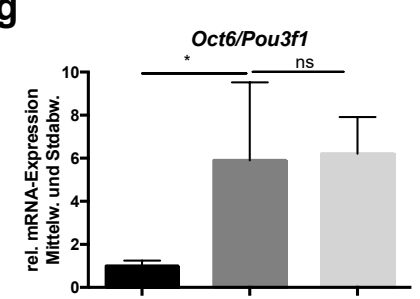

j

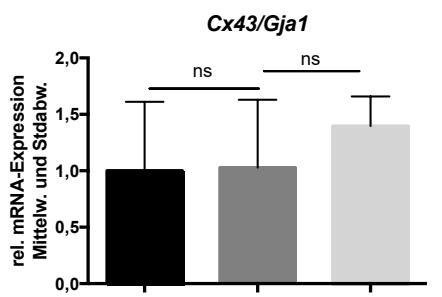

b

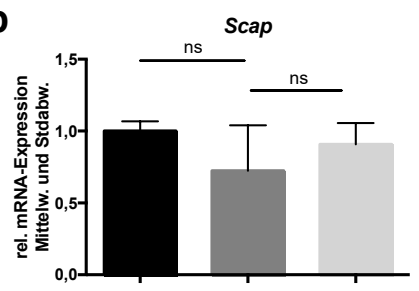

e

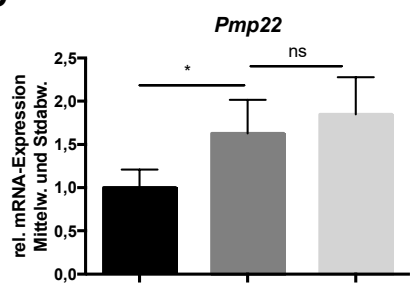

h

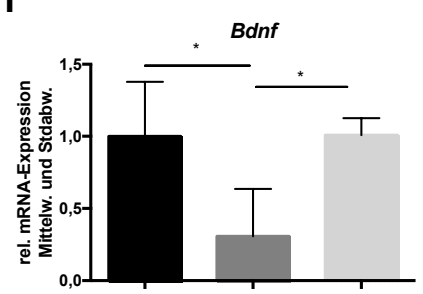

C

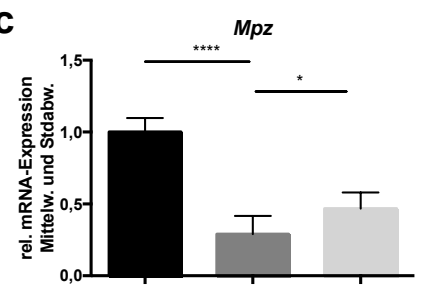

f

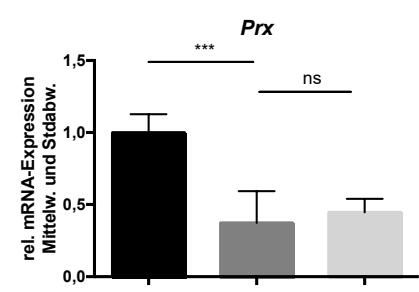

i

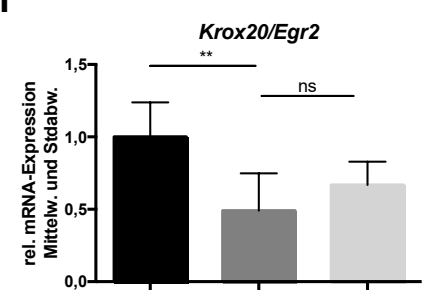

Abbildung 16: Genexpressionsanalysen aus Ischiasnerven von Pmp22-transgenen Ratten nach Lithiumbehandlung. Relative mRNA-Expression normalisiert auf unbehandelte Wildtyp-Ratten. Standardisiert auf die konstant exprimierten Gene Rplp0, Oaz1 und Cyclophylin. Vergleich von unbehandelten Wildtyp-Kontrollen mit Pmp22-transgenen Ratten mit und ohne Lithiumbehandlung. $n=5$ je Gruppe. One-way-ANOVA mit Tukey post-hoc-Test $\left(* \mathrm{p}<0,05,{ }^{* *} \mathrm{p}<0,01,{ }^{* * *} \mathrm{p}<0,001,{ }^{* * * *} \mathrm{p}<0,0001\right)$.

\subsubsection{Proteinanalyse aus Proteinlysaten von Ischiasnerven Pmp22-transgener Ratten}

Wie in Abschnitt 3.1.3 beschrieben, sind die PI3K/AKT- und MAPK/ERK-Signalwege essentiell für die Myelinisierung und können durch Lithium beeinflusst werden. Analog zu Abschnitt 3.1.3 wurden nach Lithiumbehandlung von Pmp22-transgenen Ratten Western-BlotAnalysen auf AKT und phosphoryliertes AKT sowie die $42 \mathrm{kDa}$ und $44 \mathrm{kDa}$ Isoformen 
ERK/phospho-ERK durchgeführt. Zu einer statistisch relevanten Aktivierung dieser Signalwege kam es in der Gruppe der Pmp22-transgenen Tiere nach Lithiumbehandlung nicht (Abbildung 17).

a

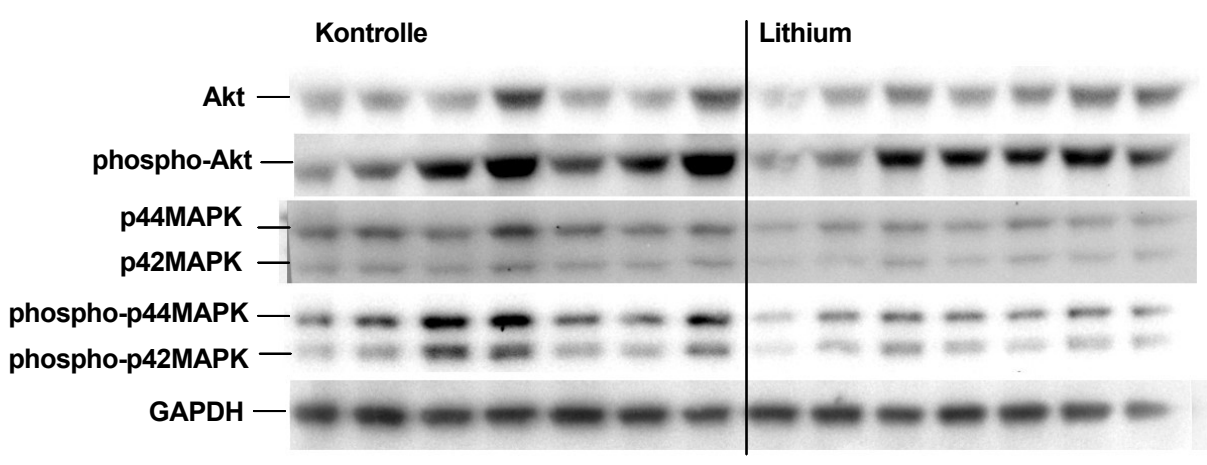

b
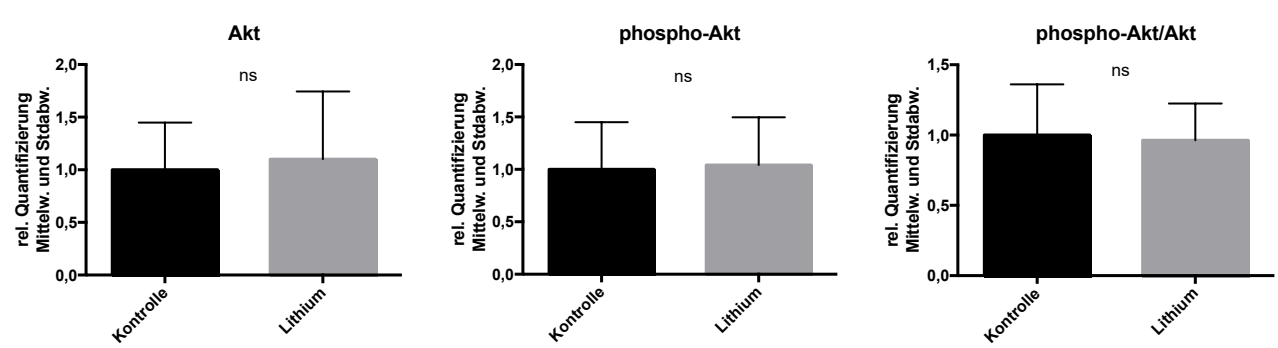

C
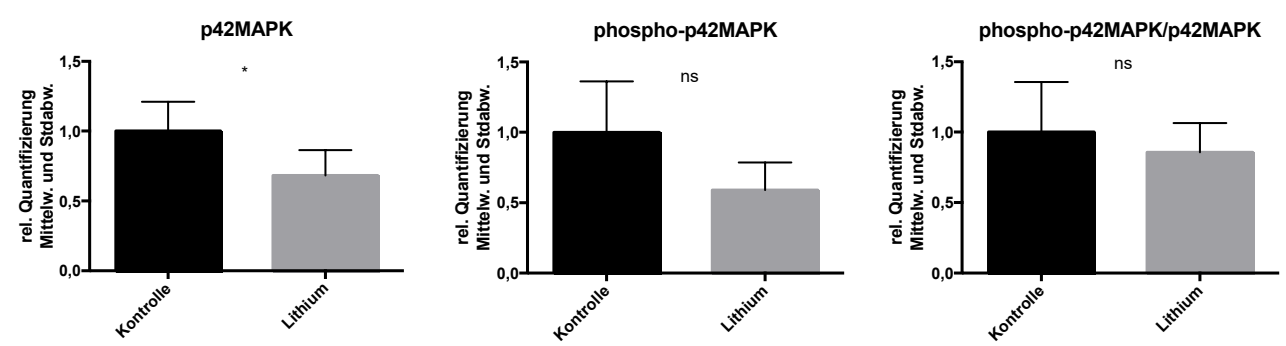

d
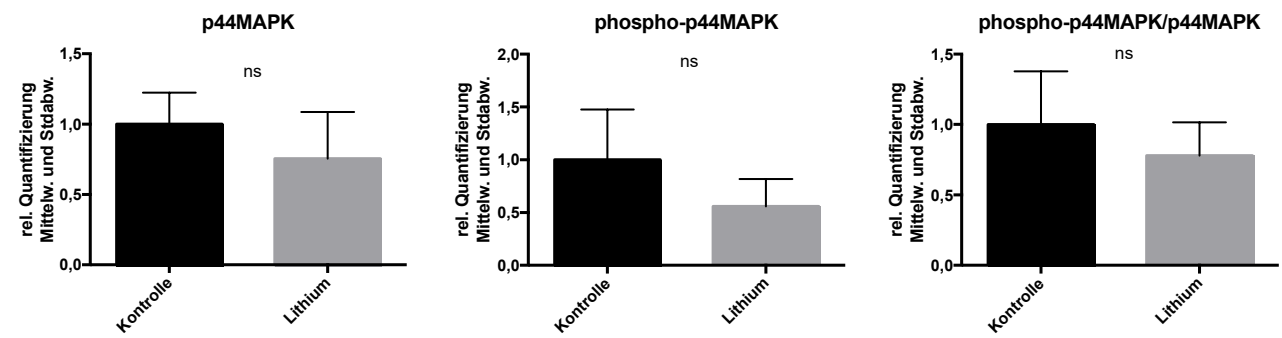

Abbildung 17: Proteinanalyse aus Ischiasnerven von Pmp22-transgenen Ratten nach Lithiumbehandlung. a) Repräsentative Western Blots mit Proteinlysaten aus Ischiasnerven Pmp22-transgener Ratten mit Lithiumbehandlung und ohne Lithiumbehandlung (Kontrolle). b-d) Semiquantitative Auswertung der Western Blots, standardisiert auf GAPDH als Ladekontrolle. In transgenen Ratten zeigte sich keine statistisch signifikante Aktivierung des PI3K- oder MAPK-Signalwegs. $\mathrm{n}=7$ je Gruppe. Mann-Whitney-U-Test $\left({ }^{*} \mathrm{p}<0,05\right)$. 


\section{Diskussion}

\subsection{Einfluss von Lithium auf die Myelinisierung in Wildtyp-Ratten}

In Ratten findet die Myelinisierung im peripheren Nervensystem früh postnatal statt und ist mit 21 Tagen weitgehend abgeschlossen (Garbay et al. 2000). Zur Untersuchung des Einflusses von Lithium auf die Myelinisierung von Wildtyp-Ratten wurden drei verschiedene Alterszeitpunkte analysiert. Dabei wurde mit p0-p6 ein früher Zeitpunkt während der Myelinisierung sowie mit p0 - p21 ein Zeitraum gewählt, der die wesentliche Myelinisierung umspannt. Der Zeitraum p30 - p117 umfasst ein Alter mit abgeschlossener Myelinisierung. Aus praktischen Gründen wurde in dieser Gruppe die orale Applikation von Lithium gewählt. Wird für adulte Ratten eine tägliche Futtermenge von 100 bis $140 \mathrm{~g} / \mathrm{kg} / \mathrm{KG}$ angenommen (Kennedy und Mitra 1963; Laaksonen et al. 2013) entspricht dies bei 0,12\% $\mathrm{Li}_{2} \mathrm{CO}_{3}$ im Futter einer Lithiumaufnahme von ca. 120 bis 170 mg/kg/KG. Nach Abschluss der Studie wurde eine Serumkonzentration von $0,33 \mathrm{mmol} / 1$ in der Gruppe mit $0,12 \% \mathrm{Li}_{2} \mathrm{CO}_{3} \mathrm{im}$ Futter erreicht, in der Gruppe mit $0,24 \% \mathrm{Li}_{2} \mathrm{CO}_{3}$ eine Serumkonzentration von $1,57 \mathrm{mmol} / 1$ (Tag 47). In der Literatur wird eine Plasma-Lithiumkonzentration von $0,2 \mathrm{bis} 0,3 \mathrm{mmol} / \mathrm{l}$ als neuroprotektiv und neurotroph angenommen (Ledoux 2003). Die therapeutische Breite von Lithium ist sehr gering. In der Gruppe mit $0,24 \% \mathrm{Li}_{2} \mathrm{CO}_{3}$ ist von einer Akkumulation des Lithiums und einer chronischen Intoxikation als Ursache für den Gewichtsverlust und die Verschlechterung des Allgemeinzustandes auszugehen.

Oral verabreichtes Lithium wird in die Muttermilch sezerniert (Oruch et al. 2014). Eine Behandlung junger, noch gesäugter Ratten via Muttermilch nach oraler Lithiumapplikation an die säugenden Muttertiere ist so grundsätzlich möglich. Viguera et al. (2007) zeigten beim Menschen, dass in der Muttermilch stillender Mütter eine Lithiumkonzentration zwischen 16,7 und 73,3\% (Mittelwert 52,2\%) der Blut-Serumkonzentration erreicht wird. In den gestillten Kindern war eine Lithium-Serumkonzentration zwischen 4,9 und 56,1 \% (Mittelwert 23,2\%) der mütterlichen Lithiumkonzentration nachweisbar. Um eine Lithium-Serumkonzentration von ca. $0,3 \mathrm{mmol} / 1 \mathrm{zu}$ erreichen, wäre daher ein Lithiumspiegel von etwa $1,5 \mathrm{mmol} / 1$ in den Muttertieren notwendig. Diese liegen in einem potentiell toxischen Bereich. Die in der Muttermilch sowie in gestillten Kindern nachgewiesenen Lithiumspiegel waren sehr variabel. Es ist anzunehmen, dass diese Ergebnisse aus dem Menschen auf Nager übertragbar sind. Die tatsächlich erreichbare Dosis in den Gruppen p0 - p6 und p0 - p21 wäre daher nach oraler Lithiumgabe sehr unsicher. Daher wurde sich in den Gruppen p0 - p6 und p0 - p21 zu einer intraperitonealen Gabe von Lithium entschieden. Makoukji et al. (2012) konnten nach intraperitonealer Gabe von Lithiumchlorid $50 \mathrm{mg} / \mathrm{kg} / \mathrm{KG}$ (entsprechend $1,17 \mathrm{mmol} / \mathrm{kg} / \mathrm{KG}$ ) eine schnellere klinische und histologische Regeneration nach Verletzung des Facialisnerven sowie eine Induktion der Expression von $M p z$ und Pmp22 zeigen. Daher wurde eine Dosis von $1 \mathrm{mmol} / \mathrm{kg} / \mathrm{KG} / \mathrm{d}$ i. p. gewählt. Leider war in 
dieser Gruppe die Bestimmung der Lithium-Serumkonzentration aufgrund der geringen Blutmenge bei den erst 6 bzw. 21 Tage alten Tiere technisch nicht möglich.

Histologisch kam es nach einer Behandlung von adulten Wildtyp-Ratten zu einer statistisch signifikanten Zunahme der Myelinschichtdicke gegenüber unbehandelten Kontrolltieren. Eine Auflockerung des Myelins oder eine Verdickung der einzelnen Myelinschichten als Hinweis auf eine Veränderung der Myelinkompaktierung konnte durch eine Messung der Einzelschichtdicke auf elektronenmikroskopischen Aufnahmen ausgeschlossen werden. In der Literatur ist ebenfalls eine Zunahme der Myelinschichtdicke (Verringerung der g-ratio) in Lithium-behandelten Tieren nach Verletzung des Ischias- und Facialisnerven (Makoukji et al. 2012) sowie nach traumatischem Ausriss und Re-Implantation der Vorderwurzel aus dem Rückenmark (Fu et al. 2014; Su et al. 2014; Fang et al. 2016) beschrieben. Interessanterweise zeigte sich in unseren Versuchstieren keine Veränderung der Myelindicke in jungen WildtypTieren, die im Verlauf der Myelinisierung mit Lithium behandelt wurden (Gruppen p0 - p6 und $\mathrm{p} 0-\mathrm{p} 21)$.

Während die älteren Ratten der Gruppe p30 - p117 mit Lithiumcarbonat behandelt wurden, erfolgte in den Gruppen p0 - p6 und p0 - p21 eine Applikation von Lithiumchlorid. Lithiumsalze dissoziieren jedoch in wässriger Lösung in $\mathrm{Li}^{+}$und $\mathrm{Cl}^{-}$bzw. $\mathrm{CO}_{3}{ }^{-} \mathrm{Li}^{+}$-Ionen, entsprechen in ihrer Permeabilität der von Natrium-Ionen und werden gut im Magen-DarmTrakt sowie im Peritoneum resorbiert. Lediglich die Dissoziationsgeschwindigkeit der verschiedenen Lithiumsalze unterscheidet sich (Oruch et al. 2014). Daher sollte die Art der verschiedenen Lithiumsalze (Lithiumchlorid, Lithiumcarbonat) keinen wesentlichen Einfluss auf die Wirkung haben.

Neureguline sind eine Gruppe von transmembranen oder sekretierten Proteinen, die über eine epidermal growth factor (EGF)-like-Domäne verfügen. Die transmembranen Neureguline werden von einer Metalloproteinase abgespalten und wirken als paracrines Signalmolekül oder bleiben im Fall von Nrg1 Typ III als juxtacrines Signalmolekül über eine zweite transmembrane Domäne an die Zelle gebunden. Die EGF-Domäne bindet an ErbB-Rezeptoren, die auf der Schwannzell-Oberfläche exprimiert werden (Nave und Salzer 2006). ErbB-Rezeptoren sind Rezeptortyrosinkinasen die eine Vielzahl von Downstream-Signalwegen wie z. B. Phospholipase C, MAPK und JNK aktivieren können (Ceresa und Vanlandingham 2008). Auf der Axonoberfläche präsentiertes neuronales Nrg1 Typ III scheint einer der entscheidenden Faktoren der Myelinisierung zu sein. Wird eine bestimmte Schwelle an axonal präsentiertem Nrg1 Typ III überschritten, so wird das Axon von einer Schwannzelle myelinisiert (Taveggia et al. 2005). Außerdem reguliert die Menge des axonal präsentierten Nrg1 Typ III die Dicke der Myelinscheide (Michailov et al. 2004). Während autonome unmyelinisierte Axone geringe Mengen Nrg1 Typ III exprimieren, exprimieren z. B. Bdnf-und Nt3abhängige, stark myelinisierte DRG-Neurone hohe Mengen Nrg1 Typ III. Wang et al. (2015) konnten zeigen, dass Bdnf in der Lage ist die Expression von Nrg1 Typ III-mRNA zu induzieren. Sowohl in der Wildtyp- als auch in der transgenen Gruppe der adulten Tiere, die nach 
Lithiumbehandlung eine dickere Myelinscheide aufwiesen, zeigte sich ebenfalls eine erhöhte $B d n f$-mRNA-Expression, während sich in den juvenilen Tieren keine Erhöhung der BdnfmRNA-Expression zeigte. Es ist daher möglich, dass die Zunahme der Myelindicke auf einer Bdnf-vermittelten Erhöhung des axonal präsentierten Nrg1 Typ III beruht. Hier wären weitere Untersuchungen zur immunhistochemischen oder molekularbiologischen Quantifizierung des Nrg1 Typ III sinnvoll.

Eine weitere denkbare Erklärung für die unterschiedliche Wirkung von Lithium in juvenilen Tieren während der Myelinisierung und adulten Tieren nach Abschluss der Myelinisierung liegt in der Applikationsform von Lithium. Möglicherweise wird in den adulten Tieren aufgrund der regelmäßigen Applikation von Lithium über die Nahrung ein gleichmäßig hoher Lithiumspiegel im Serum erreicht, während die einmal tägliche intraperitoneale Gabe eine geringere mittlere Serumkonzentration erzielt. Aufgrund der technisch zu geringen Blutmenge zur Lithiumbestimmung in den beiden Gruppen juveniler Tiere mit intraperitonealer Applikation von Lithium, bleibt die letztlich erzielte Serumkonzentration jedoch unklar. Auch die Zeitdauer der Behandlung kann in diesem Rahmen als möglicher Einflussfaktor gesehen werden. So reicht ggf. eine Behandlung von nur 6 bzw. 21 Tagen nicht aus, um einen signifikanten Einfluss auf die Myelinisierung zu erzielen. Dem steht gegenüber, dass Makoukji et al. (2012) in Mäusen bereits nach einer 4-tägigen intraperitonealen Behandlung mit $50 \mathrm{mg} / \mathrm{kg} / \mathrm{Tag}$ eine signifikante klinische und histologische Verbesserung nach nerve crush-Experimenten des Facialisnerven zeigen konnten.

Neben der Zunahme der Myelindicke in vivo konnte in der vorliegenden Arbeit in einer myelinisierenden Co-Kultur aus Schwannzellen und DRG-Neuronen eine Zunahme der myelinisierten Segmente nach Behandlung der Kulturen mit $1 \mathrm{mM}$ Lithiumcarbonat für 16 Tage gegenüber der unbehandelten Kontrollgruppe mit Standardmedium gezeigt werden. Nach Behandlung mit $5 \mathrm{mM}$ Lithium zeigten sich nahezu keine myelinisierten Segmente. Hier ist am ehesten von einer toxischen Wirkung des Lithiums auszugehen, da sich hier neben der fehlenden Myelinisierung ebenfalls eine starke Verminderung der kultivierten Neurone zeigte (nicht quantifiziert). Währenddessen ließ sich in den primären SchwannzellKulturen eine relevante Aktivierung der Myelingenexpression sowie eine Induktion der Expression von $C \times 43$ als Target des Wnt/B-Catenin-Signalwegs erst bei einer LithiumchloridDosis von $5 \mathrm{mM}$ nachweisen, wohingegen sich bei einer Behandlung der Kulturen mit $1 \mathrm{mM}$ Lithiumchlorid keine relevante Aktivierung von Myelingenen oder mit Myelinisierung assoziierter Gene fand. Um den Einfluss von Lithium auf die Myelinisierung in vitro zu untersuchen, wären zusätzliche Untersuchungen mit weiteren Dosierungen und veränderten Behandlungszeiträumen sinnvoll.

Es konnte in der Literatur gezeigt werden, dass intrazelluläre Signalkaskaden, wie z. B. der PI3K/AKT-Signalweg und MAPK/ERK-Signalweg eine wichtige Rolle in der Initiierung und Aufrechterhaltung der Myelinisierung spielen (Norrmén und Suter 2013). Lithium ist in der Lage die Aktivität dieses Signalwegs zu beeinflussen (Phiel und Klein 2001; Pasquali et 
al. 2010). Baraban (1994) wiederum beschrieb, dass es in vivo bei Säugetieren erst bei toxischen Lithiumdosierungen zu einer relevanten Beeinflussung des PI3K/AKT-Signalweg kommt. Zusätzlich wurde von den Autoren beschrieben, dass der Einfluss von Lithium auf den MAPK/ERK-Signalweg sich je nach Zelltyp unterscheidet und zeit- und dosisabhängig ist. Dies ist eine mögliche Erklärung dafür, dass sich in der vorliegenden Arbeit lediglich in der Gruppe p30-p117 eine statistisch signifikante Aktivierung des MAPK/ERKSignalwegs durch Lithium gezeigt hat.

In vivo zeigte sich in Wildtyp-Tieren bis auf eine mäßig erhöhte $M_{p} z$-Expression nach 21 Tagen Behandlung weder in der Gruppe p0 - p21 noch in der Gruppe p30 - p117 eine statistisch signifikante Regulation der Expression der Myelinproteine Pmp22, Mbp oder Prx, sowie der Hmgcr und von Scap. Im Gegensatz dazu wurde von Makoukji et al. (2012) eine dreifach erhöhte Expression von $M p$ r sowie eine sechsfach erhöhte Expression von Pmp22 in Ischiasnerven von acht Wochen alten Mäusen nach Lithiumgabe $(0,2 \% \mathrm{LiCl}$ im Trinkwasser für sieben Tage) gezeigt. In Facialisnerven konnte in derselben Publikation nach intraperitonealer Injektion von Lithiumchlorid (50 mg/kg/d über vier Tage) eine Verdopplung der Expression von Pmp22 und Mpz gezeigt werden. In beiden Gruppen war eine experimentelle Verletzung des Nervens vorangegangen. Es handelte sich hier um einen demyelinisierten und konsekutiv in Remyelinisierung begriffenen Nerven. Es kommt zunächst zu einer wallerischen Degeneration mit Fragmentierung der Axone und Kollaps der Myelinscheiden (Stoll und Müller 1999). Die Folge ist eine Dedifferenzierung der Schwannzellen und eine Aktivierung intrazellulärer Signalkaskaden (Jessen und Mirsky 2002). Dies führt wiederum zu einer Hochregulation der Expression von neurotrophischen Faktoren und Oberflächenproteinen, die ein erneutes Auswachsen der Axone fördern. Dazu gehören glial cell line-derived neurotrophic factor (GDNF), brain-derived neurotrophic factor (BDNF), Neurotrophin-3 (NT3), nerve growth factor (NGF), vascular endothelial growth factor (VEGF), Erythropoetin und weitere (Jessen und Mirsky 2016). Dies ermöglicht ein erneutes Auswachsen der Axone. Möglicherweise ist dieses durch Verletzung bedingte neurochemische Milieu zur Lithium-vermittelten Induktion von Myelingenen notwendig.

Oct6/Pou3f1 und Krox20/Egr2 sind Transkriptionsfaktoren, die für den Übergang von Schwannzell-Vorläuferzellen zu myelinisierenden Schwannzellen notwendig sind. Ihre Expression ist ein Marker für unreife bzw. pro-myelinisierende Schwannzellen (Jaegle et al. 1996; Svaren und Meijer 2008). Die Expression beider Transkriptionsfaktoren war in Wildtyp-Tieren durch die Behandlung mit Lithium nicht beeinflusst. Folglich scheint die Therapie mit Lithium in Wildtyp-Tieren keinen Einfluss auf die Reifung von Schwannzellen zu haben. In der vorliegenden Arbeit konnte in vivo im Gegensatz zu anderen Arbeiten (vgl. Meffre et al. 2015) keine wesentliche Induktion von Myelingenen durch Lithium in Wildtyp-Ratten gezeigt werden. Neben den oben beschriebenen Erklärungsansätzen kann es sich bei der Induktion der Myelingene auch um ein temporäres Ereignis handeln, dass mit den durchgeführten Experimenten nicht erfasst wurde. Konträr dazu zeigte sich in Kulturen primärer 
Schwannzellen dosisabhängig eine Induktion der Myelinproteine Pmp22 und Mpz: Außerdem stellte sich in vitro eine Induktion der Expression von Connexin 43 (Cx43) dar. Cx43 wird durch den Wnt/B-Catenin-Signalweg reguliert (Ai et al. 2000; Du et al. 2008). Lithium ist wiederum in der Lage den Wnt/B-Catenin-Signalweg zu aktivieren (Hedgepeth et al. 1997). Hieraus lässt sich schließen, dass die Wirkung von Lithium auf die Myelin-Genexpression zumindest teilweise auf der Aktivierung des Wnt/B-Catenin-Signalwegs beruht.

\subsection{Einfluss von Lithium auf den Phänotyp und die Myelinisierung in einem transgenen Rattenmodell der CMT1A}

Im Tiermodell hat es mehrere vielversprechende Ansätze zur Behandlung der CMT gegeben (Passage et al. 2004; Meyer zu Horste et al. 2007; Meyer zu Horste et al. 2011; Fledrich et al. 2014). Aufgrund positiver Ergebnisse aus dem Tierversuch wurden mehrere Studien mit Ascorbinsäure zur Behandlung der CMT1A beim Menschen durchgeführt. Ein 2015 publiziertes systematisches Review der Cochrane Library aller Studien mit Ascorbinsäure bei Menschen zeigte mit hoher Evidenz, dass Ascorbinsäure den Krankheitsverlauf der CMT1A nicht positiv beeinflusst. Nach wie vor ist keine wirkungsvolle Therapie für die CMT1A bei Menschen verfügbar.

Salze des Lithiums werden bereits seit 1850 medizinisch eingesetzt. Neben den bekannten Anwendungen bei bipolaren Affektstörungen, Manie, Depression und Cluster-Kopfschmerz (Phiel und Klein 2001) wurden in der Vergangenheit auch wiederholt neuroprotektive (Zhong et al. 2006) und antiapoptotische Effekte (Chuang 2005; Zhong et al. 2006) z. B. bei Alzheimer-Demenz (Noble et al. 2005; McBride et al. 2010) oder Morbus Parkinson (Youdim und Arraf 2004) beschrieben. Im Bereich des peripheren Nervensystems wurden vielversprechende Ergebnisse, z. B. nach Nervenverletzungen (Makoukji et al. 2012; Fang et al. 2016) oder Chemotherapie-induzierter Neuropathie (Alimoradi et al. 2012; Pourmohammadi et al. 2012) erzielt. Neben grundlagenwissenschaftlichen und tierexperimentellen Studien zur Wirkung von Lithium auf das Nervensystem gibt es mittlerweile auch erste klinische Ansätze zur Behandlung neurologischer Störungen mit Lithium. Eine PhaseIII-Studie zu den neurotrophischen Effekten von Lithiumcarbonat nach Schlaganfall (ClinicalTrials.gov Identifier: NCT01112813) wurde im Juli 2017 abgeschlossen. Eine erste Publikation aus dem Jahr 2019 zeigte nach 60-tägiger Lithiumbehandlung von Patienten nach Schlaganfall eine Korrelation zwischen einer höheren Lithiumdosis und MR-tomographisch einem erhöhten Volumen der grauen Substanz im Hirn sowie einer besseren verbalen Erinnerungsleistung (Sun et al. 2019). Eine longitudinale randomisierte doppelblinde Placebokontrollierte Phase-IV-Studie zum präventiven Effekt von Lithiumcarbonat auf kognitive Störungen im Alter wird aktuell durchgeführt (ClinicalTrials.gov Identifier: NCT03185208). Erste Ergebnisse werden für das Jahr 2022 erwartet. Neben der langen Erfahrung in der Behandlung von bipolaren Störungen konnte in der Vergangenheit gezeigt werden, dass die 
Behandlung mit Lithiumcarbonat trotz der geringen therapeutischen Breite nebenwirkungsarm und sicher ist (Delva und Hawken 2001; Macdonald et al. 2008).

Aufgrund der in der Literatur beschriebenen Effekte von Lithium sowie der Ergebnisse aus der Behandlung in Wildtyp-Tieren, wurde eine experimentelle Therapiestudie mit Lithiumcarbonat in Pmp22-transgenen Ratten durchgeführt. Pmp22-transgene Ratten sind ein anerkanntes Modell für die CMT1A (Sereda et al. 1996; Niemann et al. 1999; Fledrich et al. 2012a). Klinisch kommt es bei betroffenen Patienten wie auch bei den transgenen Ratten zu einer durch den sekundären axonalen Verlust bedingten neurogenen Muskelatrophie. Diese lässt sich im Rattenmodell gut anhand der Griffstärke von Vorder- und Hinterbeinen messen (Sereda et al. 2003; Meyer zu Horste et al. 2007). Im Verlauf des Behandlungszeitraumes von 16 Wochen kam es erwartungsgemäß zu einem statistisch signifikanten Verlust der Griffstärke in Vorder- und Hinterläufen in der Gruppe der transgenen Tiere im Vergleich mit der nicht betroffenen Kontrollgruppe. Die Therapie mit Lithium bewirkte in den transgenen Tieren eine Zunahme der Griffstärke, die jedoch bei einer großen Variabilität der Griffstärke der Vorderbeine, nur bei den Hinterläufen zum Abschluss der Studie statistisch signifikant war. Dies ist insbesondere unter dem Aspekt zu beachten, dass Lithium-behandelte Tiere gegenüber Tieren mit Standardfutter einen statistisch signifikanten Gewichtverlust von ca. $6 \%$ zeigten und damit mutmaßlich auch eine geringere Muskelmasse besaßen. Lithium-behandelte Wildtyp-Tiere zeigten keine Zunahme der Griffstärke gegenüber Tieren mit Standardfutter, so dass ein reiner anaboler Effekt von Lithium unwahrscheinlich ist.

Die verminderte NLG ist ein weiteres Merkmal der CMT1A (Birouk et al. 1997a). In der vorliegenden Untersuchung zeigten Pmp22-transgene Ratten analog zu menschlichen Patienten eine deutlich erniedrigte NLG. Nach Behandlung mit Lithium zeigten Pmp22-transgene Ratten eine signifikant erhöhte NLG gegenüber ihrer nicht behandelten Vergleichsgruppe. Die Muskelsummenaktionspotentiale in den Lithium-behandelten Gruppen waren leicht verringert. Dies ist im Zusammenhang mit dem Gewichtsverlust am ehesten als Zeichen einer geringeren Muskelmasse zu sehen. Passend zu der erhöhten NLG wiesen die behandelten Tiere eine signifikant geringere g-ratio als Ausdruck einer dickeren Myelinscheide auf. Dies entspricht den Ergebnissen aus der Behandlung der Wildtyp-Tiere. Die von Meyer zu Horste et al. (2007) beschriebene Hypermyelinisierung kleinkalibriger Axone und Hypomyelinisierung großer Axone Pmp22-transgener Ratten zeigte sich ebenfalls in den beiden transgenen Gruppen. Eine Beeinflussung der pathologischen Hyper- bzw. Hypomyelinisierung ließ sich durch die Behandlung mit Lithium nicht erzielen.

Histologisch zeigt sich in der CMT ein axonaler Verlust als Folge der Demyelinisierung. Meyer zu Horste et al. (2007) zeigten, dass es durch die therapeutische Gabe des Progesteronantagonisten Onapristone möglich ist, den axonalen Verlustes abzumildern, ohne die Myelinpathologie der CMT zu verändern. In der vorliegenden Arbeit zeigte sich im Unterschied zu Meyer zu Horste et al. (2007) nach Behandlung mit Lithium nun eine Verbesserung des Phänotyps, eine Zunahme der Myelindicke und eine verringerte Anzahl demyelinisierter 
Axone, ohne den axonalen Verlust der CMT statistisch signifikant aufhalten zu können. Im Gegensatz dazu finden sich in der Literatur Beispiele bei denen durch die Behandlung mit Lithium eine Zunahme der Anzahl myelinisierter Axone nach Nervenverletzung erzielt werden konnte (Makoukji et al. 2012; Fang et al. 2016).

Auf mRNA-Level zeigte sich in Pmp22-transgenen Ratten im Vergleich zu Wildtyp-Tieren eine statistisch signifikante Induktion der Expression des Transkriptionsfaktors Oct6/Pou3f1 sowie eine Runterregulation von Krox20/Egr2 und Prx. Gleichzeitig war die Expression myelinassoziierter Gene in den Pmp22-transgenen Tieren als Ausdruck einer Differenzierungs- und Myelinisierungsstörung der Schwannzellen deutlich erniedrigt. Durch eine Behandlung der transgenen Ratten mit Lithium kam es zu einer statistisch signifikanten Induktion von $M p z$ sowie einer statistisch nicht signifikanten Erhöhung der übrigen Myelinassoziierten Gene. Die Expression der Schwannzell-Differenzierungsmarker war nicht verändert. Es ist davon auszugehen, dass Lithium die Myelinbildung stimuliert, ohne einen signifikanten Einfluss auf den Schwannzell-Defekt zu nehmen (Jessen und Mirsky 2002; Fledrich et al. 2014).

Die transgenen Tiere zeigten eine Überexpression von Pmp22 von etwa 1,6 gegenüber der Wildtyp-Gruppe. Dies entspricht den Literaturangaben zu der Pmp22-transgenen Ratte (Sereda et al. 1996). Eine Veränderung der toxischen Pmp22-Überexpression durch Lithiumbehandlung konnte nicht erreicht werden.

Brain-derived neurotrophic factor (BDNF) ist ein endogener neurotropher Wachstumsfaktor. Strukturell ist er mit dem nerve growth factor (NGF) verwandt (Hohn et al. 1990). Er bindet mit hoher Affinität an den tropomyosin-related kinase receptor B (TrkB) (Barbacid 1995) sowie mit geringerer Affinität an den $p 75$ neurotrophin receptor (p75NTR) (Rodriguez-Tébar et al. 1990). P75NTR gehört zur Gruppe der Tumor-Nekrosefaktor-Rezeptoren. Er hat in etwa die gleiche Affinität zu allen Neurotrophinen (Terenghi 1999). P75NTR vermittelt unter anderem über nuclear factor $\varkappa B(\mathrm{NF}-\kappa \mathrm{B})$ das Überleben von Neuronen (Hamanoue et al. 1999) und ist in der Lage über die Jun-Kinase/c-Jun-Kaskade p53 und andere proapoptotische Gene (Reichardt 2006) zu aktivieren. Außerdem wurde gezeigt, dass p75NTR über die RhoGTPase RhoA ligandenabhängig das axonale Wachstum reguliert (Yamashita et al. 1999). Der TrkB bildet nach Aktivierung Dimere und initiiert die Autophosphorylierung intrazellulärer Tyrosinreste (Kaplan und Miller 2000). Phosphoryliertes TrkB ist wiederum in der Lage die Enzyme Phosphatidylinositol 3-Kinase (PI3K), mitogen-activated protein kinase (MAPK) und Phospholipase C (PLC) zu aktivieren. Hierüber wird eine Vielzahl von Prozessen, unter anderem synaptische Plastizität, Proteinbiosynthese, eine Steigerung des Dentritenwachstum sowie die Verzweigung von Axonen und vieles mehr beeinflusst (Kowiański et al. 2018). BDNF ist involviert in einer großen Anzahl neurophysiologischer Prozesse. Die bedeutendsten Funktionen von BDNF umfassen die Regulation von Neuro-, Glia- und Synaptogenese, Neuroprotektion, Entwicklungsprozesse des Nervensystems sowie die Beeinflussung von 
Lernen und Kognition (Foltran und Diaz 2016). In der Vergangenheit konnte gezeigt werden, dass BDNF neben den bekannten Aufgaben bei der neuronalen Plastizität und dem Überleben von Neuronen maßgebliche Funktionen in der Myelinisierung des peripheren Nervensystems hat. So ist exogen hinzugefügtes Bdnf in Co-Kulturen aus DRG-Neuronen und Schwannzellen in der Lage die Expression von Myelingenen zu induzieren. In vivo konnte gezeigt werden, dass subkutane Injektionen von Bdnf zu einer vermehrten Myelinisierung des Ischiasnerven führen, während eine Blockierung von Bdnf mittels eines Fusionsproteins aus der extrazellulären Domäne des TrkB-Rezeptors und Fc-Fraktion von IgG zu einer verminderten Myelinisierung führte (Chan et al. 2001). Bdnf-überexprimierende Mäuse zeigen eine Zunahme der Myelindicke, ohne dass es zu einer Erhöhung der Anzahl myelinisierter Axone kommt (Tolwani et al. 2004). Außerdem publizierten Funakoshi et al. (1993), dass Schwannzellen nach Nervenverletzung Bdnf produzieren. Cosgaya et al. (2002) konnten zeigen, dass die pro-myelinisierende Wirkung von Bdnf über den p75NT-Rezeptor vermittelt wird. In der vorliegenden Arbeit konnte gezeigt werden, dass Pmp22-transgene Ratten eine gegenüber Wildtyp-Ratten um ca. $70 \%$ reduzierte $B d n f$-Expression aufweisen. $\mathrm{Ob}$ es sich dabei um einen Teil des Pathomechanismus der CMT1A handelt, oder ob die verminderte $B d n f$-Expression ein sekundärer Effekt ist, der durch die Schwannzell-Dedifferenzierung hervorgerufen wird, sollte Ziel zukünftiger Untersuchungen sein. Lithium ist in der vorliegenden Arbeit in der Lage die erniedrigte Bdnf-Expression in Pmp22-transgenen Tieren annähernd auf Wildtyp-Niveau zu bringen. Ein ähnlicher Effekt wurde von Leyhe et al. (2009) bei Patienten mit einem Frühstadium der Alzheimer Erkrankung beschrieben. Betroffene Patienten zeigten einen erniedrigten BDNF-Spiegel im Serum. Nach Behandlung mit Lithium erhöhte sich der BDNF-Serumspiegel und der klinische Zustand besserte sich statistisch signifikant. In Ratten konnte eine Erhöhung des Bdnf-Spiegels im Gehirn nach oraler Lithiumgabe gezeigt werden (Fukumoto et al. 2001; Jornada et al. 2010; Wu et al. 2014). Die Erhöhung der Bdnf-mRNA-Expression wird epigenetisch über eine Verringerung der Methylierung des Bdnf-Promoters-IV reguliert (Dwivedi und Zhang 2014). Yasuda et al. (2009) beschrieben, dass die Aktivierung des Bdnf-Promoter-IV nach Behandlung mit Lithium über eine Inhibition der Glykogensynthasekinase 3 beta sowie nachfolgend die Histon-Deacetylase vermittelt wird.

Aus den vorliegenden Daten lässt sich schlussfolgern, dass die Lithium-vermittelte Induktion der Expression des Neurotrophins Bdnf ein möglicher Mechanismus der Zunahme der Myelindicke ist.

Insgesamt zeigte sich klinisch ein statistisch signifikanter Effekt von Lithiumcarbonat auf die Griffstärke sowie elektrophysiologisch auf die NLG. Molekularbiologisch ließ sich eine Induktion von Myelingenen sowie eine erhöhte Expression des Neurotrophins Bdnf nachweisen. Histologisch zeigte sich eine Zunahme der Myelindicke sowie eine verminderte Anzahl demyelinisierter Axone. Die Ausprägung der klinischen, elektrophysiologischen und histologischen Verbesserung ist allerdings nur gering. Für eine medikamentöse Therapie mit $\mathrm{Li}_{2} \mathrm{CO}_{3}$ 
in menschlichen Patienten mit CMT1A sind daher weitere Experimente mit anderen Behandlungszeiträumen und Dosierungen notwendig, um die Möglichkeit einer verbesserten Wirkung auf den Phänotyp der CMT1A zu untersuchen. Schlussendlich ist eine effektive Therapie der CMT1A nur möglich, wenn es gelingt den sekundären axonalen Verlust zu verringern. 


\section{$5 \quad$ Zusammenfassung}

Salze des Lithiums werden im klinischen Alltag zur Prophylaxe der bipolaren affektiven Störung sowie zur Behandlung von Major-Depressionen angewendet. Daneben gibt es vielfältige experimentelle Ansätze zur Behandlung von kognitiven Störungen und neurodegenerativen Erkrankungen mit Lithium. Die Anwendung von Lithium ist trotz der geringen therapeutischen Breite sicher und nebenwirkungsarm. In der Literatur werden zahlreiche neuroprotektive und neurotrophische Effekte von Lithium beschrieben. So ist Lithium in der Lage die Induktion von Myelingenen sowie dem Neurotrophin Bdnf zu induzieren, die Remyelinisierung nach Nervenverletzungen zu verbessern und Chemotherapie-induzierte Neuropathien abzumildern. In der vorliegenden Arbeit wurde nun in einem ersten Schritt der Einfluss von Lithium auf die Myelinisierung im peripheren Nervensystem von Wildtyp-Ratten untersucht. Hierzu wurden junge Wildtyp-Ratten von Geburt bis zum 6. bzw. 21. Lebenstag durch tägliche intraperitoneale Injektionen von Lithiumchlorid $50 \mathrm{mg} / \mathrm{kg} / \mathrm{KG}$ behandelt. Eine Gruppe adulter Ratten wurden vom 30. bis 117. Lebenstag durch orale Zufuhr von 0,12 \% Lithiumcarbonat im Futter behandelt. Im Anschluss erfolgte die histologische und molekularbiologische Analyse des peripheren Nervensystems. Während sich in jungen Tieren, innerhalb des Prozesses der Myelinisierung, kein Einfluss auf die Myelindicke durch Lithium zeigte, kam es in älteren Tieren, die erst nach Abschluss der physiologischen Myelinisierung mit Lithium behandelt wurden, zu einer Zunahme der relativen Myelindicke. In Kulturen primärer Schwannzellen von Wildtyp-Ratten ließ sich eine Induktion der Myelingenexpression von Pmp22 und Mpz sowie von $C \times 43$ als Marker für eine Aktivierung des Wnt/B-Catenin-Signalwegs nach 72-stündiger Behandlung mit Lithiumchlorid nachweisen. Der Wnt/B-Catenin-Signalweg ist entscheidend für die Regulation der embryologischen Entwicklung, Zellproliferation und Zelldifferenzierung. Co-Kulturen aus primären dorsalen Hinterwurzel-Neuronen (DRG-Neurone) und Schwannzellen von Wildtyp-Ratten zeigten nach Induktion der Myelinisierung und zeitgleicher Behandlung mit Lithium eine Zunahme der Anzahl myelinisierter Segmente.

Um in einem weiteren Schritt Lithium als Therapieansatz bei einer peripheren Neuropathie zu testen, führten wir eine Therapiestudie in einem transgenen Rattenmodell der CharcotMarie-Tooth-Erkrankung 1A (CMT1A) durch. Die CMT1A ist die häufigste genetisch bedingte periphere Neuropathie. In den meisten Fällen ist eine Duplikation des Gens für das periphere Myelinprotein 22 kDa (Pmp22) die Ursache der CMT1A. Hierdurch kommt es zu einer Demyelinisierung der Axone mit einem sekundären axonalen Schaden und führt in betroffenen Patienten zu einer progredienten, distal betonten Muskelatrophie. Die Pmp22transgene Ratte zeigt eine mäßige Überexpression von Pmp22 und spiegelt den Krankheitsverlauf im Menschen gut wider. Pmp22-transgene Ratten wurden ab dem Alter von vier Wochen für zwölf Wochen (bis zum Alter von 16 Wochen) mit 0,12 \% Lithiumcarbonat p. o. behandelt. Im Verlauf des Behandlungszeitraums erfolgten regelmäßige Untersuchungen der Muskelkraft sowie zum Abschluss der Behandlung die elektrophysiologische Untersuchung 
des peripheren Nervensystems. Nach Tötung der Tiere erfolgte die histologische und molekularbiologische Untersuchung des peripheren Nervensystems. Im Vergleich zur unbehandelten transgenen Kontrollgruppe zeigten die Tiere nach Lithiumbehandlung eine größere Kraft der Hinterbeine sowie elektrophysiologisch eine schnellere Nervenleitgeschwindigkeit in den Nerven des Schwanzes. Histologisch konnte eine Zunahme der Myelindicke bei unverändert pathologischer Hypermyelinisierung kleiner und Hypomyelinisierung großer Axone in Tibialisnerven festgestellt werden. Die Anzahl demyelinisierter Axone war in der behandelten transgenen Gruppe signifikant verringert, während sich kein Unterschied in der Gesamtanzahl der myelinisierenden Axone fand. Auf molekularbiologischer Ebene zeigten Lithium-behandelte Tiere eine Induktion der Expression des Myelingens $M p$ z sowie des Neurotrophins Bdnf in Ischiasnerven. Die Induktion der Bdnf-Expression ist ein möglicher Mechanismus für die Zunahme der Myelindicke sowie für die neuroprotektive Wirkung von Lithium.

Zusammenfassend lässt sich feststellen, dass die Behandlung mit Lithium zu einer Zunahme der Myelindicke in adulten Wildtyp-Ratten sowie zu einer Induktion von Myelingenen und des Neurotrophins Bdnf führte. In einer myelinisierenden Co-Kultur aus DRG-Neuronen und Schwannzellen führte Lithium zu einer Zunahme der myelinisierten Segmente. Außerdem zeigte sich ein positiver Einfluss von Lithium auf den Krankheitsverlauf in einem Rattenmodell der CMT1A. Für ein besseres Verständnis des Wirkungsmechanismus von Lithium auf das periphere Nervensystem sowie für die Evaluation von Lithium als mögliche medikamentöse Therapie peripherer Neuropathien beim Menschen sind jedoch noch weitere Untersuchungen notwendig. 


\section{$6 \quad$ Literaturverzeichnis}

Aghdam SY, Barger SW (2007): Glycogen synthase kinase-3 in neurodegeneration and neuroprotection: lessons from lithium. Curr Alzheimer Res 4 , 21-31

Ai Z, Fischer A, Spray DC, Brown AM, Fishman GI (2000): Wnt-1 regulation of connexin43 in cardiac myocytes. J Clin Invest $\underline{105}, 161-171$

Alimoradi H, Pourmohammadi N, Mehr SE, Hassanzadeh G, Hadian MR, Sharifzadeh M, Bakhtiarian A, Dehpour AR (2012): Effects of lithium on peripheral neuropathy induced by vincristine in rats. Acta Med Iran 50, 373-379

Anzini P, Neuberg DH, Schachner M, Nelles E, Willecke K, Zielasek J, Toyka KV, Suter U, Martini R (1997): Structural abnormalities and deficient maintenance of peripheral nerve myelin in mice lacking the gap junction protein connexin 32. J Neurosci 17, 4545-4551

Baechner D, Liehr T, Hameister H, Altenberger H, Grehl H, Suter U, Rautenstrauss B (1995): Widespread expression of the peripheral myelin protein-22 gene (PMP22) in neural and nonneural tissues during murine development. J Neurosci Res $\underline{42}, 733-741$

Baraban JM (1994): Toward a crystal-clear view of lithium's site of action. Proc Natl Acad Sci USA 91, 5738-5739

Barbacid M (1995): Neurotrophic factors and their receptors. Curr Opin Cell Biol 7, 148-155

Birouk N, Maisonobe T, Le Forestier N, Gouider R, Léger JM, Bouche P (1997a): Maladie de Charcot-Marie-Tooth : l'électromyogramme reste utile au diagnostic et à la classification. Rev Neu$\operatorname{rol} \underline{153}, 727-736$

Birouk N, Gouider R, Le Guern E, Gugenheim M, Tardieu S, Maisonobe T, Le Forestier N, Agid Y, Brice A, Bouche P (1997b): Charcot-Marie-Tooth disease type 1A with 17p11.2 duplication. Clinical and electrophysiological phenotype study and factors influencing disease severity in 119 cases. Brain $\underline{120}, 813-823$

Boerkoel CF, Takashima H, Stankiewicz P, Garcia CA, Leber SM, Rhee-Morris L, Lupski JR (2001): Periaxin mutations cause recessive Dejerine-Sottas neuropathy. Am J Hum Genet $\underline{68}$, $325-333$

Bunge RP, Bunge MB, Bates M (1989): Movements of the Schwann cell nucleus implicate progression of the inner (axon-related) Schwann cell process during myelination. J Cell Biol 109, 273284

Burns J, Ouvrier RA, Yiu EM, Joseph PD, Kornberg AJ, Fahey MC, Ryan MM (2009): Ascorbic acid for Charcot-Marie-Tooth disease type 1A in children: a randomised, double-blind, placebo-controlled, safety and efficacy trial. Lancet Neurol $\underline{8}, 537-544$

Ceresa BP, Vanlandingham PA (2008): Molecular Mechanisms that Regulate Epidermal Growth Factor Receptor Inactivation. Clin Med Oncol 2, 47-61

Chan CH, Leung AKH, Cheung YF, Chan PYC, Yeung KWA, Lai KY (2012): A rare neurological complication due to lithium poisoning. Hong Kong Med J 18, 343-345 
Chan JR, Cosgaya JM, Wu YJ, Shooter EM (2001): Neurotrophins are key mediators of the myelination program in the peripheral nervous system. Proc Natl Acad Sci USA 무, 14661-14668

Chuang D-M (2005): The antiapoptotic actions of mood stabilizers. Ann NY Acad Sci $\underline{1053}$, 195 204

Cosgaya JM, Chan JR, Shooter EM (2002): The neurotrophin receptor p75NTR as a positive modulator of myelination. Science $298,1245-1248$

De Sarno P, Axtell RC, Raman C, Roth KA, Alessi DR, Jope RS (2008): Lithium prevents and ameliorates experimental autoimmune encephalomyelitis. J Immunol 181, 338-345

Deber CM, Reynolds SJ (1991): Central nervous system myelin: structure, function, and pathology. Clin Biochem 24, 113-134

Delva NJ, Hawken ER (2001): Preventing lithium intoxication. Guide for physicians. Can Fam Physician $47,1595-1600$

Domenech-Estevez E, Baloui H, Meng X, Zhang Y, Deinhardt K, Dupree JL, Einheber S, Chrast R, Salzer JL (2016): Akt Regulates Axon Wrapping and Myelin Sheath Thickness in the PNS. J Neurosci $\underline{36}$, 4506-4521

Du W, Li J, Du W, Li J, Wang Q, Hou J, Yu B (2008): Lithium Chloride Regulates Connexin43 in Skeletal Myoblasts In Vitro: Possible Involvement in Wnt/ $\beta$-Catenin Signaling. Cell Commun Adhes $\underline{15}, 261-271$

D’Urso D, Ehrhardt P, Müller HW (1999): Peripheral myelin protein 22 and protein zero: a novel association in peripheral nervous system myelin. J Neurosci $\underline{19}$, 3396-3403

Dwivedi T, Zhang H (2014): Lithium-induced neuroprotection is associated with epigenetic modification of specific BDNF gene promoter and altered expression of apoptotic-regulatory proteins. Front Neurosci $\underline{8}, 457$

Dyck PJ, Chance P, Lebo R, Carney JA: Hereditary Motor and Sensory Neuropathy. In: Dyck PJ, Thomas PK, Griffin JW, Low PA, Poduslo JF (Hrsg.): Peripheral Neuropathy. 3rd edition; Saunders, London 1993, 1094-1136

Dytrych L, Sherman DL, Gillespie CS, Brophy PJ (1998): Two PDZ domain proteins encoded by the murine periaxin gene are the result of alternative intron retention and are differentially targeted in Schwann cells. J Biol Chem 273, 5794-5800

Einat H, Yuan P, Gould TD, Li J, Du J, Zhang L, Manji HK, Chen G (2003): The role of the extracellular signal-regulated kinase signaling pathway in mood modulation. J Neurosci $\underline{23}, 7311-$ 7316

Eldridge CF, Bunge MB, Bunge RP, Wood PM (1987): Differentiation of axon-related Schwann cells in vitro. I. Ascorbic acid regulates basal lamina assembly and myelin formation. J Cell Biol $\underline{105}, 1023-1034$

Fahrenkamp I, Friede RL (1987): Characteristic variations of relative myelin sheath thickness in 11 nerves of the rat. Anat Embryol 177, 115-121 
Fancy SPJ, Baranzini SE, Zhao C, Yuk D-I, Irvine K-A, Kaing S, Sanai N, Franklin RJM, Rowitch DH (2009): Dysregulation of the Wnt pathway inhibits timely myelination and remyelination in the mammalian CNS. Genes Dev $\underline{23}, 1571-1585$

Fang X-Y, Zhang W-M, Zhang C-F, Wong W-M, Li W, Wu W, Lin J-H (2016): Lithium accelerates functional motor recovery by improving remyelination of regenerating axons following ventral root avulsion and reimplantation. Neuroscience $\underline{329}, 213-225$

Fledrich R, Schlotter-Weigel B, Schnizer TJ, Wichert SP, Stassart RM, Meyer zu Hörste G, Klink A, Weiss BG, Haag U, Walter MC, et al. (2012a): A rat model of Charcot-Marie-Tooth disease 1A recapitulates disease variability and supplies biomarkers of axonal loss in patients. Brain $\underline{135}$, 72-87

Fledrich R, Stassart RM, Sereda MW (2012b): Murine therapeutic models for Charcot-Marie-Tooth (CMT) disease. Br Med Bull 102, 89-113

Fledrich R, Stassart RM, Klink A, Rasch LM, Prukop T, Haag L, Czesnik D, Kungl T, Abdelaal TAM, Keric N, et al. (2014): Soluble neuregulin-1 modulates disease pathogenesis in rodent models of Charcot-Marie-Tooth disease 1A. Nat Med 20, 1055-1061

Fledrich R, Akkermann D, Schütza V, Abdelaal TA, Hermes D, Schäffner E, Soto-Bernardini MC, Götze T, Klink A, Kusch K, others (2019): NRG1 type I dependent autoparacrine stimulation of Schwann cells in onion bulbs of peripheral neuropathies. Nat Commun $\underline{10}, 1467$

Foltran RB, Diaz SL (2016): BDNF isoforms: a round trip ticket between neurogenesis and serotonin? J Neurochem $\underline{138}, 204-221$

Fu R, Tang Y, Ling Z-M, Li Y-Q, Cheng X, Song F-H, Zhou L-H, Wu W (2014): Lithium enhances survival and regrowth of spinal motoneurons after ventral root avulsion. BMC Neurosci $\underline{15}, 84$

Fukumoto T, Morinobu S, Okamoto Y, Kagaya A, Yamawaki S (2001): Chronic lithium treatment increases the expression of brain-derived neurotrophic factor in the rat brain. Psychopharmacology $\underline{158}, 100-106$

Funakoshi H, Frisén J, Barbany G, Timmusk T, Zachrisson O, Verge V, Persson H (1993): Differential expression of mRNAs for neurotrophins and their receptors after axotomy of the sciatic nerve. J Cell Biol 123, 455-465

Gabreëls-Festen A, Wetering RV (1999): Human nerve pathology caused by different mutational mechanisms of the PMP22 gene. Ann NY Acad Sci $\underline{883}, 336-343$

Garbay B, Heape A, Sargueil F, Cassagne C (2000): Myelin synthesis in the peripheral nervous system. Prog Neurobiol 61, 267-304

Goebbels S, Oltrogge JH, Wolfer S, Wieser GL, Nientiedt T, Pieper A, Ruhwedel T, Groszer M, Sereda MW, Nave K-A (2012): Genetic disruption of Pten in a novel mouse model of tomaculous neuropathy. EMBO Mol Med 4, 486-499

Hamanoue M, Middleton G, Wyatt S, Jaffray E, Hay RT, Davies AM (1999): p75-mediated NFkappaB activation enhances the survival response of developing sensory neurons to nerve growth factor. Mol Cell Neurosci 14, 28-40 
Hedgepeth CM, Conrad LJ, Zhang J, Huang H-C, Lee VM, Klein PS (1997): Activation of the Wnt signaling pathway: a molecular mechanism for lithium action. Dev Biol 185, 82-91

Hohn A, Leibrock J, Bailey K, Barde YA (1990): Identification and characterization of a novel member of the nerve growth factor/brain-derived neurotrophic factor family. Nature $\underline{344}$, $339-341$

Huxley C, Passage E, Manson A, Putzu G, Figarella-Branger D, Pellissier JF, Fontés M (1996): Construction of a mouse model of Charcot-Marie-Tooth disease type $1 \mathrm{~A}$ by pronuclear injection of human YAC DNA. Hum Mol Genet $\underline{5}, 563-569$

Huxley C, Passage E, Robertson AM, Youl B, Huston S, Manson A, Sabéran-Djoniedi D, FigarellaBranger D, Pellissier JF, Thomas PK, Fontés M (1998): Correlation between varying levels of PMP22 expression and the degree of demyelination and reduction in nerve conduction velocity in transgenic mice. Hum Mol Genet $\mathbf{7}, 449-458$

Jaegle M, Mandemakers W, Broos L, Zwart R, Karis A, Visser P, Grosveld F, Meijer D (1996): The POU factor Oct-6 and Schwann cell differentiation. Science $\underline{273}, 507-510$

Jessen KR, Mirsky R (2002): Signals that determine Schwann cell identity. J Anat 200, 367-376

Jessen KR, Mirsky R (2005): The origin and development of glial cells in peripheral nerves. Nat Rev Neurosci $\underline{6}, 671-682$

Jessen KR, Mirsky R (2016): The repair Schwann cell and its function in regenerating nerves. J Physiol $\underline{594}, 3521-3531$

Jetten AM, Suter U (2000): The peripheral myelin protein 22 and epithelial membrane protein family. Prog Nucleic Acid Res Mol Biol 64, 97-129

Jornada LK, Moretti M, Valvassori SS, Ferreira CL, Padilha PT, Arent CO, Fries GR, Kapczinski F, Quevedo J (2010): Effects of mood stabilizers on hippocampus and amygdala BDNF levels in an animal model of mania induced by ouabain. J Psychiatr Res 44, 506-510

Jung-Testas I, Schumacher M, Robel P, Baulieu EE (1996): Demonstration of progesterone receptors in rat Schwann cells. J Steroid Biochem Mol Biol $\underline{58}, 77-82$

Kaplan DR, Miller FD (2000): Neurotrophin signal transduction in the nervous system. Curr Opin Neurobiol 10, 381-391

Karlsson U, Schultz RL (1965): Fixation of the central nervous system for electron microscopy by aldehyde perfusion: I. Preservation with aldehyde perfusates versus direct perfusion with osmium tetroxide with special reference to membranes and the extracellular space. J Ultrastruct Res $\underline{12}, 160-186$

Kaya F, Belin S, Bourgeois P, Micaleff J, Blin O, Fontés M (2007): Ascorbic acid inhibits PMP22 expression by reducing cAMP levels. Neuromuscul Disord $\underline{17}, 248-253$

Kennedy G, Mitra J (1963): Body weight and food intake as initiating factors for puberty in the rat. J Physiol 166, 408-418 
Khajavi M, Shiga K, Wiszniewski W, He F, Shaw CA, Yan J, Wensel TG, Snipes GJ, Lupski JR (2007): Oral curcumin mitigates the clinical and neuropathologic phenotype of the Trembler-J mouse: a potential therapy for inherited neuropathy. Am J Hum Genet $\underline{81}$, 438-453

Kirschner D, Blaurock A: Organization, phylogenetic variations, and dynamic transitions of myelin. In: Martenson RE (Hrsg.): Myelin: biology and chemistry. CRC Press, Bethesda 1992, 3-78

Kleitman N, Wood PM, Bunge RP: Tissue Culturing Methods for the Study of Myelination. In: Banker G, Goslin K (Hrsg.): Culturing Nerve Cells. 2nd edition; The MIT Press, Cambridge 1998, 545-594

Kowiański P, Lietzau G, Czuba E, Waśkow M, Steliga A, Moryś J (2018): BDNF: A Key Factor with Multipotent Impact on Brain Signaling and Synaptic Plasticity. Cell Mol Neurobiol $\underline{38}$, 579-593

Krajewski KM, Lewis RA, Fuerst DR, Turansky C, Hinderer SR, Garbern J, Kamholz J, Shy ME (2000): Neurological dysfunction and axonal degeneration in Charcot-Marie-Tooth disease type 1A. Brain $\underline{123}, 1516-1527$

Laaksonen K, Nevalainen T, Haasio K, Kasanen I, Nieminen P, Voipio H (2013): Food and water intake, growth, and adiposity of Sprague-Dawley rats with diet board for 24 months. Lab Anim 47, 245-256

LeBlanc AC, Windebank AJ, Poduslo JF (1992): P 0 gene expression in Schwann cells is modulated by an increase of cAMP which is dependent on the presence of axons. Mol Brain Res $\underline{12}, 31-$ 38

Leblanc SE, Srinivasan R, Ferri C, Mager GM, Gillian-Daniel AL, Wrabetz L, Svaren J (2005): Regulation of cholesterol/lipid biosynthetic genes by Egr2/Krox20 during peripheral nerve myelination. J Neurochem $\underline{93}, 737-748$

Ledoux J-M (2003): Features of the comparative pharmacokinetics of lithium; a potential application of its use in livestock farming. Med Hypotheses $\underline{61}, 278-281$

Lemke G, Lamar E, Patterson J (1988): Isolation and analysis of the gene encoding peripheral myelin protein zero. Neuron $\underline{1}, 73-83$

Lewis RA, McDermott MP, Herrmann DN, Hoke A, Clawson LL, Siskind C, Feely SME, Miller LJ, Barohn RJ, Smith P, et al. (2013): High-dosage ascorbic acid treatment in Charcot-MarieTooth disease type 1A: results of a randomized, double-masked, controlled trial. JAMA Neurol 70, $981-987$

Leyhe T, Eschweiler GW, Stransky E, Gasser T, Annas P, Basun H, Laske C (2009): Increase of BDNF serum concentration in lithium treated patients with early Alzheimer's disease. J Alzheimers Dis $\underline{16}, 649-656$

Livak KJ, Schmittgen TD (2001): Analysis of relative gene expression data using real-time quantitative PCR and the 2(-Delta Delta C(T)) Method. Methods $\underline{25}$, 402-408

Lowry OH, Rosenbrough NJ, Farr AL, Randall RJ (1951): Protein measurement with the Folin phenol reagent. J Biol Chem 193, 265-275

Luft JH (1961): Improvements in epoxy resin embedding methods. J Cell Biol $\underline{9}$, 409-414 
Lupski JR, de Oca-Luna RM, Slaugenhaupt S, Pentao L, Guzzetta V, Trask BJ, Saucedo-Cardenas O, Barker DF, Killian JM, Garcia CA, et al. (1991): DNA duplication associated with CharcotMarie-Tooth disease type 1A. Cell $\underline{66}$, 219-232

Lupski JR, Reid JG, Gonzaga-Jauregui C, Rio Deiros D, Chen DCY, Nazareth L, Bainbridge M, Dinh H, Jing C, Wheeler DA, et al. (2010): Whole-genome sequencing in a patient with Charcot-Marie-Tooth neuropathy. N Engl J Med $\underline{362}, 1181-1191$

Macdonald A, Briggs K, Poppe M, Higgins A, Velayudhan L, Lovestone S (2008): A feasibility and tolerability study of lithium in Alzheimer's disease. Int J Geriatr Psychiatry 233, 704-711

Magyar JP, Martini R, Ruelicke T, Aguzzi A, Adlkofer K, Dembic Z, Zielasek J, Toyka KV, Suter U (1996): Impaired differentiation of Schwann cells in transgenic mice with increased PMP22 gene dosage. J Neurosci $\underline{16}, 5351-5360$

Makoukji J, Belle M, Meffre D, Stassart R, Grenier J, Shackleford G, Fledrich R, Fonte C, Branchu J, Goulard M, et al. (2012): Lithium enhances remyelination of peripheral nerves. Proc Natl Acad Sci USA $\underline{109}$, 3973-3978

Manfioletti G, Ruaro ME, Del Sal G, Philipson L, Schneider C (1990): A growth arrest-specific (gas) gene codes for a membrane protein. Mol Cell Biol 10, 2924-2930

McBride SM, Choi CH, Schoenfeld BP, Bell AJ, Liebelt DA, Ferreiro D, Choi RJ, Hinchey P, Kollaros M, Terlizzi AM, others (2010): Pharmacological and genetic reversal of age-dependent cognitive deficits attributable to decreased presenilin function. J Neurosci $\underline{30}, 9510-9522$

Meffre D, Massaad C, Grenier J (2015): Lithium chloride stimulates PLP and MBP expression in oligodendrocytes via Wnt/ $\beta$-catenin and Akt/CREB pathways. Neuroscience 284, 962-971

Meyer zu Horste G, Prukop T, Liebetanz D, Mobius W, Nave K-A, Sereda MW (2007): Antiprogesterone therapy uncouples axonal loss from demyelination in a transgenic rat model of CMT1A neuropathy. Ann Neurol 61, 61-72

Meyer zu Horste G, Miesbach TA, Muller JI, Fledrich R, Stassart RM, Kieseier BC, Coleman MP, Sereda MW (2011): The Wlds transgene reduces axon loss in a Charcot-Marie-Tooth disease $1 \mathrm{~A}$ rat model and nicotinamide delays post-traumatic axonal degeneration. Neurobiol Dis $\underline{42}$, $1-8$

Micallef J, Attarian S, Dubourg O, Gonnaud P-M, Hogrel J-Y, Stojkovic T, Bernard R, Jouve E, Pitel S, Vacherot F, et al. (2009): Effect of ascorbic acid in patients with Charcot-Marie-Tooth disease type 1A: a multicentre, randomised, double-blind, placebo-controlled trial. Lancet Neurol $\underline{8}, 1103-1110$

Michailov GV, Sereda MW, Brinkmann BG, Fischer TM, Haug B, Birchmeier C, Role L, Lai C, Schwab MH, Nave K-A (2004): Axonal neuregulin-1 regulates myelin sheath thickness. Science $\underline{304}, 700-703$

Mo M, Erdelyi I, Szigeti-Buck K, Benbow JH, Ehrlich BE (2012): Prevention of paclitaxel-induced peripheral neuropathy by lithium pretreatment. FASEB J 26, 4696-4709 
Morgan L, Jessen KR, Mirsky R (1991): The effects of cAMP on differentiation of cultured Schwann cells: progression from an early phenotype $(04+)$ to a myelin phenotype $(\mathrm{P} 0+$, GFAP-, N-CAM-, NGF-receptor-) depends on growth inhibition. J Cell Biol 112, 457-467

Mullis K, Faloona F, Scharf S, Saiki R, Horn G, Erlich H (1986): Specific enzymatic amplification of DNA in vitro: the polymerase chain reaction. Cold Spring Harbor Symp Quant Biol $\underline{51}$, 263-273

Nave K-A, Salzer JL (2006): Axonal regulation of myelination by neuregulin 1. Curr Opin Neurobiol $\underline{16}, 492-500$

Newbern JM, Li X, Shoemaker SE, Zhou J, Zhong J, Wu Y, Bonder D, Hollenback S, Coppola G, Geschwind DH, others (2011): Specific functions for ERK/MAPK signaling during PNS development. Neuron $\underline{69}, 91-105$

Niemann S, Sereda MW, Rossner M, Stewart H, Suter U, Meinck HM, Griffiths IR, Nave KA (1999): The „CMT rat“: peripheral neuropathy and dysmyelination caused by transgenic overexpression of PMP22. Ann NY Acad Sci $\underline{883}, 254-261$

Niemann S, Sereda MW, Suter U, Griffiths IR, Nave KA (2000): Uncoupling of myelin assembly and schwann cell differentiation by transgenic overexpression of peripheral myelin protein 22 . J Neurosci $\underline{20}, 4120-4128$

Nobbio L, Sturla L, Fiorese F, Usai C, Basile G, Moreschi I, Benvenuto F, Zocchi E, De Flora A, Schenone A, Bruzzone S (2009): P2X7-mediated increased intracellular calcium causes functional derangement in Schwann cells from rats with CMT1A neuropathy. J Biol Chem $\underline{284}$, $23146-23158$

Noble W, Planel E, Zehr C, Olm V, Meyerson J, Suleman F, Gaynor K, Wang L, LaFrancois J, Feinstein B, others (2005): Inhibition of glycogen synthase kinase-3 by lithium correlates with reduced tauopathy and degeneration in vivo. Proc Natl Acad Sci USA 102, 6990-6995

Norrmén C, Suter U (2013): Akt/mTOR signalling in myelination. Biochem Soc Trans 41, 944-950

Nouri M, Rasouli MR, Rahimian R, Asadi-Amoli F, Dehpour AR (2009): Lithium improves regeneration after sciatic nerve traumatic injury in rat. J Reconstr Microsurg $\underline{25}, 151$

Oruch R, Elderbi MA, Khattab HA, Pryme IF, Lund A (2014): Lithium: a review of pharmacology, clinical uses, and toxicity. Eur J Pharmacol 740, 464-473

Palau F, Löfgren A, De Jonghe P, Bort S, Nelis E, Sevilla T, Martin JJ, Vilchez J, Prieto F, Van Broeckhoven C (1993): Origin of the de novo duplication in Charcot-Marie-Tooth disease type 1A: unequal nonsister chromatid exchange during spermatogenesis. Hum Mol Genet 2 , 2031-2035

Pardo R, Andreolotti AG, Ramos B, Picatoste F, Claro E (2003): Opposed effects of lithium on the MEK-ERK pathway in neural cells: inhibition in astrocytes and stimulation in neurons by GSK3 independent mechanisms. J Neurochem $\underline{87}, 417-426$

Pareek S, Suter U, Snipes GJ, Welcher AA, Shooter EM, Murphy RA (1993): Detection and processing of peripheral myelin protein PMP22 in cultured Schwann cells. J Biol Chem 268, 10372-10379 
Pareyson D, Marchesi C (2009): Diagnosis, natural history, and management of Charcot-MarieTooth disease. Lancet Neurol $\underline{8}, 654-667$

Pareyson D, Scaioli V, Laurà M (2006): Clinical and electrophysiological aspects of Charcot-MarieTooth disease. Neuromolecular Med $\underline{8}, 3-22$

Pareyson D, Reilly MM, Schenone A, Fabrizi GM, Cavallaro T, Santoro L, Vita G, Quattrone A, Padua L, Gemignani F, et al. (2011): Ascorbic acid in Charcot-Marie-Tooth disease type 1A (CMT-TRIAAL and CMT-TRAUK): a double-blind randomised trial. Lancet Neurol $\underline{10}, 320$ 328

Parmantier E, Cabon F, Braun C, D’Urso D, Müller HW, Zalc B (1995): Peripheral myelin protein22 is expressed in rat and mouse brain and spinal cord motoneurons. Eur J Neurosci ㄱ, 1080 1088

Pasquali L, Busceti CL, Fulceri F, Paparelli A, Fornai F (2010): Intracellular pathways underlying the effects of lithium. Behav Pharmacol 21, 473-492

Passage E, Norreel JC, Noack-Fraissignes P, Sanguedolce V, Pizant J, Thirion X, Robaglia-Schlupp A, Pellissier JF, Fontés M (2004): Ascorbic acid treatment corrects the phenotype of a mouse model of Charcot-Marie-Tooth disease. Nat Med 10, 396-401

Patel PI, Roa BB, Welcher AA, Schoener-Scott R, Trask BJ, Pentao L, Snipes GJ, Garcia CA, Francke U, Shooter EM, et al. (1992): The gene for the peripheral myelin protein PMP-22 is a candidate for Charcot-Marie-Tooth disease type 1A. Nat Genet $\underline{1}, 159-165$

Patzkó A, Shy ME (2011): Update on Charcot-Marie-Tooth disease. Curr Neurol Neurosci Rep 11, 78-88

Phiel CJ, Klein PS (2001): Molecular targets of lithium action. Annu Rev Pharmacol Toxicol $\underline{41}$, 789-813

Pourmohammadi N, Alimoradi H, Mehr SE, Hassanzadeh G, Hadian MR, Sharifzadeh M, Bakhtiarian A, Dehpour AR (2012): Lithium attenuates peripheral neuropathy induced by paclitaxel in rats. Basic Clin Pharmacol Toxicol $\underline{110}, 231-237$

Reichardt LF (2006): Neurotrophin-regulated signalling pathways. Philos Trans R Soc Lond B Biol Sci $\underline{361}, 1545-1564$

Reilly MM, Murphy SM, Laurá M (2011): Charcot-Marie-Tooth disease. J Peripher Nerv Syst $\underline{16}, 1$ 14

Reynolds ES (1963): The use of lead citrate at high $\mathrm{pH}$ as an electron-opaque stain in electron microscopy. J Cell Biol 17, 208-212

Richardson K, Jarett L, Finke E (1960): Embedding in epoxy resins for ultrathin sectioning in electron microscopy. Stain Technol $\underline{35}$, 313-323

Robert F, Guennoun R, Désarnaud F, Do-Thi A, Benmessahel Y, Baulieu EE, Schumacher M (2001): Synthesis of progesterone in Schwann cells: regulation by sensory neurons. Eur J Neurosci $\underline{13}, 916-924$ 
Rodriguez-Tébar A, Dechant G, Barde YA (1990): Binding of brain-derived neurotrophic factor to the nerve growth factor receptor. Neuron $\underline{4}, 487-492$

Rowe MK, Chuang D-M (2004): Lithium neuroprotection: molecular mechanisms and clinical implications. Expert Rev Mol Med $\underline{6}, 1-18$

Rowse AL, Naves R, Cashman KS, McGuire DJ, Mbana T, Raman C, De Sarno P (2012): Lithium controls central nervous system autoimmunity through modulation of IFN- $\gamma$ signaling. PLoS One $\underline{7}$, e52658

Rye HS, Yue S, Wemmer DE, Quesada MA, Haugland RP, Mathies RA, Glazer AN (1992): Stable fluorescent complexes of double-stranded DNA with bis-intercalating asymmetric cyanine dyes: properties and applications. Nucleic Acids Res 20, 2803-2812

Salzer JL (2003): Polarized domains of myelinated axons. Neuron 40, 297-318

Salzer JL (2012): Axonal regulation of Schwann cell ensheathment and myelination. J Peripher Nerv Syst $\underline{17}, 14-19$

Schafer DP, Rasband MN (2006): Glial regulation of the axonal membrane at nodes of Ranvier. Curr Opin Neurobiol 16, 508-514

Schenone A, Nobbio L, Monti Bragadin M, Ursino G, Grandis M (2011): Inherited neuropathies. Curr Treat Options Neurol 13, 160-179

Schneider C, King RM, Philipson L (1988): Genes specifically expressed at growth arrest of mammalian cells. Cell $\underline{54}, 787-793$

Schumacher M, Guennoun R, Mercier G, Désarnaud F, Lacor P, Bénavides J, Ferzaz B, Robert F, Baulieu EE (2001): Progesterone synthesis and myelin formation in peripheral nerves. Brain Res Brain Res Rev $\underline{37}$, 343-359

Sereda MW (1999): Altered protein synthesis in sciatic nerve by transgenic overexpression of PMP22 in the CMT rat. Ann NY Acad Sci $\underline{883}, 530-532$

Sereda MW, Nave K-Armin (2006): Animal models of Charcot-Marie-Tooth disease type 1A. Neuromolecular Med $\underline{8}, 205-216$

Sereda MW, Griffiths I, Pühlhofer A, Stewart H, Rossner MJ, Zimmerman F, Magyar JP, Schneider A, Hund E, Meinck HM, et al. (1996): A transgenic rat model of Charcot-Marie-Tooth disease. Neuron 16, 1049-1060

Sereda MW, Meyer zu Hörste G, Suter U, Uzma N, Nave K-A (2003): Therapeutic administration of progesterone antagonist in a model of Charcot-Marie-Tooth disease (CMT-1A). Nat Med $\underline{9}$, 1533-1537

Simons M, Trotter J (2007): Wrapping it up: the cell biology of myelination. Curr Opin Neurobiol $\underline{17}, 533-540$

Sinha D, Wang Z, Ruchalski KL, Levine JS, Krishnan S, Lieberthal W, Schwartz JH, Borkan SC (2005): Lithium activates the Wnt and phosphatidylinositol 3-kinase Akt signaling pathways to promote cell survival in the absence of soluble survival factors. Am J Physiol Renal Physiol $\underline{288}$, F703-F713 
Skre H (1974): Genetic and clinical aspects of Charcot-Marie-Tooth's disease. Clin Genet $\underline{6}$, 98-118

Slater H, Bruno D, Ren H, La P, Burgess T, Hills L, Nouri S, Schouten J, Choo KHA (2004): Improved testing for CMT1A and HNPP using multiplex ligation-dependent probe amplification (MLPA) with rapid DNA preparations: comparison with the interphase FISH method. Hum Mutat 24, 164-171

Snipes GJ, Suter U, Welcher AA, Shooter EM (1992): Characterization of a novel peripheral nervous system myelin protein (PMP-22/SR13). J Cell Biol 117, 225-238

Sobue G, Shuman S, Pleasure D (1986): Schwann cell responses to cyclic AMP: proliferation, change in shape, and appearance of surface galactocerebroside. Brain Res $\underline{362}$, 23-32

Sobue G, Yamamoto M, Doyu M, Li M, Yasuda T, Mitsuma T (1998): Expression of mRNAs for neurotrophins (NGF, BDNF, and NT-3) and their receptors (p75NGFR, trk, trkB, and trkC) in human peripheral neuropathies. Neurochem Res $\underline{23}, 821-829$

Sociali G, Visigalli D, Prukop T, Cervellini I, Mannino E, Venturi C, Bruzzone S, Sereda MW, Schenone A (2016): Tolerability and efficacy study of P2X7 inhibition in experimental Charcot-Marie-Tooth type 1A (CMT1A) neuropathy. Neurobiol Dis $\underline{95}, 145-157$

Stoll G, Müller HW (1999): Nerve injury, axonal degeneration and neural regeneration: basic insights. Brain Pathol 2, 313-325

Su H, Yuan Q, Qin D, Yang X, Wong W-M, So K-F, Wu W (2014): Lithium enhances axonal regeneration in peripheral nerve by inhibiting glycogen synthase kinase $3 \beta$ activation. Biomed Res Int 2014, 1-7

Sun YR, Herrmann N, Scott CJ, Black SE, Swartz RH, Hopyan J, Lanctôt KL (2019): Lithium carbonate in a poststroke population: exploratory analyses of neuroanatomical and cognitive outcomes. J Clin Psychopharmacol 39, 67-71

Suter U, Patel PI (1994): Genetic basis of inherited peripheral neuropathies. Hum Mutat $\underline{3}$, 95-102

Suter U, Scherer SS (2003): Disease mechanisms in inherited neuropathies. Nat Rev Neurosci $\underline{4}$, 714-726

Svaren J, Meijer D (2008): The molecular machinery of myelin gene transcription in Schwann cells. Glia $\underline{56}, 1541-1551$

Taveggia C, Zanazzi G, Petrylak A, Yano H, Rosenbluth J, Einheber S, Xu X, Esper RM, Loeb JA, Shrager P, others (2005): Neuregulin-1 type III determines the ensheathment fate of axons. Neuron $\underline{47}$, 681-694

Taveggia C, Feltri ML, Wrabetz L (2010): Signals to promote myelin formation and repair. Nat Rev Neurol $\underline{6}, 276-287$

Tawk M, Makoukji J, Belle M, Fonte C, Trousson A, Hawkins T, Li H, Ghandour S, Schumacher M, Massaad C (2011): Wnt/beta-catenin signaling is an essential and direct driver of myelin gene expression and myelinogenesis. J Neurosci $\underline{31}, 3729-3742$ 
Taylor V, Welcher AA, Program AE, Suter U (1995): Epithelial membrane protein-1, peripheral myelin protein 22, and lens membrane protein 20 define a novel gene family. J Biol Chem $\underline{270}$, $28824-28833$

Terenghi G (1999): Peripheral nerve regeneration and neurotrophic factors. J Anat 194, 1-14

Tolwani RJ, Cosgaya JM, Varma S, Jacob R, Kuo LE, Shooter EM (2004): BDNF overexpression produces a long-term increase in myelin formation in the peripheral nervous system. J Neurosci Res $\underline{77}$, 662-669

Topilko P, Schneider-Maunoury S, Levi G, Baron-Van Evercooren A, Chennoufi AB, Seitanidou T, Babinet C, Charnay P (1994): Krox-20 controls myelination in the peripheral nervous system. Nature $\underline{371}, 796-799$

Trepel M: Grundlagen, Begriffe und Definitionen. In: Trepel M (Hrsg.): Neuroanatomie, Struktur und Funktion. 3. Auflage; Urban Fischer, München 2004, 1-20

Van der Heyden M, Rook MB, Hermans M, Rijksen G, Boonstra J, Defize L, Destree O (1998): Identification of connexin 43 as a functional target for Wnt signalling. J Cell Sci 111, 17411749

Verhamme C, de Haan RJ, Vermeulen M, Baas F, de Visser M, van Schaik IN (2009): Oral high dose ascorbic acid treatment for one year in young CMT1A patients: a randomised, doubleblind, placebo-controlled phase II trial. BMC Med ㄱ, 70-79

Verheijen MHG, Camargo N, Verdier V, Nadra K, de Preux Charles A-S, Médard J-J, Luoma A, Crowther M, Inouye H, Shimano H, et al. (2009): SCAP is required for timely and proper myelin membrane synthesis. Proc Natl Acad Sci USA 106, 21383-21388

Viguera AC, Newport DJ, Ritchie J, Stowe Z, Whitfield T, Mogielnicki J, Baldessarini RJ, Zurick A, Cohen LS (2007): Lithium in breast milk and nursing infants: clinical implications. Am J Psychiatry $\underline{164}, 342-345$

Wang J, Hmadcha A, Zakarian V, Song F, Loeb JA (2015): Rapid transient isoform-specific neuregulin1 transcription in motor neurons is regulated by neurotrophic factors and axon-target interactions. Mol Cell Neurosci $\underline{68}, 73-81$

Warner LE, Mancias P, Butler IJ, McDonald CM, Keppen L, Koob KG, Lupski JR (1998): Mutations in the early growth response 2 (EGR2) gene are associated with hereditary myelinopathies. Nat Genet 18, 382-384

Watila M, Balarabe S (2015): Molecular and clinical features of inherited neuropathies due to PMP22 duplication. J Neurol Sci $\underline{355}, 18-24$

Weiss BG: Tierexperimentelle Behandlungsversuche der Charcot-Marie-Tooth-Erkrankung 1A. Med.Diss. Göttingen 2014

Wu R, Fan J, Zhao J, Calabrese JR, Gao K (2014): The relationship between neurotrophins and bipolar disorder. Expert Rev Neurother 14, 51-65

Yamashita T, Tucker KL, Barde YA (1999): Neurotrophin binding to the p75 receptor modulates Rho activity and axonal outgrowth. Neuron $24,585-593$ 
Yasuda S, Liang M, Marinova Z, Yahyavi A, Chuang D (2009): The mood stabilizers lithium and valproate selectively activate the promoter IV of brain-derived neurotrophic factor in neurons. Mol Psychiatry 14, 51-59

Yoshino JE, DeVries GH (1987): Effect of lithium on Schwann cell proliferation stimulated by axolemma- and myelin-enriched fractions. J Neurochem $\underline{48}, 1270-1277$

Youdim MB, Arraf Z (2004): Prevention of MPTP (N-methyl-4-phenyl-1, 2, 3, 6-tetrahydropyridine) dopaminergic neurotoxicity in mice by chronic lithium: involvements of Bcl-2 and Bax. Neuropharmacology $\underline{46}, 1130-1140$

Yu F, Wang Z, Tchantchou F, Chiu C-T, Zhang Y, Chuang D-M (2012): Lithium ameliorates neurodegeneration, suppresses neuroinflammation, and improves behavioral performance in a mouse model of traumatic brain injury. J Neurotrauma 29, 362-374

Zhong J, Yang X, Yao W, Lee W (2006): Lithium protects ethanol-induced neuronal apoptosis. Biochem Biophys Res Commun 350, 905-910

Zoidl G, Blass-Kampmann S, D’Urso D, Schmalenbach C, Müller HW (1995): Retroviral-mediated gene transfer of the peripheral myelin protein PMP22 in Schwann cells: modulation of cell growth. EMBO J 14, 1122-1128 
